DOE/ID-10845

March 2001

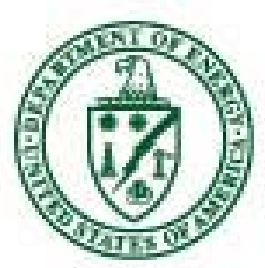

U.S. Department of Energy Idaho Operations Office

Cycle-Life Studies of Advanced Technology Development Program Gen 1 Lithium Ion Batteries 
This report was prepared as an account of work sponsored by an agency of the United States Government. Neither the United States Government nor any agency thereof, nor any of their employees, make any warranty, express or implied, or assumes any legal liability or responsibility for the accuracy, completeness, or usefulness of any information, apparatus, product or process disclosed, or represents that its use would not infringe on privately owned rights. References herein to any specific commercial product, process, or service by trade name, trademark, manufacturer, or otherwise, does not necessarily constitute or imply its endorsement, recommendation, or favoring by the United States Government or any agency thereof. The views and opinions of authors expressed herein do not necessarily state or reflect those of the United States Government or any agency thereof. 


\title{
Cycle-Life Studies of Advanced Technology Development Program Gen 1 Lithium Ion Batteries
}

\author{
Randy B. Wright
}

Chester G. Motloch

Published March 2001

Prepared for the

U.S. Department of Energy

Assistant Secretary for Energy Efficiency and Renewable Energy (EE) Idaho Operations Office 


\begin{abstract}
[Words from Life-Cycle report.]

This report presents the test results of a special calendar-life test conducted on 18650-size, prototype, lithium-ion battery cells developed to establish a baseline chemistry and performance for the Advanced Technology Development Program. As part of electrical performance testing, a new calendar-life test protocol was used. The test consisted of a once-per-day discharge and charge pulse designed to have minimal impact on the cell yet establish the performance of the cell over a period of time such that the calendar life of the cell could be determined. The calendar life test matrix included two states of charge (i.e., 60 and $80 \%)$ and four temperatures $\left(40,50,60\right.$, and $\left.70^{\circ} \mathrm{C}\right)$. Discharge and regen resistances were calculated from the test data. Results indicate that both discharge and regen resistance increased nonlinearly as a function of the test time. The magnitude of the discharge and regen resistance depended on the temperature and state of charge at which the test was conducted. The calculated discharge and regen resistances were then used to develop empirical models that may be useful to predict the calendar life or the cells.
\end{abstract}




\section{SUMMARY}

The DOE Office of Advanced Automotive Technology through the Partnership for a New Generation of Vehicles (PNGV) Advanced Energy Technology Development (ATD) Program is engaged in the study of 18650-size lithium ion cells, which baseline the high power battery chemistry being developed for use in hybrid electric vehicles (HEVs). The cells received for testing were built by a commercial vendor to specifications supplied by the ATD program. These cells contain cathodes of $84 \mathrm{wt} \% \mathrm{LiNi}_{0.8} \mathrm{Co}_{0.2} \mathrm{O}_{2}$, with graphite and carbon black added for electrical conductivity. The anode is a blend of SFG-6 and MCMB-6 carbons. The electrolyte is $1.0 \mathrm{M} \mathrm{LiPF}_{6}$ in 1:1 EC/DEC (ethylene carbonate:diethyl carbonate $=1: 1$ ). PVDF [polyvinylidene fluoride, $\left.\left(-\mathrm{CH}_{2} \mathrm{CF}_{2}-\right)_{\mathrm{n}}\right]$ binder was used in the fabrication of both electrodes. The anode current collector is copper foil; the cathode current collector aluminum foil is used for. Celgard supplied the separator (polyethylene). The cells, as part of their electrical performance testing, were tested using a new test protocol developed by the ATD program to test cycle-life. These new test cycles, which were charge neutral, had state-of-charge swings of delta 3,6, and $9 \%$.

This report presents the test results pertaining to this group of prototype lithium ion batteries. The cells had a nominal capacity of $0.9 \mathrm{~A} \cdot \mathrm{h}$ at a $\mathrm{C} / 1$ discharge rate with a voltage range of 3 to $4.1 \mathrm{~V}$. The cells were assembled into a 18650 -size container ( $64.9 \mathrm{~mm}$ high, $18.1 \mathrm{~mm}$ diameter). The cells underwent a number of electrical performance tests to determine their electrochemical performance at $25^{\circ} \mathrm{C}$. A special-cycle-life test was also conducted at elevated temperatures of $40,50,60$, and $70^{\circ} \mathrm{C}$ and had state-of-charge swings of $3 \%, 6 \%$, and $9 \%$.

The specific test for which the data are presented and discussed in this report was a special cycle-life test conducted for a period of time at specified temperatures of $40,50,60$, and $70^{\circ} \mathrm{C}$. This test, consisting of specified discharge and charge protocols, was designed to establish the cycle-life performance of the cell over a period of time such that the cycle life of the cell could be determined. Specific discharge and regen current levels for a specific time duration were used for each of the test cycles. The cycle-life test was conducted at $60 \%$ state of charge (SOC), with a SOC swing of delta 3,6, and 9\%. (Tests were also conducted at $80 \%$ SOC, with the same delta\% SOC swings, by Sandia National Laboratory, but the data had not been analyzed at the time of writing this report.) During the cycle-life test, the discharge resistance was determined from the discharge portion of the test; the regen resistance was determined from the regen portion of the test.

The specific test for which the data are presented and discussed in this report was a special cycle-life test conducted for a 4-week period for test temperatures of 40,50 , and $60^{\circ} \mathrm{C}$, and for a 2 -week period at $70^{\circ} \mathrm{C}$. This test, consisting of three specified discharge and charge protocols, was designed to have a delta 3, 6, or $9 \%$ cumulative SOC swing during the discharge portion of the test. The delta state of charge was then returned to a zero net state-of-charge swing during the charging portions of the test cycle. A new approach was developed for the ATD Program for cycle-life testing to ensure that each cell was at the target SOC at the completion of each cycle life profile. During the cycle- 
life test, the discharge resistance was determined from a 14-s discharge portion of the test; the regen resistance was determined from a 2-s regen portion of the test.

The results of the testing indicate that both the discharge and regen resistance increased nonlinearly as a function of the test time at each delta $\%$ SOC test. The magnitude of the discharge and regen resistance and the rate at which they changed depended on the temperature and delta $\%$ SOC at which the test was conducted. General observations derived from this study are as follows:

1. Both the discharge and regen resistances have a nonlinear increase with respect to time at test temperature, i.e., as the number of test cycles increased the discharge and regen resistances increased also.

2. For a given delta $\%$ SOC test, the discharge resistances are greater than the regen resistances at all of the test temperatures of $40,50,60$, and $70^{\circ} \mathrm{C}$.

3. For both the discharge and regen resistances, generally the higher the test temperature, the lower the resistance.

4. The $70^{\circ} \mathrm{C}$ discharge and regen resistance data did not always follow the general trend of the rest of the data, in that the resistance at this temperature was slightly greater than that at $60^{\circ} \mathrm{C}$. This observation appears to indicate that new physical/chemical processes are occurring that causes an anomalous increase in the resistance. The exact nature of these processes is not presently known.

5. At each of the four test temperatures, the magnitude of the discharge and regen resistance was in the following order: delta $6 \%$ SOC $>$ delta $3 \%$ SOC $>$ delta $9 \%$ SOC. No explanation is currently known for this observation. (Research groups within the ATD Program are currently conducting physical/chemical studies on the test cells and may provide insight into this observation.)

A model was developed to account for the time, temperature, SOC, and delta $\%$ SOC of the batteries during the cycle-life test. The functional form of the model is given by

$$
\mathrm{R}(\mathrm{t}, \mathrm{T}, \mathrm{SOC}, \text { delta } \% \mathrm{SOC})=\mathrm{A}(\mathrm{T}, \mathrm{SOC}, \text { delta } \% \mathrm{SOC}) \mathrm{F}(\mathrm{t})+\mathrm{B}(\mathrm{T}, \mathrm{SOC}, \mathrm{delta} \% \mathrm{SOC})
$$

where $\mathrm{t}$ is the time at test temperature, $\mathrm{T}$ is the test temperature, $\mathrm{SOC}$ is the state of charge of the cell at the start and end of the test, and delta\% SOC is the stateof-charge swing during the test. A(T,SOC,delta $\%$ SOC) and B(T,SOC,delta $\%$ SOC) are assumed to be functions of the test temperature, state of charge, and delta $\%$ SOC swing. $F(t)$ is assumed to be a function only of the test time at test temperature. Using curve fitting techniques for a number of time-dependent functions, it was found that both the discharge and regen resistances were best correlated by a square root of test time dependence. These results led to the relationship for the discharge and regen resistances having the form

$\mathrm{R}(\mathrm{t}, \mathrm{T}, \mathrm{SOC}$, delta $\%$ SOC $)=\mathrm{A}(\mathrm{T}, \mathrm{SOC}, \mathrm{delta} \% \mathrm{SOC}) \mathrm{t}^{1 / 2}+\mathrm{B}(\mathrm{T}, \mathrm{SOC}, \mathrm{delta} \%$ SOC $)$. 
The square root of test time dependence for the increase in the discharge and regen resistances can be accounted for by either a one-dimensional diffusion type of mechanism, presumably of the lithium ions, or by a parabolic growth mechanism for the growth of a thin film solid electrolyte interface (SEI) layer on the anode and/or cathode. The diffusion type of mechanism would arise from the lithium ions diffusing into/out of the electrodes, through the electrolyte, through the separator, or through the solid electrolyte interface (SEI) layer present on the surface of the electrode materials. The growth of a thin film mechanism can be related to the growth of a SEI layer on the electrodes as a function of test time, test condition, and test temperature. The growth of the SEI layer results from the decomposition of the electrolyte/salt system on the surface of the electrodes. The increased thickness of the SEI film would increase the resistance of the cell due to its hindrance of the transport of lithium ions through the SEI layer to subsequently be intercalated/de-intercalated into the active electrode material. The best physical/chemical model appears at present to be the growth of the SEI layer. The present data, however, cannot determine if the growth of the SEI layer with time occurs at the anode, the cathode, or both. However, there are characterization results, in particular electrochemical impedance spectroscopic (EIS) methods, that indicate that the resistance of the cathode is the major contributor to the resistance increase of the cell as it ages. The temperature dependence of the resistance was then investigated using various model fits to the functions $A(T)$ and $B(T)$. The results of this exercise lead to a functional form for the functions having an "Arrhenius-like" form:

$\mathrm{A}(\mathrm{T})=\mathrm{a}[\exp (\mathrm{b} / \mathrm{T})]$ and $\mathrm{B}(\mathrm{T})=\mathrm{c}[\exp (\mathrm{d} / \mathrm{T})]$

where $\mathrm{a}$ and $\mathrm{c}$ are constants, and $\mathrm{b}$ and $\mathrm{d}$ are related to an activation energy, $\mathrm{E}_{\mathrm{b}}$ and $E_{d}$, by using the gas constant, $R$, such that $b=E_{b} / R$ and $d=E_{d} / R$. The values of $E_{b}$ and $E_{d}$ were determined and were found to be about the right order of magnitude (several to several tens of kjoules/mole) for the activated transport of lithium ions, or the chemical decomposition of the electrolyte. (However, no literature references could be found that substantiated these values.) It is not known what specific process or processes the determined activation energy values correspond too. The functional form, therefore, for the discharge and regen resistance including the SOC and delta $\%$ SOC is

$\mathrm{R}(\mathrm{t}, \mathrm{T}, \mathrm{SOC}, \mathrm{delta} \% \mathrm{SOC})=\mathrm{a}(\mathrm{SOC}$, delta $\%$ SOC $)\{\exp [\mathrm{b}(\mathrm{SOC}$, delta $\%$ SOC $) / \mathrm{T}]\} \mathrm{t}^{1 / 2}$ $+\mathrm{c}(\mathrm{SOC}, \mathrm{delta} \% \mathrm{SOC})\{\exp [\mathrm{d}(\mathrm{SOC}, \mathrm{delta} \% \mathrm{SOC}) / \mathrm{T}]\}$.

The a, b, c, and d parameters are explicitly shown as being functions of the SOC and the delta\% SOC. However, due to the lack of testing at SOC values other than $60 \%$ SOC, the exact form of the SOC dependence could not be determined from the experimental data. Attempts were made to correlate consistently the observed resistance changes with the delta\% SOC of the tests. No model based on physical/chemical processes was found, nor were studies on this topic found in the literature examined. Eliminating the SOC and delta\% $\mathrm{SOC}$ from the resistance function, the function $\mathrm{R}(\mathrm{t}, \mathrm{T})$ could then be used to correlate the discharge and regen resistance data. This model also allows prediction of what the resistance would be at different test times at a particular test conditions and temperatures. The values found for the constants at a given delta $\%$ SOC in the functions $A(T)=a[\exp (b / T)]$ and $B(T)=c[\exp (d / T)]$ in 
conjunction with the square root of test time dependence permitted predicting the observed discharge and regen resistance values.

Analysis of the $\mathrm{C} / 1$ constant current discharge test results allowed determining the leakage current, i.e., the current required to maintain a given voltage on the cell. In this case, the cells where held constant at $4.1 \mathrm{~V}$. The leakage current was found to decrease quite rapidly for new cells, but after aging by testing, the magnitude of the leakage current as a function of time was found

to increase. The leakage current can be related to a leakage resistance via Ohm's law. The leakage resistance was found to decrease as the cell ages, which means that more current, i.e., charge, has to be put into the cell to maintain a given voltage. This increased charge requirement is due to IR-losses in the battery. The IR-losses increase, due to presently unknown detailed processes, as the cell ages.

Further analysis of the constant current $\mathrm{C} / 1$ charge and discharge data using the concept of differential capacity was applied to the test data. This analysis simply takes the derivative of the charge added/removed with respect to the cell voltage or charge added or removed during the test. Peaks in the differential capacity are believed to be related to specific intercalation sites within the anode and/or cathode. As the cell aged with testing, the height of the peaks changed as did their position with respect to the cell voltage or charge/discharge state. The exact nature of these sites, and how the testing influences them, is not presently known. The observed peaks are believed to arise due to specific intercalation sites within the anode and cathode. This concept of the differential capacity is believed to be useful to research groups conducting characterization studies on new, as well as aged, cells. The usefulness arises in that it provides information regarding the voltage and state of charge at which the properties of the cell are changing the most due to aging. 


\section{ACKNOWLEDGMENTS}

The authors acknowledge the assistance of various workers at the INEEL, SNL, and ANL. Thanks are due to Chinh Ho and Roger Richardson at the INEEL for conducting the testing of the batteries. Jeff Belt and Jon Christophersen (INEEL) for calculating the discharge and regen resistances from the test data. Chet Motloch (INEEL) for helpful discussions concerning the analysis of the data. Ira Bloom at ANL for helpful discussions concerning analysis and interpretation of the data. 


\section{CONTENTS}

ABSTRACT

SUMMARY

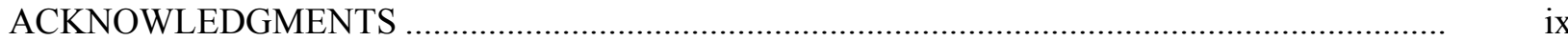

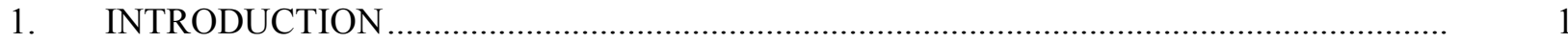

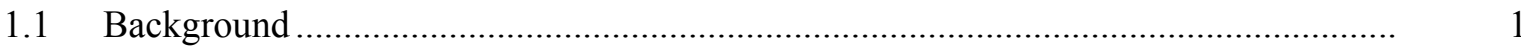

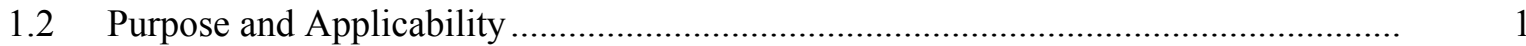

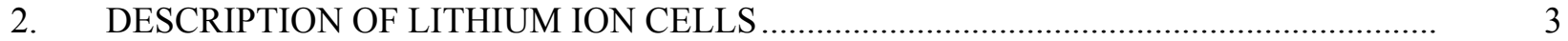

3. ELECTRICAL PERFORMANCE TESTS …................................................................ 5

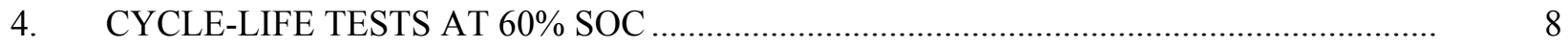

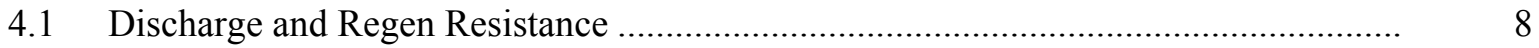

5. STATE-OF-CHARGE AND DELTA STATE-OF-CHARGE DEPENDENCE OF

THE LI-ION BATTERIES DURING CYCLE-LIFE TESTING .......................................... 21

6. LEAKAGE CURRENT, LEAKAGE RESISTANCE, AND DIFFERENTIAL CAPACITANCE OF CELLS TESTED USING THE LIFE CYCLE TEST .........................

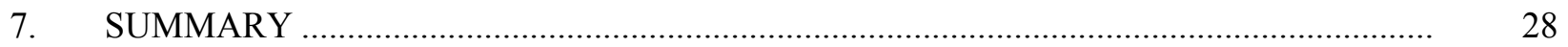

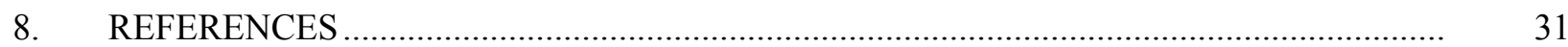

Appendix A-Figures for Cycle-Life Discharge and Regen Resistance Tests on ATD GEN 1 Li-Ion Batteries: Experimental Electrical Performance Test Cycles

Appendix B-Figures for Cycle-Life Discharge and Regen Resistance Tests on ATD GEN 1 Li-Ion Batteries at $60 \%$ State of Charge and Delta 3, 6, and 9\% State of Charge Swings

Appendix C-Figures for Cycle-Life Discharge and Regen Resistance Tests on ATD GEN 1 Li-Ion Batteries: Leakage Current, Leakage Resistance, and Differential Capacity

\section{TABLES}

1. Calendar-life test pulse profile ................................................................................ 5

2. Advanced Energy Technology Development cycle-life delta 3\% SOC pulse profile .............. 6

3. Advanced Energy Technology Development cycle-life 6\% SOC pulse profile...................... 6

4. Advanced Energy Technology Development cycle life 9\% SOC pulse profile ….................. 7 
5. Values of $\mathrm{E}_{\mathrm{act}}$ at $60 \% \mathrm{SOC}$ from analysis of cycle-life test data using the relationship: $\mathrm{R}(\mathrm{t}, \mathrm{T})=\mathrm{A}(\mathrm{T}) \mathrm{t}^{1 / 2}+\mathrm{B}(\mathrm{T})$, where $\mathrm{A}(\mathrm{T})=\mathrm{a}\left[\exp \left(\mathrm{E}_{\mathrm{act}, \mathrm{A}} / \mathrm{RT}\right)\right]$ and $\mathrm{B}(\mathrm{T})=\mathrm{c}\left[\exp \left(\mathrm{E}_{\mathrm{act}, \mathrm{B}} / \mathrm{RT}\right)\right]$. $\mathrm{E}_{\mathrm{act}}$ are activation energies, and $\mathrm{a}$ and $\mathrm{c}$ are preexponential constants ....

6. Values of the preexponential constants a and c at $60 \%$ SOC from analysis of cycle-life test data analysis at delta $3 \%$, delta $6 \%$, and delta $9 \%$ using the relationship: $\mathrm{R}(\mathrm{t}, \mathrm{T})=$ $\mathrm{A}(\mathrm{T}) \mathrm{t}^{1 / 2}+\mathrm{B}(\mathrm{T})$, where $\mathrm{A}(\mathrm{T})=\mathrm{a}\left[\exp \left(\mathrm{E}_{\mathrm{act}, \mathrm{A}} / \mathrm{RT}\right)\right]$ and $\mathrm{B}(\mathrm{T})=\mathrm{c}\left[\exp \left(\mathrm{E}_{\mathrm{act}, \mathrm{B}} / \mathrm{RT}\right)\right]$ 


\section{Cycle-Life Studies of Advanced Technology Development Program Gen 1 Lithium Ion Batteries}

\section{INTRODUCTION}

\subsection{Background}

The DOE Office of Advanced Automotive Technologies through the PNGV (Partnership for a New Generation of Vehicles) Advanced Energy Technology Development Program is engaged in the study of 18650-size lithium ion cells, which represent the high-power battery chemistry being developed for use in hybrid electric vehicles (HEVs). Concentrating on high power battery development, the Advanced Energy Technology Development (ATD) Program supports the PNGV, a government-industry partnership striving to develop, by 2004, a mid-size passenger vehicle capable of achieving up to three times the fuel economy of today's vehicles while adhering to future emissions standards and maintaining such attributes as affordability, performance, safety, and comfort. The ATD Program addresses these technical challenges through five major program areas, including baseline cell development, diagnostic evaluations, electrochemical improvements, advanced materials development, and low-cost packaging. The major objective of this work is to determine the causes of power fade after these cells are exposed to elevated temperatures and tested under various electrical performance evaluation tests. Another objective is to develop diagnostic analysis methods that can be used to determine the physical/chemical causes for cell degradation.

\subsection{Purpose and Applicability}

This report presents the electrical performance of lithium ion cells developed for the ATD program during cycle-life testing conducted at various temperatures and at $60 \%$ state of charge [1]. All tests were conducted in the Energy Storage Testing (EST) Laboratory, which is part of the Transportation Technologies and Infrastructure Department at the Idaho National Energy and Environmental Laboratory (INEEL).

The main focus of the report is to present cycle-life test data on the cells developed by the ATD program. Cycle life is of great importance, as battery systems are expected to have a lifetime of approximately ten years if they are to be a viable energy storage/source for the next generation of vehicles. Cycle life has been defined by two general statements. The USABC Electric Vehicles Battery Test Procedures Manual, Revision 2 [2] defines cycle life as "The number of cycles, each to a specified discharge, and charge termination criteria, such as depth-of-discharge, under a specified charge and discharge regime, that a battery can undergo before failing to meet its specified end-of-life criteria." This definition clearly depends on the specifics of the test protocols as specified in the test plan for a given battery system. The PNGV Battery Test Manual, Revision 2, discusses various cycle-life tests that may be used when testing batteries [3]. The cycle-life test as used in the ATD program has been designed and specified as applicable to the Generation 1 cells developed for this program.

The intent of the testing of the model lithium ion cells developed by the Advanced Technology Development (ATD) program is to characterize the electrical performance and to determine the calendarlife and cycle-life behavior of specially designed lithium ion cells having a nominal capacity of $0.9 \mathrm{~A} \cdot \mathrm{h}$. The DOE Office of Advanced Automotive Technologies (OATT) sponsored the testing and with the designated ATD Program Manager provided oversight. In general, the cells were subjected to the performance and life test procedures defined for the PNGV Program [3]. 
The testing of the cells documented in this report were conducted at the Idaho National Engineering and Environmental Laboratory (INEEL). Discussion and description of the terminology used in this report can be found in Reference 2, USABC Electric Vehicle Battery Test Procedures Manual, Revision 2, and in Reference 3, PNGV Battery Test Manual, Revision 2. The entire test procedure used to test the ATD Gen 1 cells is note reproduced here inasmuch as it is given in Reference 1, PNGV Test Plan for ATD 18650 Gen 1 Lithium Ion Cells. 


\section{DESCRIPTION OF LITHIUM ION CELLS}

The baseline lithium ion cells had the following specifications, as developed by Argonne National Laboratory (ANL) for the ATD program. Cells produced with these specified materials are referred to as Gen 1 cells.

\section{Positive electrode}

$\mathrm{LiNi}_{0.8} \mathrm{Co}_{0.2} \mathrm{O}_{2}$ (Sumitomo) (84 wt\%)

- $\quad$ Electronic additive: acetylene black (4 wt $\%)+$ SFG-6 graphite (Timcal) (4 wt \%)

- $\quad$ Binder: polyvinylidene fluoride, $-\left(\mathrm{CH}_{2} \mathrm{CF}_{2}-\right)_{\mathrm{n}}$, (PVDF) (Kureha KF-1100 (8 wt\%)

\section{Negative electrode}

- Blend of MCMB-6-2800 graphite (Osaka Gas) (75 wt\%), and SFG-6 (Timcal) (16 wt\%)

- $\quad$ Binder: PVDF (Kureha C) $(9 \mathrm{wt} \%)$

\section{Electrolyte}

- $\quad \mathrm{LiPF}_{6} / \mathrm{EC}$ (ethylene carbonate)+DEC (diethyl carbonate) $1: 1$

\section{Separator}

- $\quad$ polyethylene (PE) Celgard separator (37 micron thick)

Three hundred cells were built (18650-size; $64.9 \mathrm{~mm}$ high, $18.12 \mathrm{~mm}$ diameter) and shipped to various national laboratories (ANL, BNL, INEEL, LBNL, and SNL) for electrical performance testing, and physical/chemical diagnostic analysis. The cell distribution is given in the test plan [1]. For the various temperature tests, controlled temperature chambers having both heating and cooling capabilities were used. Temperature control was usually $\pm 3^{\circ} \mathrm{C}$.

The ATD Gen 1 cell limits are as follows:

\section{Discharge}

- $\quad$ Minimum Discharge Voltage:

- $\quad$ Maximum Discharge Current:

- $\quad$ Maximum Discharge Temperature:

\section{Charge and Regen}

- $\quad$ Maximum Charge/Regen Voltage:

- Maximum Charge/Regen Current:

\section{$3.0 \mathrm{~V}$}

2.0 A continuous; 7.2 A (8C) for up to an 18-s pulse; and $13.5 \mathrm{~A}(15 \mathrm{C})$ for up to a 2 -s pulse

$70^{\circ} \mathrm{C}$
4.1 V continuous; $4.3 \mathrm{~V}$ for up to a 2-s pulse

0.9 A continuous charge current; 12 A maximum regen current for up to a 2-s pulse 
- $\quad$ Maximum Charge Temperature: $\quad 40^{\circ} \mathrm{C}$

- $\quad$ Maximum Regen Temperature: $\quad 70^{\circ} \mathrm{C}$

\section{Recharge Procedure}

Charge at $0.9 \mathrm{~A}(\mathrm{C} / 1)$ constant current rate to $4.1 \mathrm{~V}$; continue to apply a constant voltage of $4.1 \mathrm{~V}$ for $2.5 \mathrm{hr}$ total recharge time. All recharging is to begin at $25 \pm 3^{\circ} \mathrm{C}$. 


\section{ELECTRICAL PERFORMANCE TESTS}

Characterization tests were performed on all the cells following a pretest readiness review. The characterization tests included a $\mathrm{C}_{1} / 1$ Static Capacity test; low- and medium-current Hybrid Power Pulse Characterization (L-HPPC and M-HPPC, respectively) tests at 2.7 and 7.2 A, respectively; and a 7-day self-discharge test at $3.660 \mathrm{~V}$, which corresponds to $50 \%$ state of charge (SOC) and impedance measurements at $1 \mathrm{kHz}$, at 100 and $0 \%$ SOC. Thermal Performance tests consisting of the static capacity and low-current HPPC tests were performed on four cells at temperatures of +5 and $+40^{\circ} \mathrm{C}$. Finally, reference performance tests (RPTs) were conducted on all cells before beginning life testing. The RPTs consisted of a single $\mathrm{C}_{1} / 1$ constant-current discharge, one medium-current HPPC test M-HPPC, and impedance measurements at $1 \mathrm{kHz}$ at 100 and $0 \%$ SOC. The RPTs were repeated every 4 weeks for designated cells at 40,50 , and $60^{\circ} \mathrm{C}$, and every 2 weeks for designated cells at $70^{\circ} \mathrm{C}$. All RPT tests were conducted at $25 \pm 3^{\circ} \mathrm{C}$. Further details of these tests are given in References 1 and 3. End of testing (EOT) was reached when a cell was unable to perform the medium-HPPC test at $60 \%$ depth of discharge (DOD) or falling below the $3.0-\mathrm{V}$-minimum cell voltage.

The cycle-life test profiles, which differ from the standard PNGV test profiles, were used because of the research nature of the ATD Program. They were designed to provide a family of test profiles that cycle known fractions of the cell capacity while using the same time-weighted rms (root-mean-square) current. This change was made in order to minimize the effects of different test profiles on the cycle-life results. A special calendar-life test profile was also developed for the ATD Program to obtain additional resistance data at regular (i.e., once-per-day) intervals without unduly cycling the cells undergoing this test. The idea was to apply a single-pulse profile once per day, from which the discharge and regen resistances could be calculated. The magnitude and duration of the special calendar-life test discharge and regen pulses were relatively modest, compared to the HPPC test profiles, so that the test would have minimal effect on the thermal condition of the cell under test. The magnitude and duration of the discharge test (i.e., 3.6 A for $9 \mathrm{~s}$ ) was set to half of the corresponding values used for the medium-HPPC test. The test cycle also incorporated a somewhat longer-than-normal rest period after the discharge pulse, to allow additional time for voltage recovery before the regen pulse. The calendar-life test profile is shown in Table 1 and in Figure 1 (see Appendix A). Note that positive values for the current correspond to a constant current discharge.

Each cell tested using the calendar-life test was assigned a temperature and target SOC (either 60 or $80 \%$ SOC in this ATD study). The determination of the voltage at a given SOC was determined from a calibration table provided by ANL that showed the voltage at a given SOC, found by conducting $\mathrm{C} / 25$ discharges on a number of test cells. The discharge and regen resistances were calculated by using $\mathrm{R}=$ $\Delta \mathrm{V} / \Delta \mathrm{I}$, i.e., the change of the voltage of the cell at the beginning of the discharge (or charge) to the end of

Table 1. Calendar-life test pulse profile.

\begin{tabular}{ccccc}
\hline $\begin{array}{c}\text { Step Time } \\
(\mathrm{s})\end{array}$ & $\begin{array}{c}\text { Cumulative Time } \\
(\mathrm{s})\end{array}$ & $\begin{array}{c}\text { Current } \\
(\mathrm{A})\end{array}$ & $\begin{array}{c}\text { Charge } \\
(\mathrm{A} \cdot \mathrm{s})\end{array}$ & $\begin{array}{c}\text { Cumulative } \\
\text { Charge } \\
(\mathrm{A} \cdot \mathrm{s})\end{array}$ \\
\hline 9 & 9 & 3.6 & 32.40 & 32.40 \\
60 & 69 & 0.0 & 0.00 & 32.40 \\
2 & 71 & -3.6 & -7.20 & 25.20 \\
2 & 73 & 0 & 0 & 25.20 \\
47 & 120 & -0.54 & 25.38 & 0.18 \\
\hline
\end{tabular}


the discharge (or charge) divided by the change in the current during the discharge (or charge). For the calendar life tests (see Figure 1 and Table 1) the discharge was held constant, but the voltage changed during the course of the discharge or recharge. The test was conducted once per day for a 4-week period for the 40,50 , and $60^{\circ} \mathrm{C}$ tests, and for a 2 -week period for the $70^{\circ} \mathrm{C}$ test.

This report discusses those cells subjected to cycle-life testing as part of their performance evaluation. The test results and modeling for these cells are presented. The cycle-life test profiles for the delta 3, 6, and 9\% SOC are given in Tables 2 through 4 and in Figures 2 through 4, respectively. These profiles are charge neutral, as shown. The test profiles were conducted once the cell had reached the test temperature (either $40,50,60$, or $70^{\circ} \mathrm{C}$ ). Each cell undergoing cycle-life testing was tested at the target temperature and SOC for 100 iterations, with a 1-hr rest period before and after the 100 profiles.

Designated cells underwent the cycle-life test for a 4-week period for the cells tested at 40,50 , and $60^{\circ} \mathrm{C}$, and for a 2-week interval for different cells tested at $70^{\circ} \mathrm{C}$. As for the calendar-life tests, $\mathrm{C} / 1$ and MHPPC reference tests $\left(\right.$ at $\left.25^{\circ} \mathrm{C}\right)$ were performed before and after the 4-week or 2-week test interval.

Table 2. Advanced Energy Technology Development cycle-life delta 3\% SOC pulse profile.

\begin{tabular}{ccccc}
\hline $\begin{array}{c}\text { Step Time } \\
(\mathrm{s})\end{array}$ & $\begin{array}{c}\text { Cumulative } \\
\text { Time } \\
(\mathrm{s})\end{array}$ & $\begin{array}{c}\text { Current } \\
(\mathrm{A})\end{array}$ & $\begin{array}{c}\text { Charge } \\
(\mathrm{A} \cdot \mathrm{s})\end{array}$ & $\begin{array}{c}\text { Cumulative } \\
\text { Charge } \\
(\mathrm{A} \cdot \mathrm{s})\end{array}$ \\
\hline 14 & 14 & 7.20 & 100.80 & 100.80 \\
10 & 24 & 0.00 & 0.00 & 100.80 \\
2 & 26 & -6.48 & -12.96 & 87.84 \\
2 & 28 & 0.00 & 0.00 & 87.84 \\
32 & 60 & 2.745 & -87.84 & 0.00 \\
20 & 80 & & & \\
\hline
\end{tabular}

Table 3. Advanced Energy Technology Development cycle-life 6\% SOC pulse profile.

\begin{tabular}{ccccc}
\hline $\begin{array}{c}\text { Step Time } \\
(\mathrm{s})\end{array}$ & $\begin{array}{c}\text { Cumulative } \\
\text { Time } \\
(\mathrm{s})\end{array}$ & $\begin{array}{c}\text { Current } \\
(\mathrm{A})\end{array}$ & $\begin{array}{c}\text { Charge } \\
(\mathrm{A} \cdot \mathrm{s})\end{array}$ & $\begin{array}{c}\text { Cumulative } \\
\text { Charge } \\
(\mathrm{A} \cdot \mathrm{s})\end{array}$ \\
\hline 14 & 14 & 7.20 & 100.80 & 100.80 \\
10 & 24 & 0.00 & 0.00 & 100.80 \\
2 & 26 & -6.48 & -12.96 & 87.84 \\
2 & 28 & 0.00 & 0.00 & 87.84 \\
14 & 42 & 7.2 & 100.80 & 188.64 \\
10 & 52 & 0.00 & 0.00 & 188.64 \\
2 & 54 & -6.48 & -12.96 & 175.68 \\
2 & 56 & 0.00 & 0.00 & 175.68 \\
64 & 120 & 2.745 & -175.68 & 0.00 \\
40 & 160 & & & \\
\hline
\end{tabular}


Table 4. Advanced Energy Technology Development cycle life 9\% SOC pulse profile.

\begin{tabular}{|c|c|c|c|c|}
\hline $\begin{array}{c}\text { Step Time } \\
(\mathrm{s})\end{array}$ & $\begin{array}{c}\text { Cumulative } \\
\text { Time } \\
(\mathrm{s})\end{array}$ & $\begin{array}{c}\text { Current } \\
(\mathrm{A})\end{array}$ & $\begin{array}{c}\text { Charge } \\
(\mathrm{A} \cdot \mathrm{s})\end{array}$ & $\begin{array}{c}\text { Cumulative } \\
\text { Charge } \\
(\mathrm{A} \cdot \mathrm{s})\end{array}$ \\
\hline 14 & 14 & 7.20 & 100.80 & 100.80 \\
\hline 10 & 24 & 0.00 & 0.00 & 100.80 \\
\hline 2 & 26 & -6.48 & -12.96 & 87.84 \\
\hline 2 & 28 & 0.00 & 0.00 & 87.84 \\
\hline 14 & 42 & 7.20 & 100.80 & 188.64 \\
\hline 10 & 52 & 0.00 & 0.00 & 188.64 \\
\hline 2 & 54 & -6.48 & -12.96 & 175.68 \\
\hline 2 & 56 & 0.00 & 0.00 & 175.68 \\
\hline 14 & 70 & 7.20 & 100.80 & 276.48 \\
\hline 10 & 80 & 0.00 & 0.00 & 276.48 \\
\hline 2 & 82 & -6.48 & -12.96 & 263.52 \\
\hline 2 & 84 & 0.00 & 0.00 & 263.52 \\
\hline 96 & 180 & 2.745 & -263.52 & 0.00 \\
\hline 60 & 240 & & & \\
\hline
\end{tabular}




\section{CYCLE-LIFE TESTS AT $60 \%$ SOC \\ 4.1 Discharge and Regen Resistance}

For the cycle-life tests conducted at $60 \%$ SOC, cells were only tested at the INEEL. The following data combined all of the available discharge and regen resistances, measured at the INEEL. Note, however, that some of the cells tested under a given temperature and delta $\%$ SOC condition failed prior too, or during, the cycle-life test. When this occurred, the data for that cell was not included in the averaged data presented below. Figures 5 through 8 present the discharge and regen resistances as a function of the square root of test time at temperature in hours. The test conditions were at 40,50,60, and $70^{\circ} \mathrm{C}$, respectively at $60 \% \mathrm{SOC}$, delta $3 \% \mathrm{SOC}$. The notation convention used in this report is to identify the test condition as xxZyy, where xx gives the $\%$ SOC (always $60 \%$ for this report) of the cell during the test, $\mathrm{Z}$ is 3,6 , or 9 and signifies that it is a cycle-life test at either delta 3,6 , or $9 \%$. yy specifies the test temperature (either $40,50,60$, or $70^{\circ} \mathrm{C}$ ). Thus, 60340 would specify a cell tested at $60 \%$ SOC, using the delta $3 \%$ SOC swing cycle-life test, and tested at $40^{\circ} \mathrm{C}$.

Figure 5 shows the discharge (designated Rdis) and regen (designated Rreg) resistances as a function of the square root of time at test temperature at the 60340 test condition. Data from three test cells are shown. The corresponding cell, numbered at the INEEL, is shown in the figure legend. Note that each data point shown represents the discharge or regen value measured after 100 cycle-life cycles had been completed, i.e., between the data points shown 100 test cycles were done. Note also that the data points do not start at zero hours, as the scatter in the cell's resistance had not stabilized until the time shown in the figure. This was due to the period of time the cell was being heated and equilibrated to the test temperature. The data shown also do not correspond to a period of 4 weeks. Due to instrumentation problems, the data collection and/or temperature control caused problems (particularly with the 40,50, and $60^{\circ} \mathrm{C}$ data) with data collection at the longer test times. Also observe that the cell-to-cell resistance variation was quite small, on the order of 3 to 4 milliohms. With regard to the plots showing the resistance as a function of the square root of test time, other time-dependent fitting functions were used in attempts to correlate the data given in this figure (as well as Figures 6 through 8). The square root of test time gave the best fit. This particular functional form can also be related to certain physical/chemical processes that may be occurring in the cells, discussed later in the report. Figures 6 through 8 show the discharge resistance as a function of the square root of the test time for the 50,60 , and $70^{\circ} \mathrm{C}$ tests. Each test temperature had its own group of test cells. Thus, a cell was tested only at a designated temperature (and delta\% SOC). For the $50^{\circ} \mathrm{C}$ test, three cells made it through the first 4 -week test period. For the $60^{\circ} \mathrm{C}$ test, three cells were tested at this temperature. Three cells were tested at $70^{\circ} \mathrm{C}$ for the first 2 -week period. In Figure 9, the average (over all of the available test data) is given of the discharge resistance (Rdis) and regen resistance (Rreg) as a function of the square root of the test time at temperatures of 40, 50,60 , and $70^{\circ} \mathrm{C}$ at delta $3 \%$ SOC. Note, as pointed out below, that it was assumed that all tests at a given temperature were actually done at that temperature. There was, however, some variation in the test temperatures for a given cell at a nominally specified target test temperature. This variation in the test temperature was not accounted for in Figure 9, as the variation was usually only several degrees centigrade. This temperature variation is addressed in the detailed treatments of the data presented below. The averaged data shown in Figure 9 have also been corrected for the time it took the cells to stabilize, which is why all data start at approximately time $=0 \mathrm{hr}$. In general, the resistances decrease as the temperature is increased. This is true for all data except that at $70^{\circ} \mathrm{C}$, where the resistance is slightly greater than that measured at $60^{\circ} \mathrm{C}$. One would expect that the resistance at this temperature would follow the general trend and be lower than at the other temperatures. The unusual behavior of the $70^{\circ} \mathrm{C}$ data probably indicates that an additional mechanism (or mechanisms) responsible for cell degradation is (are) occurring at this temperature. This point is discussed latter in the report. 
Figure 10 displays the fits of Rdis to the square root of test time in hours, using an expanded y-axis scale, for the four test temperatures. The slopes of the best fit to this time-dependent function, as well as the time-equal-to-zero intercepts are given in the figure. The goodness of fit at each of the test temperatures, $\mathrm{R}^{2}$, is also given. The fits to the data were done using Microsoft Excel. The slopes and the intercept values are generally seen to decrease with increasing temperature. The $\mathrm{R}^{2}$ values are also quite good. The exception is the $70^{\circ} \mathrm{C}$ data, which have a slope and intercept larger than the data at $60^{\circ} \mathrm{C}$. Similarly, in Figure 11 the fits to Rreg are shown for the four test temperatures. Again, the fits are quite good. The general trend is the same as that observed for Rdis in that as the temperature is increased, the slopes and intercepts decrease. The exception is the $70^{\circ} \mathrm{C}$ data. Also note from Figures 10 and 11 that the Rdis slopes and intercept values are larger than those for Rreg at the same test temperature. This means that the discharge resistance is increasing at a greater rate than the regen resistance at the same temperature, and also that the discharge resistance at zero time is also larger than the zero time regen resistance. These observations are also evident in Figure 9.

A functional form for the description of the time, temperature, state of charge, and delta state-ofcharge dependence of the discharge and regen resistances was assumed to have the following functional form:

$\mathrm{R}(\mathrm{t}, \mathrm{T}, \mathrm{SOC}, \operatorname{delta} \% \mathrm{SOC}))=\mathrm{A}(\mathrm{T}, \mathrm{SOC}$, delta$\% \mathrm{SOC}) \mathrm{F}(\mathrm{t})+\mathrm{B}(\mathrm{T}, \mathrm{SOC}, \mathrm{delta} \% \mathrm{SOC})$

where $t$ is the time at test temperature (in hours), $\mathrm{T}$ is the test temperature, $\mathrm{SOC}$ is the state of charge of the battery at the start of the cycle-life test, and delta\% SOC is the state-of-charge swing during the cyclelife test. A(T,SOC.delta\% SOC) and B(T,SOC,delta $\%$ SOC) are assumed to be only functions of the temperature, the state of charge, and the delta $\% \mathrm{SOC}$ only. The function $\mathrm{F}(\mathrm{t})$ is assumed to be only a function of the test time. The following results concern the verification of this relationship and are used to find the functional forms for $\mathrm{A}(\mathrm{T}, \mathrm{SOC}, \mathrm{delta} \% \mathrm{SOC})$ and $\mathrm{B}(\mathrm{T}, \mathrm{SOC}, \mathrm{delta} \% \mathrm{SOC})$. The best functional form, at least for the present data, for $\mathrm{F}(\mathrm{t})$ is the square root of test time. For brevity, $\mathrm{A}(\mathrm{T}, \mathrm{SOC}$, delta\% SOC) is simply referred too as $\mathrm{A}$, and $\mathrm{B}(\mathrm{T}, \mathrm{SOC}$,delta $\% \mathrm{SOC})$ is referred to as $\mathrm{B}$ unless the SOC dependence is specifically discussed. Once the functions for $\mathrm{A}$ and $\mathrm{B}$ have been determined, a physical/chemical basis for the functional forms are attempted, using the fits to the discharge and regen resistance as a guide.

As mentioned, in an attempt to understand the nonlinear increase in the resistance as a function of test time (in hours), the resistance data were fit to a number of functional forms, such as the logarithm of the test time, the test time raised to a power such as to the first and 3/2 power, and the test time raised to a power as best determined from the fits to the data. Polynomial functions were, of course, also used, and they give quite good fits, but the physical/chemical significance of such fits is in question, other than to simply correlate the data. As stated, the underlying reason for plotting the data as various functions of test time is to try to determine not only the time dependence of the resistance increase but, if a functional form for the time dependence can be found, to ascertain a physical/chemical process that will account for the resistance increase with cycle time. This information could then be used to understand the process(es) responsible for the cell degradation and, in turn, suggest possible changes in the construction of the cells. An additional aspect of the determination of the functional form of the time-dependant degradation would be to predict the cycle life of the cells at various other test temperatures. In Figures 12 (for Rdis) and 13 (for Rreg) for the 603-40,50,60,70 test conditions, the A parameter, i.e., the slopes of the fits to the data shown in Figures 10 and 11 are shown as a function of test temperature in degrees centigrade. Note that at a given nominal test temperature there is a slight variation in the actual test temperature. Three values of $\mathrm{A}$ are plotted at each nominal test temperature. The best fit using a linear function of the test temperature and the $\mathrm{R}^{2}$ value are given in each figure. For both Rdis and Rreg, the A function is observed to decrease as the test temperature increases. In Figure 14, the Rdis and Rreg A parameters are plotted as the exponential of the inverse of the Kelvin temperature. The best-fit fitting parameters are shown in the 
figure for both the discharge and regen values. Both the linear and exponential functions for the temperature dependence of the A parameter correlate the data reasonably well, but due to the scatter in the data the $\mathrm{R}^{2}$ values are not very high. From the fits given in Figures 12 through 14, the Rdis A parameter decreases at a slightly greater rate with increasing temperature than does the Rreg A parameter.

Figures 15 through 17 give similar treatments of the temperature dependence of the B parameter, also for the 603-40,50,60,70 test conditions. The discharge and regen B parameters as linear functions of the temperature (in degrees centigrade) are given in Figure 15 and 16, respectively. The fitting parameters are also given in the figures. Note that the scatter in the B parameter is much less than the scatter in the A parameter. As observed in this study, the A parameter determined from the square root of test time data fits is very sensitive to the data. This occurs since subtle changes in the slopes of the data curves fitted to the square root of the test time can significantly alter the A parameter. The B parameter, which represents the intercept of the square root of test time fits, is less sensitive to the test data. From the fits given in Figures 15 and 16, it can be seen that the Rdis B parameter decreases at a slightly greater rate with increasing temperature than does the Rreg B parameter. The intercept values are also larger for the A parameter, indicating that the discharge resistance is higher than the regen resistance, as has been pointed out. Figure 17 plots the Rdis and Rreg B parameters as a function of the exponential of the inverse of the Kelvin temperature. The fitting values are given in the figure. The fit to this functional form is not bad. Hence, as was the case for the A parameter, the fits to the temperature dependence of the $\mathrm{B}$ parameter can be reasonably correlated by both the linear in temperature and the exponential of the inverse temperature relations.

What are the mechanisms responsible for the resistance and increase in the resistance of a lithium ion battery? Zhang et al. [5] have discussed some of the possible mechanisms. The total resistance of the carbon anode and the metal oxide cathode is the sum of the following resistances: (a) electrolyte solution resistance, (b) surface layer resistance, (c) anode and cathode particle to particle contact resistance, (d) anode and cathode to current collector resistance, and (e) the charge transfer resistance. The interfacial impedance at the discharged state is larger when compared with the charged state for both the carbon and metal oxide electrodes. Experimental results using electrochemical impedance spectroscopy (EIS) show that the impedance of Li-ion cells, at least with $\mathrm{LiCoO}_{2}$ electrodes, is dominated by the positive electrode, i.e., the cathode. The total cell impedance was found to increases with a decrease in the SOC. Upon consideration of the multitude of possible mechanisms that can lead to resistance increases as the cell ages, the fact that a thin film, often referred too as the SEI (solid electrolyte interface) layer arising from the decomposition of the electrolyte and salt is a likely candidate. When the electrodes are in the charged state, a large portion of the $\mathrm{Ni}^{+4}$ and $\mathrm{Co}^{+4}$ cations will be present in the cathode. These ions have a strong oxidizing power, which can react with the electrolyte at the cathode/electrolyte interface. This reaction can cause the decomposition of the electrolyte to form a solid electrolyte interface (SEI) layer on the cathode. After extended cycling, the $\mathrm{LiNi}_{1-\mathrm{x}} \mathrm{Co}_{\mathrm{x}} \mathrm{O}_{2}$ electrode will be heavily passivated, resulting in a large resistance at the interface. Due to this increase in resistance, the reaction rate will be lower for both lithium ion insertion (intercalation) and lithium ion removal (de-intercalation). The earliest reference to the SEI layer that the authors are aware of is that by Goodenough et al. [6] They state that the polymeric surface layer must be in a dynamic state, dependent on cell temperature and state of charge, as well as the extent of aging of the cell. The resistances relate directly to the thickness of the surface layer. The SEI layer on carbonaceous electrode materials consists of many different materials, including $\mathrm{LiF}, \mathrm{Li}_{2} \mathrm{CO}_{3}$, LiCO-R, $\mathrm{Li}_{2} \mathrm{O}$, lithium alkoxides ( $\mathrm{Li}-\mathrm{O}-\mathrm{R}$, where $\mathrm{R}$ is a hydrocarbon), nonconductive polymers, and a number of other possible chemical compounds composed of electrolyte and salt decomposition products. The formation of the SEI layer occurs mainly during the initial formation (charging) cycle of the battery. The implication of the SEI layer on the carbon electrode is that it will cause a voltage drop across the layer. This will, in turn, modify the structure of the double layer at the carbon electrode/electrolyte interface, which generally increases the charge transfer resistance at this interface. Cycling will also cause capacity loss due to damage and disorder in the metal oxide cathode 
particles. Cycling induces severe strain, high-defect densities, and occasional fracture of the particles [5]. Severely strained particles exhibit cation disorder. These processes lead to changes in the thermodynamic properties and contact resistance of the metal oxide particles. The accumulation of strain in the particles may cause partial shedding of the electrode material from its current collector. A portion of the lithium ions in the cathode can also become inactive due to cation disorder. However, the main loss in the cathode, for example $\mathrm{LiCoO}_{2}$, is mainly caused by the change in resistance on the surface of the particles.

White et al. [7] have also discussed some of the processes that are known to result in capacity fade in lithium ion cells. These are lithium deposition on the anode (over-charge condition), electrolyte decomposition, anode and/or cathode active material dissolution, phase changes in the anode and cathode materials, and passive film formation over the electrode and current collector surfaces (SEI layer formation). The negative electrode material is metallic (carbon) and, therefore, its contribution to the overall ohmic resistance should be negligible. Its electrical conductivity is not expected to change with cycling. The metal oxide positive electrode (i.e., the cathode) if comprised of $\mathrm{Li}_{\mathrm{y}} \mathrm{CoO}_{2}$ is a

semiconductor. Therefore, its conductivity would be invariant with cycling when measured at a certain voltage, i.e., when the lithium-ion content in the cathode solid matrix is kept at a certain level. Ionic conductivity of the electrolyte, also, does not contribute significantly to the measured conductivity. This is substantiated by the work of Narayanan et al. [8], who state that the process of lithium ion diffusion in the anode and cathode lattice is considerably slower that that in the electrolyte. Therefore, the lithium ion diffusion in the electrode materials would be one of the rate-limiting steps. Thus, the processes affecting the impedance directly relate to the electrode materials and their interactions with the electrolyte, i.e., the SEI layer. Ozawa [9], and Megahed and Scrosati [10] have also discussed and confirmed these processes. G. Nagasubramanian [11], using EIS methods, found that the impedance and changes in the impedance are mostly due to the cathode. He also found that the interfacial impedance increases as the SOC of the cell decreases. From his measurements, he finds that the cell impedance comes mostly from the cathode/electrolyte interface, not from the anode/electrolyte interface. Guyomard et al. [12] also conclude that the oxidation of the electrolyte is the main failure mechanism for lithium ion batteries.

The extensive work of Auerbach et al. [13 and 14] also give an overview of the processes occurring in a lithium ion cell. In parallel to the flux of lithium ions to and into the electrodes, there is a flux of electrons from the current collector to the anode or cathode materials, which balances the charge. This electron flux also has to overcome resistance that exists among the electrode particles, all of which are partially covered by electronically insulating surface films, i.e., a SEI layer. Lithium intercalation into the graphite anode or the metal oxide cathode is a serial multistep process in which lithium ions have to first migrate through the electrolyte, then through the surface films that covers the electrodes. After this migration, the insertion into the electrode material is accompanied by charge transfer at the film/electrode material interface. This is then followed by solid-state diffusion of lithium into the electrode material. Finally, lithium accumulates within crystallographic sites in the bulk electrode material via phase transition(s) between the various intercalation stages. The intercalation stages, particularly for the metal oxide, depend on the crystalline structure of the electrode material. The process of charge transfer resistance can be related to three different processes: Li-ion transfer at the solution-surface film interface, Li-ion transfer at the surface film-electrode interface, and interparticle electron transfer between the particles constituting the electrode material. They also state that the increased resistance observed upon cycling the battery mostly reflects changes in the surface structure of the electrodes. After prolonged cycling, there are phenomena such as expansion and contraction of the electrode material's volume, which leads to local breakdown of the electrode's passivation layer (on a microscopic level). This allows continuous reduction and oxidation of electrolyte species. While the process occurs on a very small scale, it thickens the surface films, and, consequently, the electrode's impedance increases, particularly over the time constants that relate to lithium ion migration through the surface films, whose increasing thickness upon cycling makes them more resistive. The electrolyte composition has great impact on the surface films and, depending on its composition, the surface films may be the dominant factor determining the 
impedance of the electrode. However, this behavior may not be stable, i.e., the electrode's impedance, especially in the features that relate to the surface films, increases upon storage, and may also change as a result of thermal cycling, and charging and discharging of the battery.

The above discussion on the processes occurring in a lithium ion battery is a brief overview only of the processes involved. The literature concerning this topic is extensive. In summary, the overall insertion process of lithium in the battery electrodes is quite complicated. It includes diffusion of lithium ions in the solution phase, their migration through the surface films (SEI layer) covering the electrode particles (which are ionically conducting and electrically insulating), solid state diffusion, accumulation/consumption of lithium in the bulk (accompanied by a flux of electrons which counterbalance the charge), and, finally, phase transition(s) among the crystalline structures of the electrode materials. Thus, a lithium ion battery is a very dynamic system that depends on its construction, the materials used in its assembly, the rate of charge and discharge during electrical cycling, the state of charge, and its temperature. One physical/chemical process that stands out as a candidate for having the greatest impact on the impedance of the cell is the SEI layer, its growth, composition, structure, and thickness.

Looking at possible analogous processes that grow thin films upon a solid surface, one can consider the oxidation of metals. Upon examining the various reaction rates and corresponding rate equations for the oxidation of metals, one finds they are functions of a number of factors, such as temperature, oxygen pressure, elapsed time of reaction, surface preparation, and pretreatment of the metal. Although rate equations alone are insufficient to interpret oxidation mechanisms, these equations may be used to classify the oxidation of metals and may as such often limit the interpretation to a class of alternative mechanisms. The rate equations most commonly encountered may be classified as logarithmic, parabolic, and linear. They represent only limiting and ideal cases. Deviations from these rate equations and intermediate rate equations are also often encountered. In many instances, it may be difficult to fit rate data to any simple rate equation or combination of rate equations. In the following discussion, an analogy is made between a process occurring at the various surfaces present in a lithium ion battery, the exact nature having been, as yet, not definitively determined, and the growth of an oxide film on a metal surface [15-18].

Logarithmic Rate Process. This process is characteristic of the oxidation of a large number of metals at low temperatures where the reaction is initially quite rapid and then drops off to low or negligibly small values. This law is generally found to apply to the formation of very thin films of oxide between 20 and 40 angstroms thick, and formed at low temperatures. This behavior is often described by logarithmic rate equations that include the direct logarithmic rate equation:

Differential form: $\mathrm{dx} / \mathrm{dt}=\mathrm{k} /\left(\mathrm{t}+\mathrm{t}_{\mathrm{o}}\right)$

or

Integral form: $\mathrm{x}=(\mathrm{k})\left[\operatorname{Ln}\left(\mathrm{t}+\mathrm{t}_{\mathrm{o}}\right)\right]+\mathrm{a}$

where $\mathrm{k}$ is the rate constant, and $\mathrm{t}_{\mathrm{o}}$ is the initial time at which the thickness, $\mathrm{x}$, of the film at time zero from the start of the continued film growth is a. Interpretations of the logarithmic rate law have been based on the adsorption of reactive species, among other processes. Adsorption has been assumed to be the rate determining process during early oxide formation. The processes of adsorption and subsequent nucleation have been shown to lead to the initial nucleation of metal oxide at discrete sites on the metal surface. These oxide islands then proceed to grow rapidly over the metal surface until complete coverage is eventually achieved. 
Parabolic Rate Equation. At high temperatures, many metals are found to follow a parabolic time dependence:

Differential form: $[\mathrm{dx} / \mathrm{dt}]=\mathrm{k} / \mathrm{x}$

Integral form: $\mathrm{x}^{2}=\mathrm{kt}+\mathrm{c}$

or

$\mathrm{x} \propto \mathrm{t}^{1 / 2}$

Thus, the thickness of the thin film is proportional to the square root of the time that the film growth is occurring. As a general rule, parabolic oxidation signifies that a thermal diffusion process is rate determining $[15,16]$. Thermal diffusion processes generally have a temperature dependence given by an Arrhenius-like process (discussed later), where the diffusion is given by [19]

$\mathrm{D}=\mathrm{D}_{\mathrm{o}}[\exp (-\mathrm{E} / \mathrm{RT})]$

where $\mathrm{D}$ is the diffusion constant in $\mathrm{cm}^{2} / \mathrm{sec}, \mathrm{D}_{\mathrm{o}}$ is the diffusion constant at very high temperature, and $\mathrm{E}$ is the activation energy associated with the diffusion process. $\mathrm{R}$ is the gas constant, and $\mathrm{T}$ is the Kelvin temperature. Such a process may include a uniform diffusion of one or both of the reactants through a growing scale, or a uniform diffusion of gas into the metal.

Linear Rate Equation. Linear oxidation may be described by

Differential form: $[\mathrm{dx} / \mathrm{dt}]=\mathrm{k}$

or

Integral form: $\mathrm{x}=\mathrm{kt}+\mathrm{c}$

where $\mathrm{k}$ is the linear rate constant and $\mathrm{c}$ is the integration constant, i.e., the thickness of the film at time $\mathrm{t}=0$. In contrast to the parabolic and logarithmic rate equations, for which the rate of reaction decreases with time, the rate of linear oxidation is constant with time and is thus independent of the amount of gas or metal previously consumed in the reaction. This growth law is found to describe metal oxidation reactions whose rate is controlled by a surface reaction step or by diffusion of one of the reactants to the metal surface.

The analogy to the case of the lithium ion battery is that there would be a film growing on the surface of the anode and/or cathode materials over a period of time that is temperature-dependent. The thickness of this thin film could give rise to an increase in the resistance of the cell as the rate of migration into/out of the anode and/or cathode materials is impeded by the thin film. The thicker the thin film, the lower the mobility of the lithium ions and, thus, the higher the resistance.

Of the various model fits to the test time dependence of the cycle life resistance data discussed above, the only one found to fit the resistance data quite well is the square root of the test time.

The square root of test time could also correspond to a one-dimensional diffusion process [20-22]. The test time raised to the first power could correspond to a two-dimensional diffusion process, and the test time raised to the 3/2-power to a three-dimensional diffusion process [20-22]. The best fit to the time dependence of the cycle life resistance data is the square root of the time at test temperature, as the $\mathrm{R}^{2}$ 
values are quite high, as shown in Figures 5 through 11, and for the resistance data discussed below. It may well be that as the cell ages the SEI layer grows in thickness, leading to an increase in the resistance due to the migration (diffusion) of the lithium ions into/out of the anode and/or the cathode. The stresses experienced by the cathode particles during change and discharge, and during temperature variation, could lead to fracturing of the particles, as mentioned. This would effectively expose new surfaces on which a SEI layer would grow, thus effectively increasing the cathode resistance. This resistance would be observed as an increase of the discharge and regen resistances measured during the cycle-life test. If the increase in the discharge and regen resistance is proportional to the square root of time at test temperature, then the resistances can be expressed by a function having the form

$\mathrm{R}(\mathrm{t}, \mathrm{T}, \mathrm{SOC}, \operatorname{delta} \%$ SOC $)=\mathrm{A}(\mathrm{T}, \mathrm{SOC}, \operatorname{delta} \%$ SOC $) \mathrm{t}^{1 / 2}+\mathrm{B}(\mathrm{T}, \mathrm{SOC}, \mathrm{delta} \%$ SOC $)$

where the discharge and regen resistance, $\mathrm{R}(\mathrm{t}, \mathrm{T}, \mathrm{SOC}$,delta $\% \mathrm{SOC})$, is a function of test time, $\mathrm{t}$, test temperature, T, state-of-charge, SOC, and the delta $\%$ SOC. (That there is a dependence on the SOC has been verified by comparing the discharge and regen resistance when the calendar-life tests were conducted at 80 or $60 \%$ SOC.) The functions A(T,SOC,delta $\%$ SOC), referred to simply as A, and $\mathrm{B}(\mathrm{T}, \mathrm{SOC}$,delta\% SOC), referred to simply as $\mathrm{B}$, are assumed to be functions of the test temperature, SOC, and delta $\%$ SOC. To determine the temperature dependence of the functions A and B, one can plot the fitting coefficients determined from the fits shown in Figures 10 and 11 as various functions of the test temperature. The two best functional fits to A and B are the fits shown in Figures 12 through 17, i.e., as linear in temperature and as the exponential of the inverse temperature. Due to the scatter in the data, all four test temperatures appear to correlate with the fitting function. This excludes, with any degree of certainty, that something unusual is happening at one of the test temperatures, at least at the delta $3 \%$

SOC test condition. However, this analysis does not account for the observation that the $70^{\circ} \mathrm{C}$ resistances do not follow the general trend of the resistances observed at 40,50 , and $60^{\circ} \mathrm{C}$, as shown in Figures 10 and 11 .

Figures 14 and 17 show that if $A$ and $B$ are plotted as the exponential of the inverse temperature, i.e., $\mathrm{A}=\mathrm{a}[\exp (\mathrm{b} / \mathrm{T})]$ and $\mathrm{B}=\mathrm{c}[\exp (\mathrm{d} / \mathrm{T})]$, then a reasonably good fit to $\mathrm{A}$ and $\mathrm{B}$ could be obtained. The fitting coefficients from these fitting functions provide the values of $a, b, c$, and d. This type of function occurs in a number of physical/chemical processes, such as chemical kinetics, and in diffusion. A functional form or this kind is generally referred to as Arrhenius-like behavior, as it applies to a chemical reaction or to a diffusion-type of process. Arrhenius initially proposed the following equation for the interpretation of the temperature dependence of chemical reactions:

$\mathrm{k}=\mathrm{A}\left[\exp \left(-\mathrm{E}_{\mathrm{a}} / \mathrm{RT}\right)\right]$

where $\mathrm{k}$ is the rate of the process, $\mathrm{A}$ is a preexponential factor having the same units as $\mathrm{k}, \mathrm{E}_{\mathrm{a}}$ is an activation energy representative of an energy barrier over which the process (chemical reactants, diffusing species, etc.) must overcome in order to proceed, $\mathrm{R}$ is the gas constant, and $\mathrm{T}$ is the temperature in Kelvin. The physical process leading to Arrhenius-like behavior is that the rate of the process requires an energy barrier be overcome in order for the thermally activated process to occur. The probability of overcoming the energy barrier, in its simplest form, is given by the probability to overcome this barrier as a function of temperature, being $\propto \exp (-\mathrm{E} / \mathrm{RT})$. The fit of A and B to this functional form of the temperature is quite good for all four of the test temperatures, as discussed. Concerning the linear temperature fits to A and B (see Figures 12 and 13 and Figures 15 and16), the authors know of no physical/chemical process that would lead to a process leading to this form for the temperature dependence of the resistance. Using then the fit to the exponential of the inverse temperature, the A parameter can be expressed as

$\mathrm{A}(\mathrm{T})=\mathrm{a}[\exp (\mathrm{b} / \mathrm{T})]$ 
where $a$ is the fitting coefficient having the units of ohms/test time ${ }^{1 / 2}$, and $b$ has the units of temperature in Kelvin. The $b$ fitting parameter can be related to an activation energy, $E_{\text {dis, } A}$, using $b=E_{\text {dis, } A} / R$, where $R$ is the gas constant equal to $8.315 \mathrm{~J} / \mathrm{mole} / \mathrm{K}$, or 1.987 calories $/ \mathrm{mole} / \mathrm{K}$. Similarly, the discharge and regen B parameter, assuming an Arrhenius-like functional form, is given by the expression:

$\mathrm{B}(\mathrm{T})=\mathrm{c}[\exp (\mathrm{d} / \mathrm{T})]$

where $\mathrm{c}$ is a coefficient having the units of ohms and $\mathrm{d}$ is the fitting parameter having the units of temperature in Kelvin. As before, the $\mathrm{d}$ parameter can be related to an activation energy using $\mathrm{d}=$ $\mathrm{E}_{\mathrm{dis}, \mathrm{B}} / \mathrm{R}$, where $\mathrm{R}$ is the gas constant $(8.314$ joules $/ \mathrm{mole} / \mathrm{K}$, or 1.987 calories $/ \mathrm{mole} / \mathrm{K}) . \mathrm{E}_{\mathrm{dis}, \mathrm{B}}$ can be expressed in units of joules/mole or calories/mole, depending on the values used for the gas constant. For the 603-40,50,60,70 cycle life resistance, the value of $\mathrm{E}_{\mathrm{act}, \mathrm{A}}$ for the discharge resistance is calculated to be $18.2 \mathrm{kjoule} / \mathrm{mole}(4.35 \mathrm{kcal} / \mathrm{mole})$. The value of $\mathrm{E}_{\mathrm{act}, \mathrm{A}}$ for the regen resistance is calculated to have the value of $13.8 \mathrm{kjoule} / \mathrm{mole}(3.30 \mathrm{kcal} / \mathrm{mole})$. The values for the discharge $\mathrm{B}$ parameter would be $\mathrm{E}_{\mathrm{act}, \mathrm{B}}=$ $5.95 \mathrm{kjoules} / \mathrm{mole}(1.42 \mathrm{kcal} / \mathrm{mole})$. For the regen $\mathrm{B}$ parameter, $\mathrm{E}_{\mathrm{act}, \mathrm{B}}=5.76 \mathrm{kjoule} / \mathrm{mole}(1.38$ $\mathrm{kcal} / \mathrm{mole})$. Note that the parameters $\mathrm{a}, \mathrm{b}$, c, and $\mathrm{d}$ can be state-of-charge dependent and delta $\% \mathrm{SOC}$ dependent, as explicitly shown in the following equation:

$$
\begin{aligned}
& \mathrm{R}(\mathrm{t}, \mathrm{T}, \mathrm{SOC}, \mathrm{delta} \% \text { SOC })=\mathrm{a}(\mathrm{SOC}, \mathrm{delta} \% \mathrm{SOC})\{\exp [\mathrm{b}(\mathrm{SOC}, \mathrm{delta} \% \mathrm{SOC}) / \mathrm{T}]\} \mathrm{t}^{1 / 2}+\mathrm{c}(\mathrm{SOC}, \mathrm{delta} \% \\
& \text { SOC })\{\exp [\mathrm{d}(\mathrm{SOC}, \mathrm{delta} \% \text { SOC }) / \mathrm{T}]\}
\end{aligned}
$$

Since only one state of charge, $60 \%$, was studied in this report, the state-of-charge dependence of the various parameters could not be determined. The dependence of the parameters on delta $\% \mathrm{SOC}$ is discussed later in this report.

Figures 18 to 28 show the same treatment of the $60 \%$ SOC, delta $6 \%$ SOC data at the four test temperatures as used to analyze the $60 \%$, delta $3 \%$ SOC data. Figure 18 shows the discharge and regen resistances as a function of the square root of test time in hours for $40^{\circ} \mathrm{C}$ at this test condition. Four cells were tested as this test temperature. There is a rather large variation in the data for the four cells, in particular for the discharge resistance. However, most of the resistance values correlate well with the square root of test time. There is no consistent explanation why some of the discharge data do not follow this time dependence, as the corresponding regen resistances all correlated quite well with this type of time relation. Figure 19 shows the discharge and regen resistances for three cells at a test temperature of $50^{\circ} \mathrm{C}$. For most of the cells, the test time relationship used in the figure correlates well with data. Again, the discharge data has the most scatter. Figure 20 shows the resistances for two cells when the delta SOC was $6 \%$ at a temperature of $60^{\circ} \mathrm{C}$. Similarly, Figure 21 shows the data for a test temperature of $70^{\circ} \mathrm{C}$ for three cells. The scatter of the resistance is quite low in this data set. Averages of the data sets shown in Figures 18 to 21 are presented in Figure 22. All of the data were used to obtain these averages over the test times where there were values to average. The test time dependence of the averaged data follows the square root of test time quite well for all of the four test temperatures. The general trend in the discharge and regen resistance is that the discharge resistance is greater than the regen resistance, and that the higher the test temperature the smaller the resistance, except at the longer test times, where the resistance at $70^{\circ} \mathrm{C}$ became greater than those at $60^{\circ} \mathrm{C}$. Following the analysis of the data expressed in Equation (10), the temperature dependence of the A function in terms of a linear function of test temperature is given in Figure 23 for all of the cells studied at the delta $6 \%$ SOC condition. In this figure and in those that follow, the actual test temperature for each cell was used in the plot. As is apparent, there is considerable scatter in the data. There really is no reasonable reason to exclude a particular cell from the temperature data sets. The figure gives the resulting fitting parameters for the fit. As expected, the $\mathrm{R}^{2}$ value is not very good. Plotting the regen A parameter as a linear function of temperature, the fits to the data are shown in Figure 24. The scatter in the data is considerably less than that for the discharge A parameter. Using the same A values used in Figures 23 and 24, the correlation of A in terms of an exponential of the 
inverse of the test temperature for the discharge and regen values are given in Figure 25. Again, the scatter in the A parameter is considerable. The fits to this temperature relation are given in the figure. Figures 26 through 28 follow the same analysis of the B parameter presented above for the A parameter. The scatter in the data is considerably less than that for the A parameter, leading to the conclusion previously made that the A parameter is extremely sensitive to the slope of the resistance values plotted as a function of the square root of the test time.

The activation energies obtained from the Arrhenius-like fits, i.e., the temperature dependence being represented by the exponential of the inverse of the Kelvin temperature, for A and B as given in Figures 25 and 27 are as follows [using Equations (12) and (13)]: for A discharge, $\mathrm{E}_{\mathrm{act}, \mathrm{A}}=30.2$ kjoules $/$ mole $(7.23 \mathrm{kcal} / \mathrm{mole})$; for $\mathrm{A}$ regen, $\mathrm{E}_{\mathrm{act}, \mathrm{A}}=19.0 \mathrm{kjoules} / \mathrm{mole}(4.53 \mathrm{kcal} / \mathrm{mole})$; for $\mathrm{B}$ discharge, $\mathrm{E}_{\mathrm{act}, \mathrm{B}}=4.52 \mathrm{kjoules} / \mathrm{mole}(1.08 \mathrm{kcal} / \mathrm{mole})$; and for $\mathrm{B}$ regen, $\mathrm{E}_{\mathrm{act}, \mathrm{B}}=4.88 \mathrm{kjoule} / \mathrm{mole}(1.17 \mathrm{kcal} / \mathrm{mole})$. The values for the A activation energy for the $60 \%$ SOC, delta $6 \%$ SOC test for discharge and regen are larger, especially the discharge value, than those for the $60 \%$, delta $3 \%$ test. The B activation energy values for the $60 \%$ SOC, delta $6 \%$ test are slightly smaller than the B values for the $60 \%$ SOC, delta $3 \%$ test.

The discharge and regen resistance data for the $60 \%$, delta $9 \%$ tests are shown in Figures 29 through 32. At $40^{\circ} \mathrm{C}$ (Figure 29), two cells were used in the test, as some of the cells failed during the preceding RPTs (reference performance tests). Figure 30 shows the test results for three cells at the delta $9 \%$ test at $50^{\circ} \mathrm{C}$. From these data, it appears that something was wrong with Cell 50, as its discharge resistance as a function of the square root of test time behaved very strangely. The data from this cell was excluded from further consideration. The data from the other two cells were very similar. The test data for $60^{\circ} \mathrm{C}$, acquired on three cells, are shown in Figure 31. There was scatter in the data, especially for the discharge resistance. The data from the $70^{\circ} \mathrm{C}$ test are shown in Figure 32 for three cells. The data variation between the three cells was relatively small, and all of the data correlated well with the square root of test time. Figure 33 shows the average of the discharge and regen resistances for the delta $9 \%$ test averaged over the times and resistances for the four test temperatures. The data averages included those cells that appeared to behave in a similarly with the other cells at each test temperature. Due to lack of reasonable resistances at longer test times caused by tester/environmental chamber malfunctions, some of the data sets could not be averaged over the full time period of the test. The discharge resistance values had the most scatter and displayed a greater increase in resistance with time compared to the regen resistances. In general, the higher the test temperature, the smaller the resistance. However, at longer test times, the resistances at $50^{\circ} \mathrm{C}$ became greater than those at $60^{\circ} \mathrm{C}$.

Fits to the square root of test time using Equation (10) allowed determining the temperature dependence of A and B for each cell at each of the four test temperatures. As described, the A parameter for the discharge and regen resistances are plotted as linear functions of test temperature in Figure 34 and 35, respectively. As can be seen, the scatter in the A parameter is very large for both discharge and regen. The fits to a function linear in test temperature are given in each of the two figures. The A parameter is seen to decrease with increasing temperature, which indicates that the time rate of change of the resistance values decreases as the temperature is increased. The same A parameters for the discharge and regen are plotted in Figure 36 as a function of the exponential of the inverse of the Kelvin temperature. The fits to this form of the temperature-dependent function did not greatly improve the quality of the fit (represented by the $\mathrm{R}^{2}$ value). A similar analysis of the discharge and regen $\mathrm{B}$ parameter is given in Figures 37 through 39 . The scatter in the B parameter data is not nearly as great as was the case for the A parameter. From the exponential fits of the inverse of the Kelvin temperature, the activation energies can be calculated as before, using Equations (12) and (13). For the discharge A parameter, the value is 11.0 kjoule $/ \mathrm{mole}(2.63 \mathrm{kcal} / \mathrm{mole})$; for the regen A parameter the value is $9.51 \mathrm{kjoule} / \mathrm{mole}(2.27 \mathrm{kcal} / \mathrm{mole})$. The activation energy for the discharge $\mathrm{B}$ parameter is $5.57 \mathrm{kjoules} / \mathrm{mole}(1.33 \mathrm{kcal} / \mathrm{mole})$; the regen $\mathrm{B}$ 
values are $4.88 \mathrm{kjoule} / \mathrm{mole}(1.17 \mathrm{kcal} / \mathrm{mole})$. These values and those determined for the delta $3 \%$ and delta $6 \%$ tests are given in Table 5 .

Upon examination of the activation energies presented in Table 5, several overall trends can be observed. The discharge activation energies for $\mathrm{E}_{\mathrm{act}, \mathrm{A}}$ are greater than the corresponding regen $\mathrm{E}_{\mathrm{act}, \mathrm{A}}$ activation energies. From Equation (10), this indicates that the time rate of change of the discharge resistance is greater than the regen resistance. There appears to be no general trend for the $\mathrm{E}_{\text {act, } \mathrm{A}}$ activation energies, except to observe that the delta $6 \%$ values are higher that those for delta $3 \%$ and delta $9 \%$. The $\mathrm{E}_{\text {act, } \mathrm{B}}$ activation energies are less than the $\mathrm{E}_{\mathrm{act}, \mathrm{A}}$ activation energies. The $\mathrm{E}_{\mathrm{act}, \mathrm{B}}$ activation energies are all about the same, probably within experimental error. At present, the authors know of no reason why the values given in Table 6 are what they are. They are about the correct order of magnitude for processes that may occur in a battery such as the various diffusion processes that appear to have activation energies of several tens of kilo-joules. The authors have been unable to find any literature references to prior work in this area that would assist in the analysis or verification of these quantities.

Using Equation (14) with the values of $a, b$, c, and $d$ as determined from the analysis of the data given above, it is possible to compare the results of the model with the measured discharge and regen resistances at the four test temperature and the three state-of-charge swings. The activation energies that correspond to the $\mathrm{b}$ and $\mathrm{d}$ terms are given in Table 5. This comparison is made for the discharge and regen resistances for the delta 3\% cycle life data in Figures 40 and 41 . Selective averaged resistance data are plotted as a function of the test time compared with the model predictions for the $40,50,60$, and $70^{\circ} \mathrm{C}$ data. The model predictions are quite good for the 40 and $50^{\circ} \mathrm{C}$ data. The model, however, would predict

Table 5. Values of $\mathrm{E}_{\text {act }}$ at $60 \%$ SOC from analysis of cycle-life test data using the relationship: $\mathrm{R}(\mathrm{t}, \mathrm{T})=$ $\mathrm{A}(\mathrm{T}) \mathrm{t}^{1 / 2}+\mathrm{B}(\mathrm{T})$, where $\mathrm{A}(\mathrm{T})=\mathrm{a}\left[\exp \left(\mathrm{E}_{\mathrm{act}, \mathrm{A}} / \mathrm{RT}\right)\right]$ and $\mathrm{B}(\mathrm{T})=\mathrm{c}\left[\exp \left(\mathrm{E}_{\mathrm{act}, \mathrm{B}} / \mathrm{RT}\right)\right] . \mathrm{E}_{\text {act }}$ are activation energies, and $\mathrm{a}$ and $\mathrm{c}$ are preexponential constants.

\begin{tabular}{|c|c|c|}
\hline Test Condition $^{(a)}$ & $\mathrm{E}_{\mathrm{act}, \mathrm{A}}$ & $\mathrm{E}_{\mathrm{act}, \mathrm{B}}$ \\
\hline Rdis $(603-40,50,60,70)$ & $\begin{array}{l}18.2 \mathrm{kjoule} / \mathrm{mole} \\
(4.35 \mathrm{kcal} / \mathrm{mole})\end{array}$ & $\begin{array}{l}5.96 \mathrm{kjoule} / \mathrm{mole} \\
(1.42 \mathrm{kcal} / \mathrm{mole})\end{array}$ \\
\hline Rreg $(603-40,50,60,70)$ & $\begin{array}{l}13.8 \mathrm{kjou} / \mathrm{e} / \mathrm{mole} \\
(3.30 \mathrm{kcal} / \mathrm{mole})\end{array}$ & $\begin{array}{l}5.76 \mathrm{kjoule} / \mathrm{mole} \\
(1.38 \mathrm{kcal} / \mathrm{mole})\end{array}$ \\
\hline Rdis $(606-40,50,60,70)$ & $\begin{array}{l}30.2 \mathrm{kjoule} / \mathrm{mole} \\
(7.23 \mathrm{kcal} / \mathrm{mole})\end{array}$ & $\begin{array}{l}4.52 \mathrm{kjoule} / \mathrm{mole} \\
(1.08 \mathrm{kcal} / \mathrm{mole})\end{array}$ \\
\hline $\operatorname{Rreg}(606-40,50,60,70)$ & $\begin{array}{l}19.0 \mathrm{kjou} / \mathrm{e} / \mathrm{mole} \\
(4.53 \mathrm{kcal} / \mathrm{mole})\end{array}$ & $\begin{array}{l}4.88 \mathrm{kjoule} / \mathrm{mole} \\
(1.17 \mathrm{kcal} / \mathrm{mole})\end{array}$ \\
\hline Rdis $(609-40,50,60,70)$ & $\begin{array}{l}11.0 \mathrm{kjou} / \mathrm{e} / \mathrm{mole} \\
(2.63 \mathrm{kcal} / \mathrm{mole})\end{array}$ & $\begin{array}{l}5.57 \mathrm{kjoule} / \mathrm{mole} \\
(1.33 \mathrm{kcal} / \mathrm{mole})\end{array}$ \\
\hline Rreg $(609-40,50,60,70)$ & $\begin{array}{l}9.51 \mathrm{kjou} / \mathrm{e} / \mathrm{mole} \\
(2.27 \mathrm{kcal} / \mathrm{mole})\end{array}$ & $\begin{array}{l}4.88 \mathrm{kjoule} / \mathrm{mole} \\
(1.17 \mathrm{kcal} / \mathrm{mole})\end{array}$ \\
\hline \multicolumn{3}{|c|}{$\begin{array}{l}\text { a. The terminology } 60 \mathrm{X}-40,50,60,70 \text { designates that the cycle-life test was conducted at } 60 \% \mathrm{SOC} \text {, delta } \mathrm{X} \% \mathrm{SOC} \text {, and the data } \\
\text { analysis used all four test temperatures of } 40,50,60 \text {, and } 70^{\circ} \mathrm{C} \text {. } \\
\text { b. The values for the activation energies were determined from the fits of } \mathrm{A}(\mathrm{T}) \text { and } \mathrm{B}(\mathrm{T}) \text { to an exponential of the inverse of the } \\
\text { test temperature in Kelvin. The slope of this fit provides a number, say } \mathrm{x} \text {, that is related to an activation energy by } \mathrm{x}=\text { Eact } / \mathrm{R} \text {, } \\
\text { where } \mathrm{R} \text { is the gas constant }(\mathrm{R}=8.314 \text { joules } / \text { mole/Kelvin or } 1.987 \text { calories } / \text { mole } / \text { Kelvin }) \text {. }\end{array}$} \\
\hline
\end{tabular}


that the $60^{\circ} \mathrm{C}$ resistance would be larger than the $70^{\circ} \mathrm{C}$ resistance. Experimentally, this is not the case, as the $70^{\circ} \mathrm{C}$ resistance values are higher than the $60^{\circ} \mathrm{C}$ values. Based on the model and the experimental data, new physical/chemical processes may be occurring at 60 and $/$ or $70^{\circ} \mathrm{C}$ that cause the resistance to not follow the general trend of a lower resistance the higher the temperature. Also shown in Figures 40 and 41 are the discharge and regen resistances for a test temperature of $25^{\circ} \mathrm{C}$. This ability to predict the discharge and regen resistance at temperatures other than the ones studied experimentally is one of the main points in conducting this modeling effort. Unfortunately, there were no data acquired at $25^{\circ} \mathrm{C}$, or other temperatures, that may be used to validate the model, particularly at the lower temperatures.

Similarly, experimental discharge and regen resistances are compared to the model predictions for the case of the delta $6 \%$ SOC tests. Figures 42 and 43 make the comparisons. The 40 and $50^{\circ} \mathrm{C}$ data are well represented by the model. The model is not bad for the 60 and $70^{\circ} \mathrm{C}$ data, but it does not account for the greater discharge and regen resistance at 70 than at $60^{\circ} \mathrm{C}$. The model predictions for the resistances at $25^{\circ} \mathrm{C}$ are also shown in the figures. As expected from the model, the $25^{\circ} \mathrm{C}$ resistances are larger than at the other temperatures.

The delta 9\% SOC swing data are compared to the model in Figures 44 and 45 . Overall, the fits to the experimental data are not bad, but for this case the data at 50,60 , and $70^{\circ} \mathrm{C}$ are not as well predicted by the model. As for the other delta $\%$ SOC data, the 60 and $70^{\circ} \mathrm{C}$ resistances are reversed in that the $70^{\circ} \mathrm{C}$ resistance data are larger than those at $60^{\circ} \mathrm{C}$.

As discussed, several physical/chemical processes may account for the square root of test time dependence and for the use of an Arrhenius-like activated process to account for the temperature dependence of the cycle life resistance data. The model used to evaluate the data had the following general form:

$\mathrm{R}(\mathrm{t}, \mathrm{T}, \mathrm{SOC}$, delta $\%$ SOC $)=\mathrm{a}(\mathrm{SOC}$, delta $\%$ SOC $)\{\exp [\mathrm{b}(\mathrm{SOC}$, delta $\%$ SOC $) / \mathrm{T}]\} \mathrm{t}^{1 / 2}+\mathrm{c}(\mathrm{SOC}$, delta $\%$ SOC $)\{\exp [\mathrm{d}(\mathrm{SOC}, \mathrm{delta} \% \mathrm{SOC}) / \mathrm{T}]\}$.

Due to the lack of data at various initial states of charge, it was not possible to determine the dependence of the resistance on this variable. With regard to the temperature, there are several relevant possible processes. The diffusion constant is often found to vary with temperature, as [19]

$\mathrm{D}=\mathrm{D}_{\mathrm{o}} \exp (-\mathrm{E} / \mathrm{RT})$

where $\mathrm{D}$ is the diffusion constant or diffusivity and has the unit of $\mathrm{cm}^{2} / \mathrm{sec} . \mathrm{D}_{\mathrm{o}}$ is the limiting diffusion at high temperatures, $\mathrm{E}$ is the activation energy for diffusion, $\mathrm{R}$ is the gas constant, and $\mathrm{T}$ is the temperature in Kelvin. E corresponds to the energy barrier for the thermally activated diffusion of the atom or ion in the solid. The exponential term accounts for the fact that the atom or ion will have sufficient thermal energy to pass over the potential energy barrier a fraction $\exp (-\mathrm{E} / \mathrm{RT})$ of the time and, thus, is a probability function. The diffusion coefficient of lithium in the electrolyte is four to five orders of magnitude larger than the diffusion coefficient of lithium in the cathode and, presumably, through the SEI layer. For the case when the diffusion species are charged, the ionic mobility and the conductivity from the diffusivity are given by the relations [19]

Ionic mobility $\propto(1 / \mathrm{RT}) \mathrm{D}=(1 / \mathrm{RT}) \mathrm{D}_{\mathrm{o}} \exp (-\mathrm{E} / \mathrm{RT})$

Conductivity $\propto$ Ionic mobility $\propto(1 / \mathrm{RT}) \mathrm{D}_{\mathrm{o}} \exp (-\mathrm{E} / \mathrm{RT})$

Inasmuch as the resistivity is inversely proportional to the conductivity, then one may model the resistance, which is proportional to the resistivity, as 
This expression is similar to that used previously except for the additional temperature term, $\mathrm{T}$, multiplying the exponential function of the inverse of the temperature. From this relationship, an additional model for the discharge and regen resistances could be to fit the temperature dependence using Equation (18) and compare it to the model predictions when there is not the preexponential temperature factor as in Equation (14). This approach has been used to analyze calendar-life data for a different group of ATD cells that were part of the ATD Program. The approach used consisted of using the square root of time at test temperature to correlate the time dependence of the discharge and regen resistances as in Equation (14). The temperature dependence of $\mathrm{A}(\mathrm{T}, \mathrm{SOC})=(\mathrm{a})(\mathrm{T}) \exp (\mathrm{b} / \mathrm{T})$, with $\mathrm{B}(\mathrm{T}, \mathrm{SOC})=$ (c) $(T) \exp (d / T)$, were as described above. In order to fit these expressions for $A(T)$ and $B(T)$, the expressions where these parameters were determined from fitting the square root of time dependence, the functions $A(T) / T=(a) \exp (b / T)$ and $B(T) / T=(c) \exp (b / T)$ were used. In this case, there was only a very slight difference between the two different methods. This is because the exponential term of the inverse of the temperature dominates the expression, causing the preexponential $\mathrm{T}$ term to have only a minor influence on the fits for A and B. These differences are probably well within the experiment errors of the data used for the curve fitting. The two models have a physical basis in ion diffusion-types of mechanisms for, presumably, the transport of the lithium ions into/out of the electrodes and/or through the SEI layers on each of the electrodes. The ion conductivity model, that has a preexponential factor in temperature, is probably the most physically satisfying as the temperature dependence naturally has the form $\mathrm{R}(\mathrm{T}) \propto \exp \left(\mathrm{E}_{\mathrm{act}} / \mathrm{RT}\right)$. The diffusion model also gives this natural form if it is rationalized that if the diffusion of the lithium is slower at a given temperature then this process would lead to $\mathrm{R} \propto 1 / \mathrm{D} \propto$ $\exp \left(\mathrm{E}_{\mathrm{act}} / \mathrm{RT}\right)$, i.e., it would cause the resistance to increase as the temperature is reduced. However, the cycle life data are not sufficiently accurate to discriminate between the conductivity model and the pure diffusion model, i.e., when the preexponential temperature is not included in the model. The conductivity model naturally accounts for the resistance being related to the inverse of the conductivity and the resulting temperature dependence of the resistance decreasing as the temperature increases. This is observed, in general, experimentally. Although the conductivity model has a preexponential factor linear in temperature, as previously stated, the model is dominated by the exponential function of the inverse temperature, at least over the temperature range of the tests.

Neither using the exponential of the inverse of the temperature nor the temperature dependence being a linear function of temperature (see for example Figures 12, 13, 15, 16, 23, 24, 26, 27, 34, 35, 37, and 38) for $\mathrm{A}(\mathrm{T})$ and $\mathrm{B}(\mathrm{T})$ can account for the discharge and regen resistances at $70^{\circ} \mathrm{C}$ (and sometimes at $60^{\circ} \mathrm{C}$ ) not following the general trend of the higher the test temperature the lower the resistance. A quadratic (or higher order polynomial) function in the test temperature may account for this experimental observation, but the underlying physical/chemical processes would be lost in using such a purely curve fit-based correlation method. This approach does not provide physical/chemical insight into the processes giving rise to the time and temperature dependence of the experimental data.

For completeness, the values of the preexponential constants obtained from the fits to the delta 3,6 , and 9\% cycle life data for the case when Equation (14) is used to correlate the data are shown in Table 6. At present, there is no explanation for the magnitude of these values based on a physical/ chemical model, nor have literature values been found that provides insight into the values. 
Table 6. Values of the preexponential constants a and $\mathrm{c}$ at $60 \% \mathrm{SOC}$ from analysis of cycle-life test data analysis at delta $3 \%$, delta $6 \%$, and delta $9 \%$ using the relationship: $\mathrm{R}(\mathrm{t}, \mathrm{T})=\mathrm{A}(\mathrm{T}) \mathrm{t}^{1 / 2}+\mathrm{B}(\mathrm{T})$, where $\mathrm{A}(\mathrm{T})$ $=\mathrm{a}\left[\exp \left(\mathrm{E}_{\mathrm{act}, \mathrm{A}} / \mathrm{RT}\right)\right]$ and $\mathrm{B}(\mathrm{T})=\mathrm{c}\left[\exp \left(\mathrm{E}_{\mathrm{act}, \mathrm{B}} / \mathrm{RT}\right)\right]$.

\begin{tabular}{lll}
\multicolumn{1}{c}{ Test Condition $^{(\text {a) }}$} & $-^{\mathrm{a}}$ & $-^{\mathrm{c}}$ \\
\hline Rdis $(603-40,50,60,70)$ & $7.53 \times 10^{-7} \mathrm{ohm} /(\text { day })^{1 / 2}$ & $4.97 \times 10^{-3} \mathrm{ohm}$ \\
Rreg $(603-40,50,60,70)$ & $2.14 \times 10^{-6} \mathrm{ohm} /(\text { day })^{1 / 2}$ & $3.72 \times 10^{-3} \mathrm{ohm}$ \\
Rdis $(606-40,50,60,70)$ & $1.14 \times 10^{-8} \mathrm{ohm} /(\text { day })^{1 / 2}$ & $8.30 \times 10^{-3} \mathrm{ohm}$ \\
$\operatorname{Rreg}(606-40,50,60,70)$ & $3.65 \times 10^{-7} \mathrm{ohm} /(\text { day })^{1 / 2}$ & $5.22 \times 10^{-3} \mathrm{ohm}$ \\
Rdis $(609-40,50,60,70)$ & $1.21 \times 10^{-5} \mathrm{ohm} /(\text { day })^{1 / 2}$ & $5.55 \times 10^{-3} \mathrm{ohm}$ \\
$\operatorname{Rreg}^{1 / 2}(69-40,50,60,70)$ & $1.25 \times 10^{-5} \mathrm{ohm} /(\text { day })^{1 / 2}$ & $5.08 \times 10^{-3} \mathrm{ohm}$
\end{tabular}

a. The terminology $60 \mathrm{X}-40,50,60,70$ indicates that the modeling used the data $60 \%$ SOC, $\mathrm{X}=$ delta $3 \%$, delta $6 \%$ or delta $9 \%$ at the test temperatures of $40,50,60$, and $70^{\circ} \mathrm{C}$.

b. The values for the preexponential constants a and c were determined from the fits of $A(T)$ and $B(T)$ to an exponential of the inverse of temperature in Kelvin. The intercept of this fit at infinite temperature defines the values of a and c. 


\section{STATE-OF-CHARGE AND DELTA STATE-OF-CHARGE DEPENDENCE OF THE LI-ION BATTERIES DURING CYCLE-LIFE TESTING}

This section presents and discusses the discharge and regen resistances measured when the cells were at $60 \%$ SOC, as a function of delta states of charge of 3, 6, and 9\%. Equation (14) was initially assumed to correlate the discharge and regen resistances measured during the cycle-life tests. In this expression, it was assumed that the resistance was a function of the state of charge (SOC) of the cell at the beginning of the test pulse sequence, and also a function of the state-of-charge swing during the test, delta $\%$ SOC. As only one state of charge was tested, $60 \%$ SOC, the dependence of the resistances on this variable could not be determined. Three delta SOCs were used, but from the tests it was possible to extract only very general observations. From the values determined for a(delta\% SOC), b(delta\% SOC), $\mathrm{c}($ delta $\%$ SOC), and $\mathrm{d}($ delta $\% \mathrm{SOC}$ ) as given in Tables 5 and 6 , these parameters as a function of delta $\%$ SOC are given in Figures 46 to 49 . The values for both the discharge and regen are given in these figures. Figure 46 shows the a(delta\% SOC) values as a function of delta\% SOC. Note that the a value's scale is logarithmic. The apparent straight lines in the plot are exponential fits to the data and are used only as a means to guide the eye. Note that the a values span a range of almost three decades, with delta $6 \%$ being the smallest for both discharge and regen, with the regen a values the largest. From these data, one cannot derive any definite conclusions, except that the a(delta $\%$ SOC) at delta $6 \%$ SOC is considerably the smallest. For comparison, Figure 47 shows the $b(d e l t a \%$ SOC) values as a function of delta $\%$ SOC. [The values are given in Kelvin that can be converted to joules/mole (calories/mole) by multiplying by the gas constant $\mathrm{R}=8.314$ joules $/ \mathrm{mole} / \mathrm{K}(1.987$ calories $/$ mole $/ \mathrm{K}$. $)$ ] Again, the quadratic polynomial fit to the data is only a guide. In this instance, the delta $\%$ SOC for delta $6 \%$ SOC is larger than the other delta $\mathrm{SOC}$ values for both discharge and regen. The discharge $\mathrm{b}$ value is also greater at each delta $\% \mathrm{SOC}$ than are the regen values. Note that it is the combination of the preexponential value a and the exponential of the $b$ value divided by the Kelvin temperature that gives the function $\mathrm{A}(\mathrm{T}$, delta\% SOC), which multiplies the square root of test time. The $\mathrm{A}(\mathrm{T}, \mathrm{delta} \% \mathrm{SOC})$ is the slope of the resistance data plotted as a function of the square root of the test time. The time rate of change of the resistance is given by

$\mathrm{dR}(\mathrm{T}, \mathrm{delta} \% \mathrm{SOC}) / \mathrm{dt}=\mathrm{A}(\mathrm{T}, \mathrm{delta} \% \mathrm{SOC}) /\left(2 \mathrm{t}^{1 / 2}\right)$

Thus, $\mathrm{A}(\mathrm{T}$,delta $\% \mathrm{SOC})$ is a temperature and delta $\% \mathrm{SOC}$ a dependent function that multiples the time rate of change of the resistance $\left(1 / t^{1 / 2}\right)$. The greater the A value, the greater will be the relative time rate of change of the resistance. Currently, there is no known physical/chemical model that would provide insight into the delta $\%$ SOC dependence of $a(d e l t a \%$ SOC $)$ and $b($ delta $\%$ SOC). With only three delta $\%$ SOC values for $a$ and $b$ as a function of delta $\%$ SOC, an attempt to fit these values with a model was not pursued in this test.

The c(delta $\%$ SOC) values as a function of delta $\%$ SOC are shown in Figure 48. The quadratic fits through the discharge and regen c parameters are, again, simply used as a guide. The c parameter values appear to be highly nonlinear; thus, given the limited range of delta $\%$ SOC no fit to any sort of model was attempted. The c parameter is the highest at delta $6 \% \mathrm{SOC}$, and the discharge values are greater than the regen values. Similarly, the d(delta\% SOC) values (in Kelvin) are shown as a function of delta $\%$ SOC in Figure 49. The quadratic fit through the three data points is, again, only meant as a guide. In this instance, the d value is the lowest at delta $6 \%$ SOC for both discharge and regen. Note again that it is the combination of the $\mathrm{c}$ parameter and the exponential of the $\mathrm{d}$ parameter divided by the Kelvin temperature that determines the resistances at test time equal to zero, as given by Equation (14).

As a summary to this portion of the report, the values of the dependence of the $a, b$, c, and $d$ functions [shown in Equation (14)] as delta\% SOC changes were presented and discussed. No attempt at 
developing a model for the observed delta $\%$ SOC dependence of these parameters was attempted. It appears, however, that for some reason the delta $6 \%$ SOC discharge and regen values cause the parameters not to follow a general trend with regard to the delta $\%$ SOC. The cause for this difference in the delta $6 \%$ SOC test data is not now known. 


\section{LEAKAGE CURRENT, LEAKAGE RESISTANCE, AND DIFFERENTIAL CAPACITANCE OF CELLS TESTED USING THE LIFE CYCLE TEST}

Representative leakage-current, leakage-resistance, and differential-capacitance data are now examined for the those ATD Gen 1 cells tested at the $60 \%$ SOC condition and for the delta $\%$ SOC swings of 3,6 , and $9 \%$. For the leakage current, following each one of the $\mathrm{C} / 1$ charge steps there was a duration of $\sim 1.5 \mathrm{hr}$ during which the voltage of the cell was held at $4.1 \mathrm{~V}$ and the current monitored. The current during this time period slowly decreased after the cell had reached a voltage of $4.1 \mathrm{~V}$. This test time was not sufficient for the cell to reach a true equilibrium value but was sufficient to describe the general trends in the current, as described below. This current can be referred too as the leakage current, i.e., that amount of charge that the cell will still accept due to losses arising from the resistance of the cell as the cell reaches an equilibrium charge capacity. This decaying leakage current for a representative cell that was undergoing a 60970 test, i.e., $60 \%$ SOC, cycle-life test at delta $9 \%$, at a test temperature of $70^{\circ} \mathrm{C}$, is shown in Figure 50. The data shown were acquired when the cell was held at $25^{\circ} \mathrm{C}$. The three plots are for when the cell had undergone four $\mathrm{C} / 1$ discharges (Test 1); after it had undergone four $\mathrm{C} / 1$ discharges, characterization tests, and an RPT (Test 2); and finally after it had undergone four C/1 discharges, characterization tests, an RPT, and a cycle life delta $9 \% \mathrm{SOC}$ test at $70^{\circ} \mathrm{C}$ (Test 3 ). The cell failed the $25^{\circ} \mathrm{C}$ RPT test following the first cycle-life test. Note that the logarithm of the current is plotted as a function of test time in hours. Time zero was that time at which the cell had reached $4.1 \mathrm{~V}$ and the voltage subsequently held at this value. As can be seen in the figure, the current decay is not linear, nor is it logarithmic. Attempts at fitting these data to a functional form were not attempted. The point to be made in the plot is that as the cell ages through testing, the leakage current as a function of time increases due to, at present, unknown physical/chemical changes in the cell. The leakage current can be related to a leakage resistance via Ohm's Law, i.e., $\mathrm{R}_{\text {leakage }}(\mathrm{ohms})=(4.1 \mathrm{~V}) /$ Leakage current $(\mathrm{A})$. These data are shown in Figure 51, where it is seen that the resistance of the cell decreases as the cell ages. Initially for the fresh cell, the leakage resistance slowly approached a value of $\sim 600 \mathrm{ohms}$. Upon further testing, this resistance decreased over the same time period until at the final test at the same test time the resistance was $\sim 200$ ohms. Given sufficient time, the other leakage resistances may indeed approach the initial value, but a crude extrapolation to longer times indicates that at the final condition the resistance would be $\sim 300 \mathrm{ohms}$. Thus, due to testing, some properties of the cell have changed. This decreased resistance with use would mean that if the battery were to be trickle charged over a period of time it would require a higher current to maintain the constant voltage. It would also take longer for the battery to come to an equilibrium charge state.

Figure 52 shows the voltage of the cell (the same cell discussed above) over a voltage range of $\sim 3.2$ to $4.1 \mathrm{~V}$ as a function of charge added during three different $\mathrm{C} / 1$ discharges done at various stages in the cell's life. The same three states of life of the cell (listed in the figure) were those described above for the leakage current tests; each $\mathrm{C} / 1$ immediately preceded the leakage current test. It can be seen in the figure that when the cell is new (Test 1), its capacity is greater than when aged by the various characterization, RPTs, and calendar-life tests. Just before failing, the cell's capacity had decreased considerably from $\sim 0.82$ to $\sim 0.56 \mathrm{~A} \cdot \mathrm{h}$. Note that in the curves shown in Figure 52, there is a sharp voltage increase at the initiation of the charge pulse. This has been attributed to a voltage increase arising from a model that has a series resistor, sometimes referred to as an equivalent series resistor, connected to the battery, i.e., a battery assumed not to have a constant voltage as charge is removed. The voltage on the cell before initiation of the charge is $\mathrm{V}_{\mathrm{o}}$, the voltage at the instant of the discharge of current, $\mathrm{I}$, results in a voltage of $\mathrm{V}_{\mathrm{B}}=\mathrm{V}_{\mathrm{o}}+\mathrm{IR}$ for the battery using this model. As the cell ages, this equivalent series resistor is observed to increase. Note also in the curves given in Figure 52 the subtle change in the shape of the three curves as a function of voltage and charge added. To accentuate these differences, the derivative of the charge 
added with respect to the voltage can be calculated numerically. The method used to calculate the numerical derivative is known as a three-point derivative, given by the formula [23]

$\mathrm{df}\left(\mathrm{x}_{\mathrm{i}}\right) / \mathrm{dx}_{\mathrm{i}}=[1 / 2 \mathrm{~h}]\left[-\mathrm{f}\left(\mathrm{x}_{\mathrm{o}}-\mathrm{h}\right)+\mathrm{f}\left(\mathrm{x}_{\mathrm{o}}+\mathrm{h}\right)\right]$

where $f(x)$ is a function of $x$, and $h$ is the difference of the $x$ value from one point to the next, assuming that the differences are equal. A modification of his formula when $\mathrm{h}$ is not a constant is

$d f\left(x_{i}\right) / d x_{i}=\left[-f\left(x_{i-1}\right)+f\left(x_{i+1}\right)\right] /\left[\left(x_{i+1}-x_{i-1}\right)\right]$.

In this formula, the slope, i.e., the derivative at a particular point, is given by the slope of a straight line connecting the points before and after it. Equation (21) means that the derivative of the first and last points in a series of data points would not have a derivative taken at those points. Recognize that a numerical derivative accentuates any noise in the data, as will be seen in the presentation of the data. The derivative of the charge added (normalized by the total charge put into the cell during the $\mathrm{C} / 1$ charging portion of the test) with respect to the voltage will be referred to as one form of the differential capacity. The concept of differential capacity has previously been discussed in the literature [24-26]. This concept arises because of the fact that the capacity, $\mathrm{C}$, of the cell times its voltage, $\mathrm{V}$, is equal to the charge, $\mathrm{Q}$, contained in the cell. Thus, $\mathrm{CV}=\mathrm{Q}$ and $\mathrm{dC}=(\mathrm{dQ} / \mathrm{dV})$ where $\mathrm{C}$ is the capacity, $\mathrm{V}$ is the voltage, and $\mathrm{Q}$ is the charge. The purpose of calculating the differential capacity is to determine at what voltage (or SOC) the ability of the cell to accept charge changes as the cell ages. Minima (or maxima) in the differential capacity data have been ascribed to ordered compositions of the anode and/or cathode host lattice. These minima or maxima are thought to arise from specific structural sites in the anode and cathode where the lithium can reside during intercalation. For example, first principle calculations [27] done on $\mathrm{Li}_{x} \mathrm{NiO}_{2}$, have shown that there are, at low temperatures, ordered structures that are predicted to be stable when $\mathrm{x}=$ $0.75,0.66,0.5,0.33$, and 0.25 . These values of $x$ correspond to states of charge of $25,34,50,67$, and $75 \%$. Shown in Figure 53 are the differential capacities of the same cell discussed above for the same three states of life of the cell tested using the (60970) test condition. The increase in noise due to taking the derivative is apparent in the figure although a five-point moving average smoothing (a Microsoft Excel function) of the derivative data was taken in an attempt to reduce the noise. It is also apparent in the figure that the IR jump in the initial voltage of the battery increases as the cell ages due to the IR jump at the onset of the constant current discharge. In this figure, also notice that there are various peaks that show up in the differential capacity at various cell voltages. There may be other peaks in the derivative, but one would have to have a model, and a reason, to deconvolute the derivative spectra. This could be done numerically, but a peak shape would have to be assumed and initial estimates of the peak positions, number of peaks, and an assumed peak shape would have to be input to the deconvolution program. The interpretation of the peaks seen in Figure 53 is that the higher the peak the greater the ability of the cell to accept charge at that voltage and, therefore, represents an increase in the capacity of the cell at that voltage, since the derivative is positive. This is because the slopes of the curves in Figure 52 are positive, so the cell is accepting more charge. For example, for Test 1 there are apparent peaks at $\sim 3.53, \sim 3.68$, and $\sim 3.97 \mathrm{~V}$. As the cell ages (Test 2 ), the peak at $\sim 3.53 \mathrm{~V}$ apparently shifts to higher voltage, as does the peak at $3.68 \mathrm{~V}$. The peak at $\sim 3.97 \mathrm{~V}$ remains at about the same voltage. As the cell ages, it is also apparent that the area under the derivative, equal to the charge capacity of the cell, decreases as the cell ages, which is the same total charge input to the cell, as shown in Figure 52. With further aging, the differential capacity changes considerably. The peak at $\sim 3.53 \mathrm{~V}$ either disappears completely or shifts to $\sim 3.6 \mathrm{~V}$. The peak at $\sim 3.68 \mathrm{~V}$ decreases substantially, and the peak at $\sim 3.97 \mathrm{~V}$ apparently shifts to $\sim 4.1 \mathrm{~V}$ but is higher than when the cell was newer. The apparent shifts in the peak positions may be a result of the voltage jump at the onset of the constant current discharge. As a possible aid to researchers conducting diagnostics on the cells, differential capacity curves like those shown in Figures 53 may be used as a guide to investigate the changes in the physical/chemical processes where the greatest changes in cell capacity are occurring. Thus, studies at the voltage range of $\sim 3.53, \sim 3.68$, and $\sim 3.97 \mathrm{~V}$ may be of 
particular interest. One thing to point out in the differential capacity curves is that the apparent shifts in the peaks in the plot may occur because the voltage jump at the beginning of the charge causes the peaks to shift. An appropriate way to account for these apparent shifts needs to be found.

Another way of examining the differential capacity for the charging data is to plot it versus the percent SOC of the battery. This plot is shown in Figure 54, where the normalized differential capacity is plotted as a function of the percent SOC of the cell. The percent state of charge was calculated using the formula percent $\mathrm{SOC}=100$ (charge added to cell)/(total charge added to cell). The total capacity of the cell was determined during the constant current $(\mathrm{C} / 1)$ charge test for these measurements. The greatest changes occur at $\sim 15 \% \mathrm{SOC}$, where the capacity is actually seen to increase at this state of charge. The capacity, however, decreases over the SOC range of $\sim 25$ to $50 \%$ SOC. The capacity then increases from $\sim 53$ to $100 \%$ SOC. Notice also that the presentation of the differential capacity data in this manner eliminates the apparent peak shifts observed in the differential capacity as a function of voltage.

A similar treatment can be applied to the constant current discharge experimental data. For the same cell used in Figures 50 through 54, the C/1 discharge curves are shown at various stages of the cell testing in Figure 55. In this figure, there are three discharge curves at various stages in the life of the cell. These discharge curves are labeled Test 1 , Test 2, and Test 3 and were acquired at $25^{\circ} \mathrm{C}$. Test 1 is after the first three-charge/discharge $\mathrm{C} / 1$ tests. Test 2 is after the $3 \mathrm{C} / 1 \mathrm{~s}$, a characterization test, and after the first RPT test. Test 3 is after the $3 \mathrm{C} / 1 \mathrm{~s}$, a characterization test, an RPT, and after the first 2-week cyclelife test conducted at $70^{\circ} \mathrm{C}$. As was the case for the charging $\mathrm{C} / 1 \mathrm{~s}$, there is a change in the shape of the discharge curves. There is also a change in the IR voltage drop as the cell ages. Especially noticeable is the IR drop for Test 3. The total discharge capacity also decreases as the cell ages, decreasing from $\sim 0.92 \mathrm{~A} \cdot \mathrm{h}$ at Test 1 to $\sim 0.74 \mathrm{~A} \cdot \mathrm{h}$ at Test 3 .

The differential capacities of the data sets shown in Figure 55 are shown in Figures 56 through 58. Note that the negative of the differential capacity is plotted in this instance. When examining the discharge differential capacity presented in this manner, one should keep in mind that the higher the curve the worse the cell is performing, since charge is being removed at a more rapid rate. Figure 56 includes the data sets for the discharge curve after the $3 \mathrm{C} / 1 \mathrm{~s}$ (Test 1 ), the $3 \mathrm{C} / 1 \mathrm{~s}$, a characterization test, and an RPT (Test 2), and after the $3 \mathrm{C} / 1 \mathrm{~s}$, a characterization test, an RPT, and a life-cycle test at delta $9 \%$ and $70^{\circ} \mathrm{C}$ (Test 3 ). For the initial $25^{\circ} \mathrm{C}$ test, Test 1 , three peaks are apparent in the differential capacity curves: at $\sim 3.95, \sim 3.8$, and $\sim 3.52 \mathrm{~V}$. There is a slight decrease in the capacity for Test 2 and an apparent large decrease in the capacity at $\sim 3.95 \mathrm{~V}$. For Test 3 , there is a dramatic decrease in the capacity between $\sim 3.85$ and $\sim 4.02 \mathrm{~V}$. There is also a large decrease in the capacity at $\sim 3.4 \mathrm{~V}$. There is a substantial IR drop at the onset of the constant current $\mathrm{C} / 1$ discharge for all three tests, in particular for Test 3 . One aspect of the discharge (and charge) differential capacity curves is the apparent shift in the curves if the IR drop (or IR jump) is substantial. For example, Test 3 in Figure 56 should actually be shifted to the right in the figure. One possible method for accounting for this apparent shift can be accounted for by using the simple equation $\mathrm{V}_{\text {experinental }}=\mathrm{V}_{\text {battery }}$ - IR. The actual open circuit voltage $\left(\mathrm{V}_{\text {battery }}\right)$ on the battery would be $V_{\text {battery }}=V_{\text {experimental }}+$ IR, where $V_{\text {experimental }}$ is the battery voltage under load, and IR is the IR drop. (The sign in front of the IR term would be negative for the IR jump resulting from a constant current charge.) The resistance can be calculated by using the initial voltage drop divided by the current change. (To calculate the IR drop, the values of the voltage and the current from the first two data points collected by the battery tester were used.) The data were examined using this model. The results are shown in Figure 57. As can be seen, the data sets move to the right, in particular Test 3. From this figure, it would appear that the change in the differential capacity occurs mostly over the voltage range of $\sim 3.6$ to $\sim 3.8 \mathrm{~V}$. A better method appears to be required to account for the apparent shift in the differential capacity if the IR jump or IR drop is large at the beginning of the charge or discharge. As used previously, the differential capacity can be plotted as a function of the percent DOD. The data are plotted in this manner in Figure 58. The greatest change in the differential capacity presented in this manner is 
over the percent DOD range of $\sim 30$ to $\sim 90 \%$ DOD. If one wishes, the differential capacity can be plotted as a function of percent $\mathrm{SOC}$, since $\% \mathrm{SOC}=1-\% \mathrm{DOD}$.

A similar treatment as that given above for a 60970 cell was done on a cell tested using the 60340 test. The 60340 test should be a considerably less abusive test than the 60970 test, not only because of the lower delta\% SOC swing but because of the lower cycle-life test temperature. Note that the cycle-life portion of the 60340 test was conducted for a period of 4-weeks instead of the 2-weeks for the 60970 test. The leakage current at various stages of the aging of the cell are shown in Figure 59, where the logarithm of the leakage current following a $\mathrm{C} / 1$ charge is plotted as a function of the test time. Data Set 1 (Test 1 ) was acquired after the cell had four C/1 tests performed on it. Data Set 2 (Test 2) was after four C/1s, a characterization test, an RPT, and a calendar-life test at $40^{\circ} \mathrm{C}$. It is seen that as the cell ages, the leakage current does not fall off as rapidly as when the cell is relatively new. Figure 60 shows the corresponding leakage resistances. Comparing the leakage resistance of the cell tested under the 60970 condition (Figure 51), observe that the leakage resistance is larger for the 60340 condition as the cell ages. This means that in order to maintain $4.1 \mathrm{~V}$ on the cell, less current, i.e., charge, must be provided to compensate for the smaller IR losses when the cell is tested under the 60340 test condition. Therefore, the $70^{\circ} \mathrm{C}$ calendar-life test for 2 weeks is indeed more severe than is the $40^{\circ} \mathrm{C}$ test for 4 weeks and has a greater impact on the subsequent cell performance.

Figure 61 presents data from constant current charge tests, where the voltage as a function of charge added is graphed for two stages in the life of the cell. It is again apparent that as the cell ages, the cell's capacity (from 3.3 to $4.1 \mathrm{~V}$ ) falls from $\sim 0.78$ to $\sim 6.3 \mathrm{~A} \cdot \mathrm{h}$. Close inspection of the curves themselves reveals that there are changes in the shapes of the curves. Using again the concept of the differential capacity to magnify these changes, the resulting curves are shown in Figure 62. In the figure, the differential capacity, normalized to the capacity of the cell as measured during the $\mathrm{C} / 1$ charge, is shown as a function of the uncorrected cell voltage. Major changes are observed to occur as the cell ages (Test 1 is after four $\mathrm{C} / 1$ tests; Test 2 is after four $\mathrm{C} / 1$ tests, a characterization test, an RPT, and a cycle-life test at $40^{\circ} \mathrm{C}$ ). These changes occur the most at $\sim 3.53, \sim 3.68$, and at $\sim 3.97 \mathrm{~V}$. Comparing these data with the data shown in Figure 53 for the 60970 test, it can be seen that the voltages where the major changes occur are the about the same. However, the cell tested using the 60970 test displays a greater change, i.e., a reduced capacity for accepting charge. The changes in the IR jump are also more pronounced during the 60970 test compared to the 60340 test. The differential capacity during charging as a function of percent SOC is shown in Figure 63 for the 60340 test. These test data indicate that the major decrease in the capacity of the cell occurs at those processes responsible for peaks in the differential capacity occurring at $\sim 5$ to $\sim 15 \%, \sim 20$ to $50 \%$, and $\sim 55$ to $\sim 100 \%$ SOC. These are about the same percent SOC ranges as the major changes that occurred in the cell tested at the 60970 condition.

Several C/1 constant current discharge test measurements are shown in Figure 64 for the same 60340 cell discussed above. The cell voltage is plotted as a function of charge removed. Two tests are shown: Test 1 after $3 \mathrm{C} / 1$ discharge/charge cycles, and Test 2 after $3 \mathrm{C} / 1$, a characterization test, an RPT, and a cycle-life test at delta $3 \%$ SOC and $40^{\circ} \mathrm{C}$. The cell failed the M-HPPC test after this cycle-life test. Three things can be observed in the two curves in Figure 64: (1) there is a decrease in the charge removed from the cell from $0.87 \mathrm{~A} \cdot \mathrm{h}$ when the cell is new to $\sim 0.77 \mathrm{~A} \cdot \mathrm{h}$ when the cell is aged before failure; (2) there is an increase in the IR drop as the cell ages; and (3) there is a change in the shape of the curves as the cell ages. These three general observations are similar to those made when a cell was tested using the 60970 test (see Figure 55), as discussed above. Figure 65 shows the differential capacity for the two test data curves (the voltages have not been corrected). There is a substantial change in the curve as the cell ages. Due to the way the data are plotted minus the differential capacity, remember that the higher the curve, the worse the cell is performing. The major changes occur at about $\sim 3.96, \sim 3.7$, and $\sim 3.4 \mathrm{~V}$. The corresponding presentation of the data when the differential capacity is shown as a function of the percent DOD is given in Figure 66. The data in this figure again clearly show that the properties of the 
cell are changing as it ages. The major changes occur at $\sim 25$ and $\sim 45 \%$ DOD. The changes in the differential capacity for the 60340 test are qualitatively similar to those found to occur for the 60970 test (see Figures 57 and 58). However, the magnitudes of the changes are greater when the cell is tested under the harsher cycle life delta $9 \% \mathrm{SOC}, 70^{\circ} \mathrm{C}$ test condition. Also note that the capacity decrease for the cell tested at 60970 was greater than that at 60340 . After the final test preceding the last $\mathrm{C} / 1$ discharge was obtained, the capacity values had changed from $\sim 0.92$ to $\sim 0.75 \mathrm{~A} \cdot \mathrm{h}(18.5 \%)$ for the 60970 test compared to decreasing from $\sim 0.87$ to $\sim 0.77 \mathrm{~A} \cdot \mathrm{h}(11.5 \%)$ for the 60340 test].

From the data discussed above, i.e., the leakage current, leakage resistance, voltage change as a function of charge added and charge removed, and as the differential charge and discharge capacity, it is presently not know in detail what physical/chemical changes are responsible for the observations. It is hoped that the characterization tests being conducted on the cells will elucidate the mechanisms responsible for these observations.

In summary, the use of the concept of differential capacity as determined from the constant current charge and discharge tests may be a useful method of examining the physical/chemical processes responsible for the decrease in the electrical performance of lithium ion batteries as they undergo various test protocols. This information should be of help to researchers conducting physical/chemical characterization/diagnostic studies of the batteries and to those doing first principle theoretical calculations. 


\section{SUMMARY}

This report presents the test results pertaining to a group of prototype lithium ion batteries that were produced by the Advanced Technology Development (ATD) program. The cells had a nominal capacity of $0.9 \mathrm{~A} \cdot \mathrm{h}$ at a $\mathrm{C} / 1$ discharge rate, with a voltage range of 3 to $4.1 \mathrm{~V}$. The composition of the anode was carbon with binders; the composition of the cathode was $\mathrm{LiNi}_{0.8} \mathrm{Co}_{0.2} \mathrm{O}_{2}$, also containing binders. Aluminum was used as the cathode current collector; the anode current collector was copper. The electrolyte consisted of a $1 \mathrm{M} \mathrm{LiPF}_{6}$ in ethylene carbonate (EC):diethyl carbonate (DEC) in a 1:1 ratio. Polyethylene was used as the separator. The cells were assembled into a size 18650 container. The cells underwent a number of electrical performance tests to determine their electrochemical performance at $25^{\circ} \mathrm{C}$. A special cycle-life test was also conducted at elevated temperatures of $40,50,60$, and $70^{\circ} \mathrm{C}$.

The specific test for which the data are presented and discussed in this report was a special cyclelife test conducted for a 4-week period at test temperatures of 40,50 , and $60^{\circ} \mathrm{C}$, and for a 2 -week period at $70^{\circ} \mathrm{C}$. This test, consisting of three specified discharge and charge protocols, was designed to have a delta 3,6 ,or $9 \%$ cumulative state-of-charge (SOC) swing during the discharge portion of the test cycle. The delta state of charge was then returned to a zero net state-of-charge swing during the charging portions of the test cycle. A new approach was developed for the ATD Program for cycle-life testing to ensure that each cell was at the target SOC at the completion of each cycle-life profile. This report discussed the cycle-life tests conducted at $60 \%$ SOC with delta $3 \%, 6 \%$, and $9 \%$ SOC swings at test temperatures of 40 , 50,60 , and $70^{\circ} \mathrm{C}$. During the cycle-life test, the discharge resistance was determined from a 14-s discharge portion of the test; the regen resistance was determined from a 2-s regen portion of the test.

The results of the testing indicate that both the discharge and regen resistance increased in a nonlinear manner as a function of the test time at each delta $\%$ SOC test. The magnitude of the discharge and regen resistances depended on the temperature and delta $\%$ SOC at which the test was conducted. General observations derived from this study are as follows:

1. Both the discharge and regen resistances have a nonlinear increase with respect to time at test temperature, i.e., as the number of test cycles increased, the discharge and regen resistances increased also.

2. For a given delta $\%$ SOC test, the discharge resistances are greater than the regen resistances at all of the test temperatures of $40,50,60$ and $70^{\circ} \mathrm{C}$.

3. For both the discharge and regen resistances, generally the higher the test temperature, the lower the resistance.

4. The $70^{\circ} \mathrm{C}$ discharge and regen resistance data do not always follow the general trend of the rest of the data in that the resistances at this temperature are slightly greater than at $60^{\circ} \mathrm{C}$. This observation appears to indicate that new physical/chemical processes are occurring that causes the resistance anomalously to increase. The exact nature of these processes is not presently known.

5. At each of the four test temperatures, the magnitude of the discharge and regen resistance was in the following order: delta $6 \%$ SOC $>$ delta $3 \%$ SOC $>$ delta $9 \%$ SOC. No explanation is currently known for this observation. There are research groups within the ATD Program currently conducting physical/chemical studies on the test cells that may offer insight into this observation. 
A model was developed to account for the time, temperature, SOC, and delta $\%$ SOC of the batteries during the cycle-life test. The functional form of the model is given by

$\mathrm{R}(\mathrm{t}, \mathrm{T}, \mathrm{SOC}$, delta $\% \mathrm{SOC})=\mathrm{A}(\mathrm{T}, \mathrm{SOC}, \mathrm{delta} \% \mathrm{SOC}) \mathrm{F}(\mathrm{t})+\mathrm{B}(\mathrm{T}, \mathrm{SOC}, \mathrm{delta} \% \mathrm{SOC})$

where $\mathrm{t}$ is the time at test temperature, $\mathrm{T}$ is the test temperature, SOC is the state of charge of the cell at the start and end of the test, and delta\% SOC is the state-of-charge swing during the test. A(T,SOC, delta $\%$ SOC) and B(T,SOC,delta $\%$ SOC) are assumed to be functions of the test temperature, state of charge, and delta \% SOC swing. $\mathrm{F}(\mathrm{t})$ is assumed to only be a function of the test time at a given test temperature. Using curve fitting techniques for a number of time-dependent functions, it was found that both the discharge and regen resistances were best correlated by a square root of test time dependence. These results led to the relationship for the discharge and regen resistances, having the form

$\mathrm{R}(\mathrm{t}, \mathrm{T}, \mathrm{SOC}, \operatorname{delta} \%$ SOC $)=\mathrm{A}(\mathrm{T}, \mathrm{SOC}, \operatorname{delta} \%$ SOC $) \mathrm{t}^{1 / 2}+\mathrm{B}(\mathrm{T}, \mathrm{SOC}, \operatorname{delta} \%$ SOC $)$.

The square root of test time dependence for the increase in the discharge and regen resistances can be accounted for by either a one-dimensional diffusion type of mechanism, presumably of the lithium ions, or by a parabolic growth mechanism for the growth of a thin film solid electrolyte interface (SEI) layer on the anode and/or cathode. The diffusion type of mechanism would arise from the lithium ions diffusing into/out of the electrodes, through the electrolyte, through the separator, or through the solid electrolyte interface (SEI) layer present on the surface of the electrode materials. The growth of a thin film mechanism could relate to the growth of an SEI layer as a function of test time, test condition, and test temperature. The growth of the SEI layer results from the decomposition of the electrolyte/salt system on the surface of the electrodes. The increased thickness of the SEI film would increase the resistance of the cell due to hindrance of the transport of lithium ions through the SEI layer to subsequently be intercalated/de-intercalated into the active electrode material. The best physical/chemical model appears at present to be the growth of the SEI layer. The present data, however, cannot determine if the growth of the SEI layer with time occurs at the anode, the cathode, or both. However, there are characterization results, in particular electrochemical impedance spectroscopic (EIS) studies, that indicate that the resistance of the cathode is the major contributor to the resistance increase of the cell as it ages. The temperature dependence of the resistance was then investigated using various model fits to the functions $\mathrm{A}(\mathrm{T})$ and $\mathrm{B}(\mathrm{T})$. The results of this exercise lead to a functional form for the functions having an Arrhenius-like form:

$\mathrm{A}(\mathrm{T})=\mathrm{a}[\exp (\mathrm{b} / \mathrm{T})]$ and $\mathrm{B}(\mathrm{T})=\mathrm{c}[\exp (\mathrm{d} / \mathrm{T})]$

where $\mathrm{a}$ and $\mathrm{c}$ are preexponential constants and $\mathrm{b}$ and $\mathrm{d}$ are related to an activation energy, $\mathrm{E}_{\mathrm{b}}$ and $\mathrm{E}_{\mathrm{d}}$, by using the gas constant, $R$, such that $b=E_{b} / R$ and $d=E_{d} / R$. The values of $E_{b}$ and $E_{d}$ were determined and were found to be about the right order of magnitude (several to several tens of kjoules/mole) for the activated transport of lithium ions, or the chemical decomposition of the electrolyte. [However, there are no literature values found that substantiated these values.] It is not known what specific process or processes the determined activation energy values correspond to. The functional form, therefore, for the discharge and regen resistances, including the SOC and delta $\%$ SOC, is then

$\mathrm{R}(\mathrm{t}, \mathrm{T}, \mathrm{SOC}$, delta $\%$ SOC $)=\mathrm{a}(\mathrm{SOC}$, delta $\%$ SOC $)\{\exp [\mathrm{b}(\mathrm{SOC}, \operatorname{delta} \%$ SOC $) / \mathrm{T}]\} \mathrm{t}^{1 / 2}+\mathrm{c}($ SOC,delta $\%$ SOC $)\{\exp [\mathrm{d}(\mathrm{SOC}, \mathrm{delta} \% \mathrm{SOC}) / \mathrm{T}]\}$.

The $a, b, c$, and d parameters are explicitly shown as functions of the SOC and the delta $\%$ SOC. However, due to the lack of testing at SOC values other than $60 \%$ SOC, the exact form of the SOC dependence could not be determined from the experimental data. Attempts were made to find a consistent correlation of the observed resistance changes with the delta $\%$ SOC of the tests. No model 
based on physical/chemical processes was found, nor were studies on this topic found in the literature examined. Eliminating the SOC and delta\% SOC from the resistance function, the function R(t,T) could then be used to correlate the discharge and regen resistance data and to predict what the resistance would be at different test times and test temperatures. The values found for the constants at a given delta\% SOC in the functions $A(T)=a[\exp (b / T)]$ and $B(T)=c[\exp (d / T)]$ in conjunction with the square root of test time dependence permitted the correlation of the observed discharge and regen resistance values.

Analysis of the $\mathrm{C} / 1$ constant current discharge test results allowed determination of the leakage current, i.e., the current required to maintain a given voltage on the cell as a function of time. In this case, the cells where held constant at $4.1 \mathrm{~V}$. The leakage current was found to decrease quite rapidly for new cells, but after aging due to testing, the magnitude of the leakage current was found to increase. The leakage current can be related to a leakage resistance via Ohm's law. The leakage resistance was found to decrease as the cell ages, which means that more current, i.e., charge, has to be put into the cell to maintain a given voltage. This increased charge is due to IR losses in the battery. The IR losses increase, due to presently unknown detailed processes, as the cell ages.

Further analysis of the constant current $\mathrm{C} / 1$ charge and discharge data using the concept of differential capacity was applied to the test data. This analysis simply takes the derivative of the charge added/removed with respect to the cell voltage, or charge added or removed during the test. Peaks in the differential capacity are believed to relate to specific intercalation sites within the anode and/or cathode. As the cell aged with testing, the height of the peaks changed, as did their position with respect to the cell voltage or charge/discharge state. The exact nature of these sites, and how the testing influences them, is not presently known. This concept of the differential capacity is believed to be useful to research groups conducting characterization/diagnostic studies on fresh, as well as aged, cells. Usefulness arises in that it provides information regarding the voltage and state of charge at which the properties of the cell are changing the most due to use. 


\section{REFERENCES}

1. PNGV Test Plan for ATD 18650 Gen 1 Lithium Ion Cells, EHV-TP-90, Revision 0, March 23, 1999.

2. USABC Electric Vehicle Battery Test Procedures Manual, Revision 2, DOE/ID-10479, Revision 2, January 1996.

3. PNGV Battery Test Manual, Revision 2, DOE/ID-10597, August 1999.

4. FY 1999 Progress Report for the Advanced Technology Development Program, U.S. Department of Energy, Office of Advanced Automotive Technologies, 1000 Independence Avenue S.W., Washington, D.C. 20585-0121, March 2000.

5. D. Zhang et al., Journal of Power Sources, 91 (2000) 122-129. See also H. Wang et al., Journal of the Electrochemical Society, Vol. 146, 1999, p. 473.

6. M. G. S. R. Thomas, P. G. Bruce, J. B. Goodenough, Journal of the Electrochemical Society, Vol. 132, 1985, p. 1521.

7. P. Arora, R. E. White, M. Doyle, Journal of the Electrochemical Society, Vol. 145, 1998, p.3647.

8. S. R. Narayana et al., Journal of the Electrochemical Society, Vol.140, No. 7, July 1993.

9. K. Ozawa, Solid State Ionics, Vol. 69, 1994, p. 212.

10. S. Megahed, B. S. Scrosati, Journal of Power Sources, Vol. 51, 1994, p. 79.

11. G. Nagasubramanian in FY 1999 Progress Report for the Advanced Technology Development Program, March 2000, p. 42. See also J. Baker et al., Proceedings of the Electrochemical Society, Volume 99-25, New Jersey, 2000, p. 664.

12. D. Guyomard and J. M. Tarascon, Journal of Power Sources, Vol. 54, 1995, p. 92-98.

13. D. Aurbach et al., Electrochemica Acta, Vol. 45, 1999, p. 67-86.

14. B. Markovsky, M. D. Mikhail, D. Aurbach, Electrochemica Acta, Vol. 16-17, 1998, pp. 22872304.

15. N. Birks and G. H. Meier, Introduction to High Temperature Oxidation of Metals, Edward Arnold Ltd., London, 1983.

16. Per Kofstad, High-Temperature Oxidation of Metals, John Wiley \& Sons, New York, 1966.

17. K. Hauffe, Oxidation of Metals, Plenum Press, New York, 1965.

18. G. E. Blomgren, Journal of Power Sources, Vol. 81-82, 1999, p. 112.

19. C. Kittel, Introduction to Solid State Physics, fourth edition, John Wiley \& Sons, New York, 1971. 
20. W. Jost, Diffusion in Solids, Liquids, Gases, third printing with Addendum, Academic Press Inc., New York, 1960.

21. J. Crank, The Mathematics of Diffusion, second edition, Clarendon Press, Oxford, 1975.

22. Per Kofstad, Nonstoichiometry, Diffusion, and Electrical Conductivity in Binary Metal Oxides, John Wiley \& Sons, New York, 1972.

23. R. L. Burden, J. D. Faires, and A. C. Reynolds, Numerical Analysis, Prindle, Weber \& Schmidt, Boston, 1978, p. 177.

24. M. D. Levi and D. Aurbach, Electrochimica Acta, Vol. 45, 1999, pp. 167-185.

25. J. N. Reimers and J. R. Dahn, Journal of the Electrochemical Society, Vol. 139, 1992, p. 2091.

26. R. R. Haering and R. MacKinnon, Chapter 4 in Modern Aspects of Electrochemistry, Vol. 15, eds. B. E. Conway, J. O’M. Bockris, and R. White, Plenum Publishing Co., New York, 1981.

27. M. E. Arroyo y de Dompablo, C. Marianetti, A. Van der Ven, G. Ceder, "First Principles Investigations in $\mathrm{Li}_{\mathrm{x}} \mathrm{NiO}_{2}$," Abstract 179, The 198th Meeting of the Electrochemical Society, October 22-27, 2000, Phoenix, Arizona. 


\section{Appendix A}

Figures for Cycle-Life Discharge and Regen Resistance Tests ON ATD GEN 1 Li-ION Batteries: Experimental Electrical Performance Test Cycles 



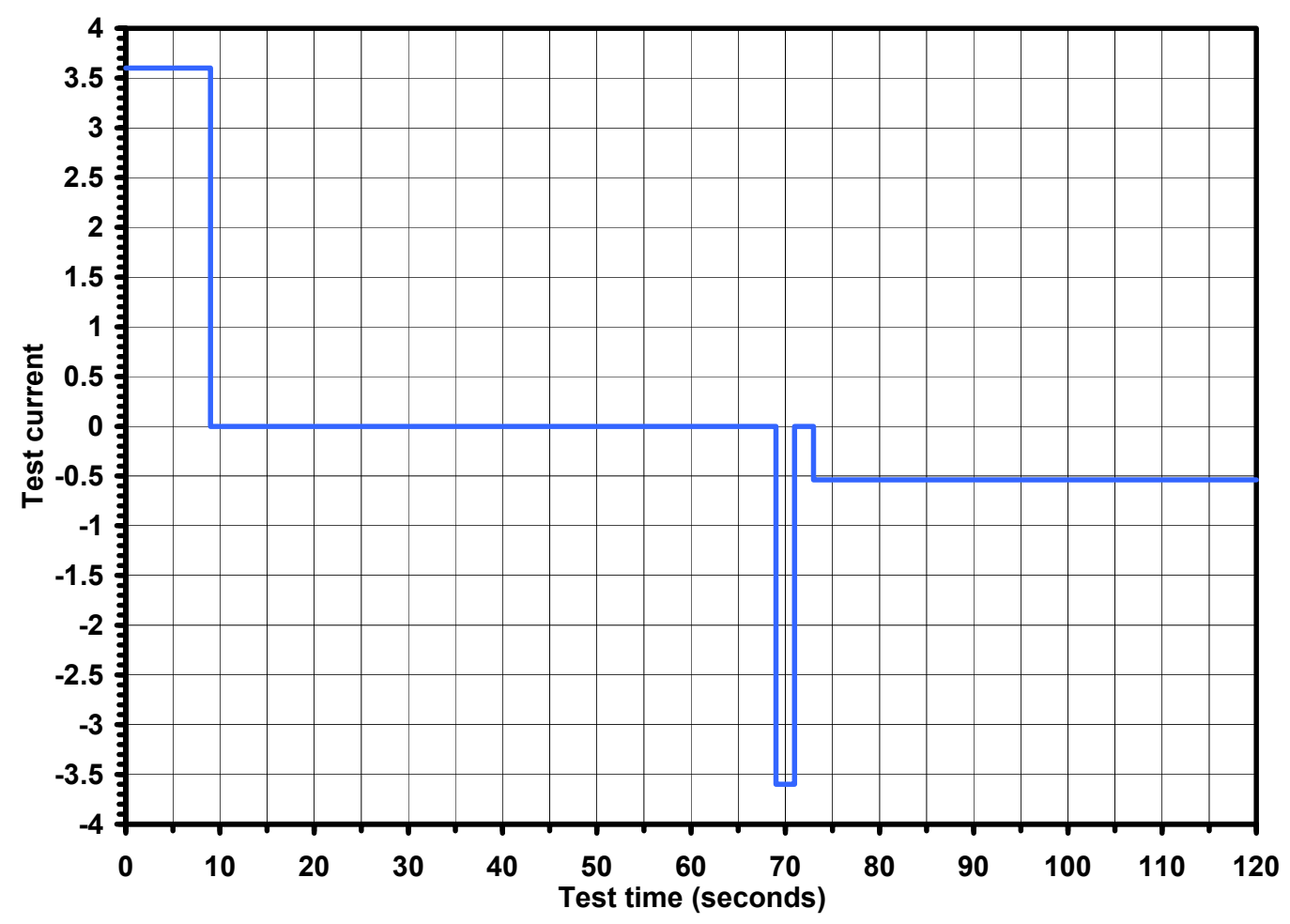

Figure 1. Calendar-life test sequence.

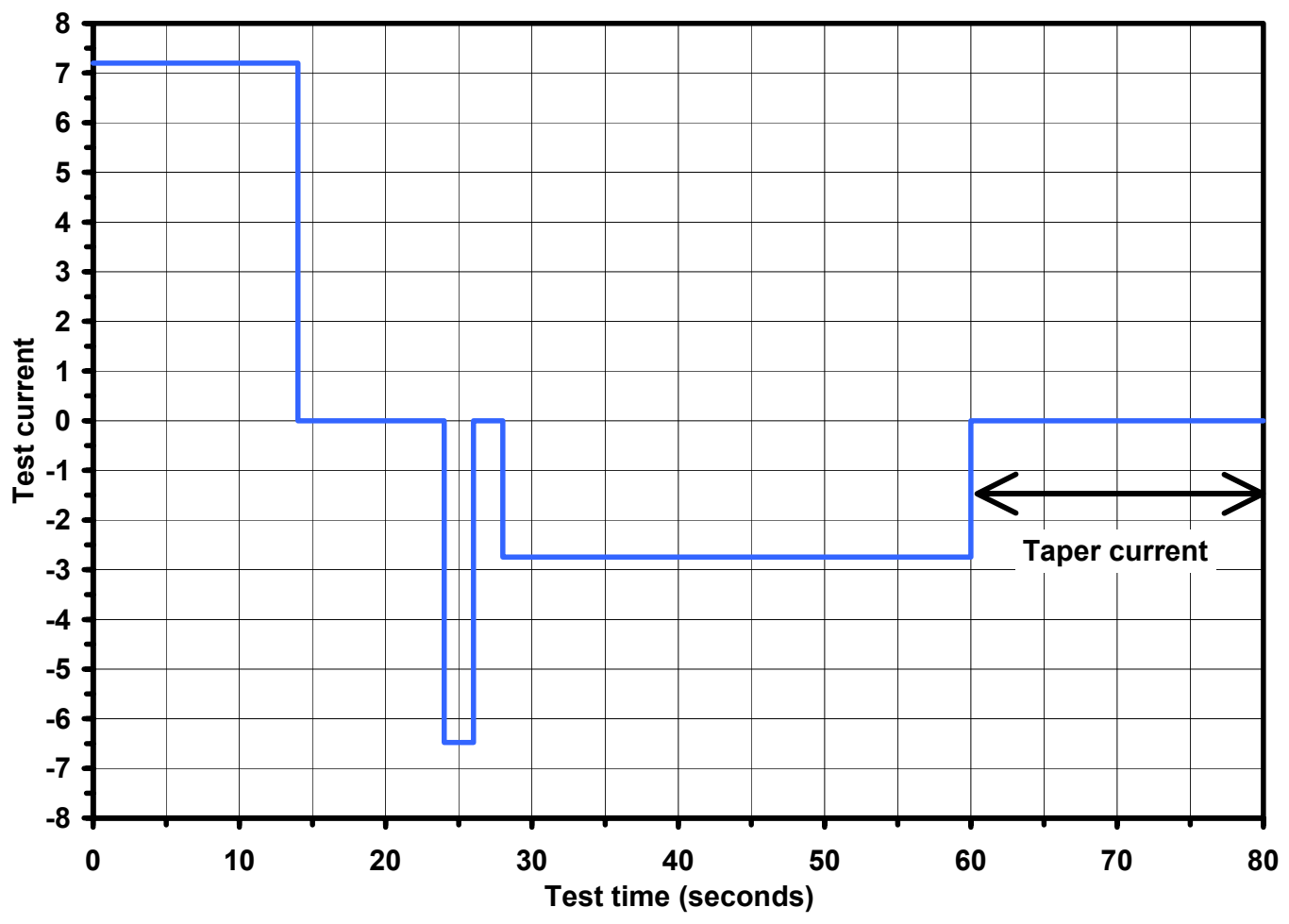

Figure 2. Delta 3\% cycle-life test sequence. 


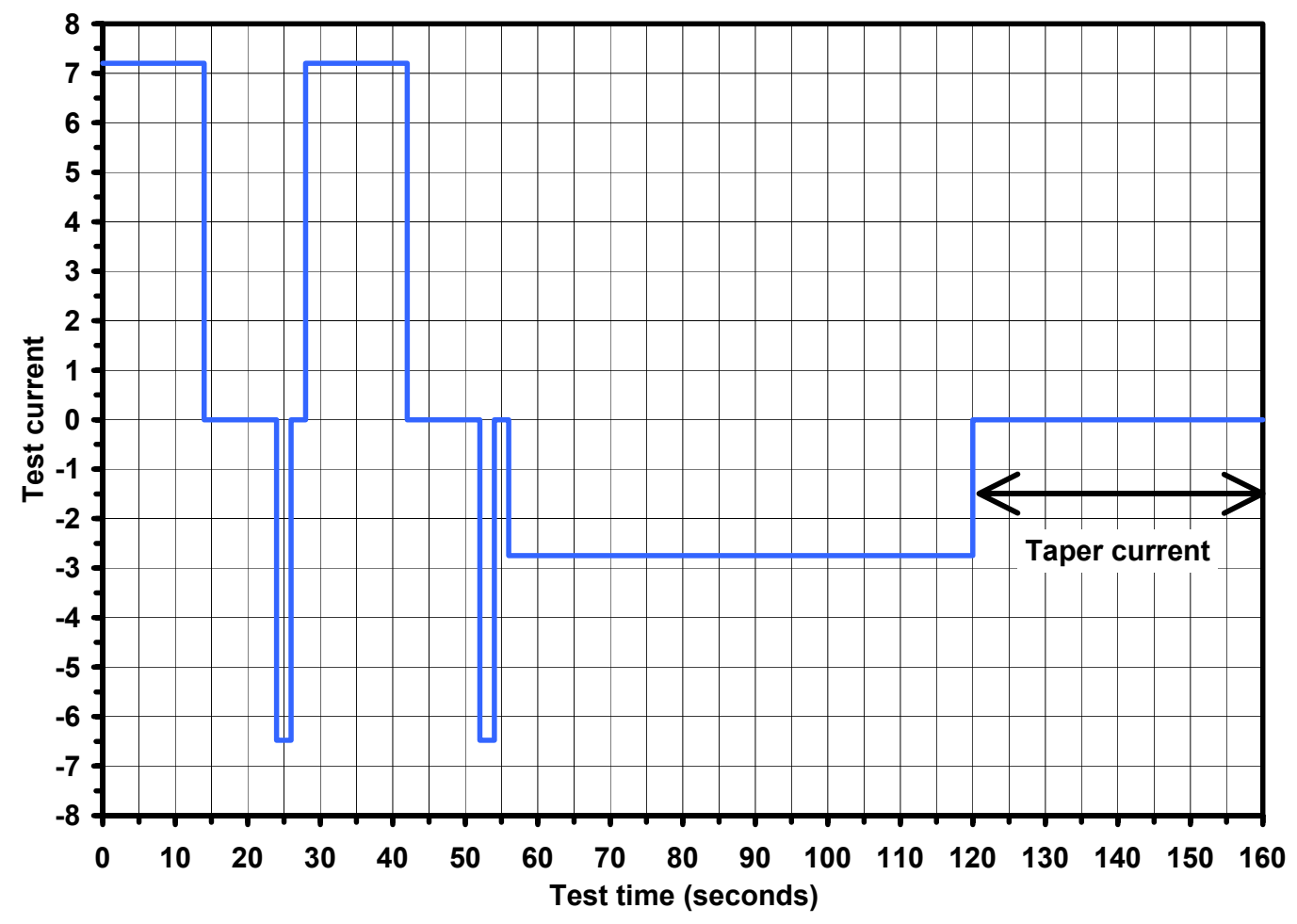

Figure 3. Delta $6 \%$ cycle-life test sequence.

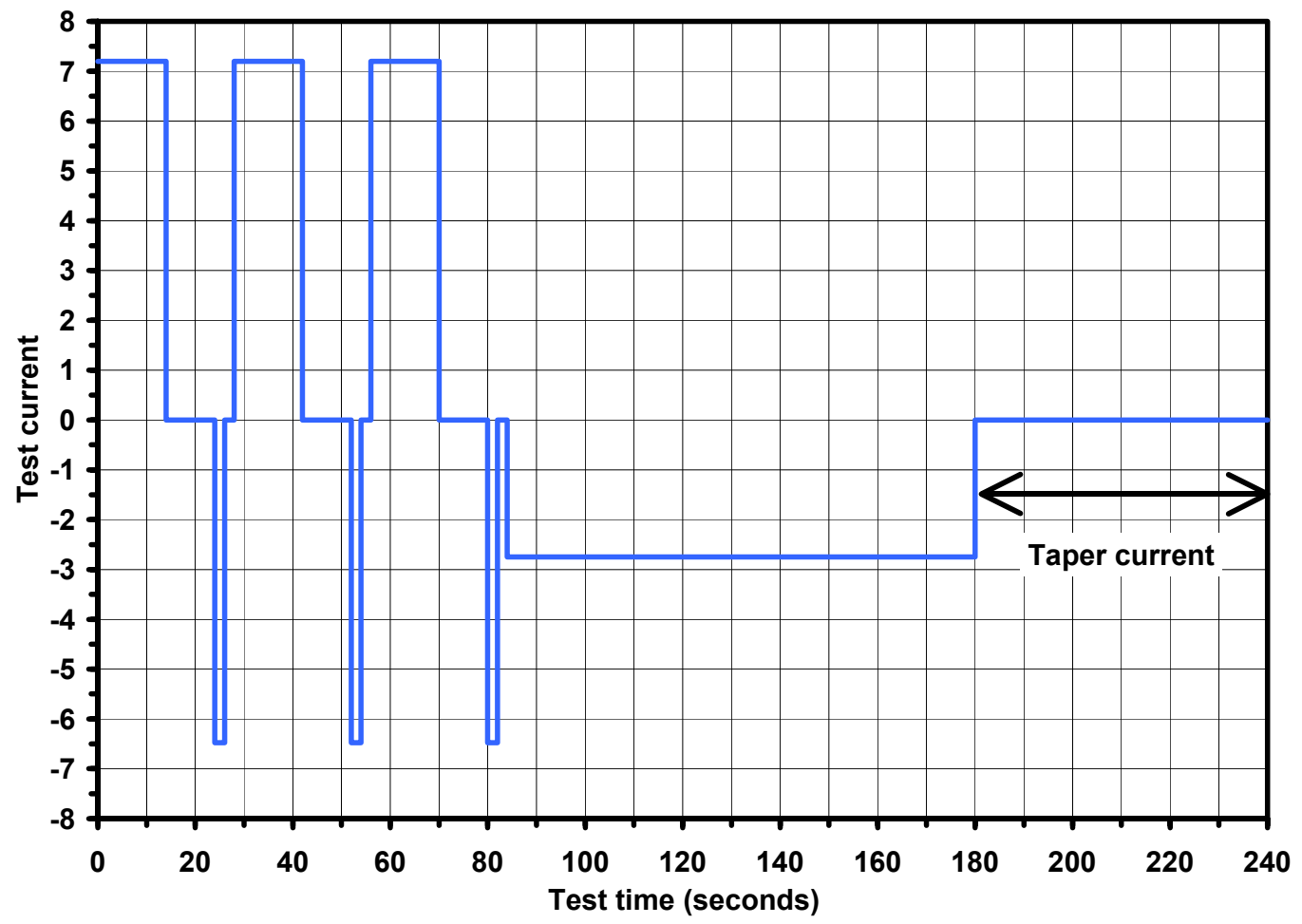

Figure 4. Delta $9 \%$ cycle-life test sequence. 


\section{Appendix B}

Figures for Cycle Life Discharge and Regen Resistance Tests on ATD GEN 1 Li-ION Batteries at $60 \%$ State-of-Charge and Delta $3 \%, 6 \%$, and $9 \%$ State-of-Charge Swings 



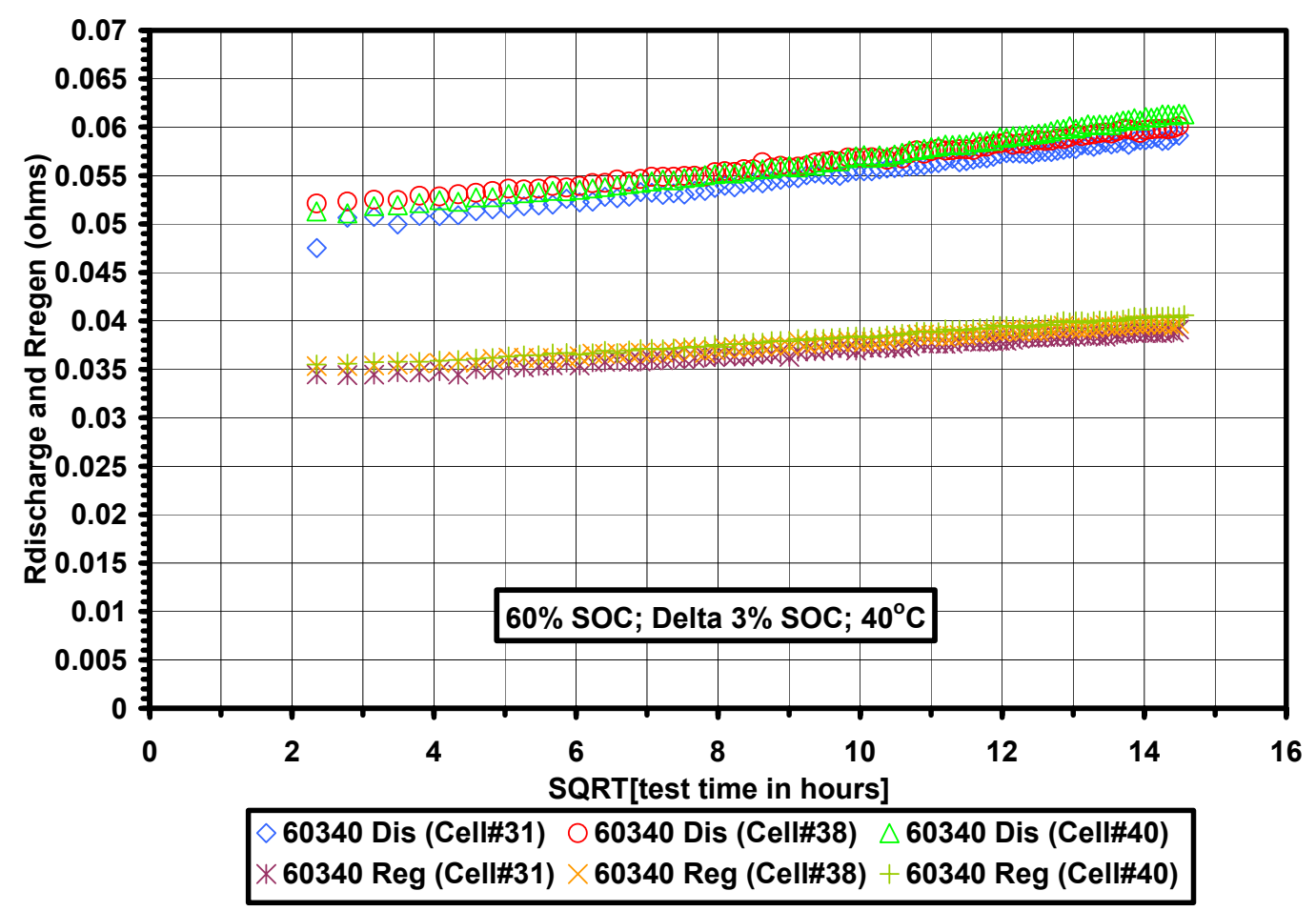

Figure 5. INEEL cycle-life discharge and regen resistance data for ATD Gen 1 (60340) cells.

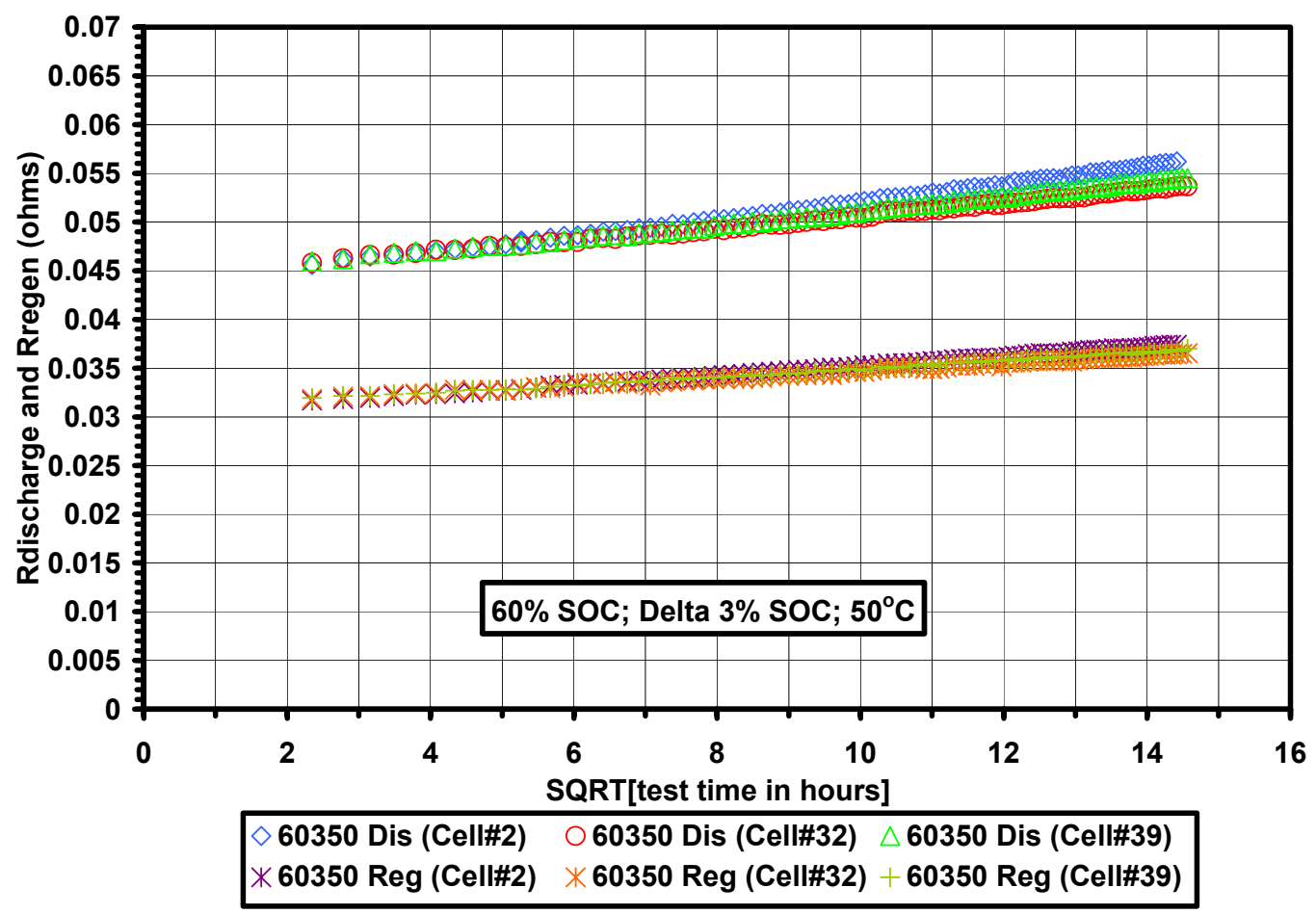

Figure 6. INEEL cycle-life discharge and regen resistance data for ATD Gen 1 (60350) cells. 


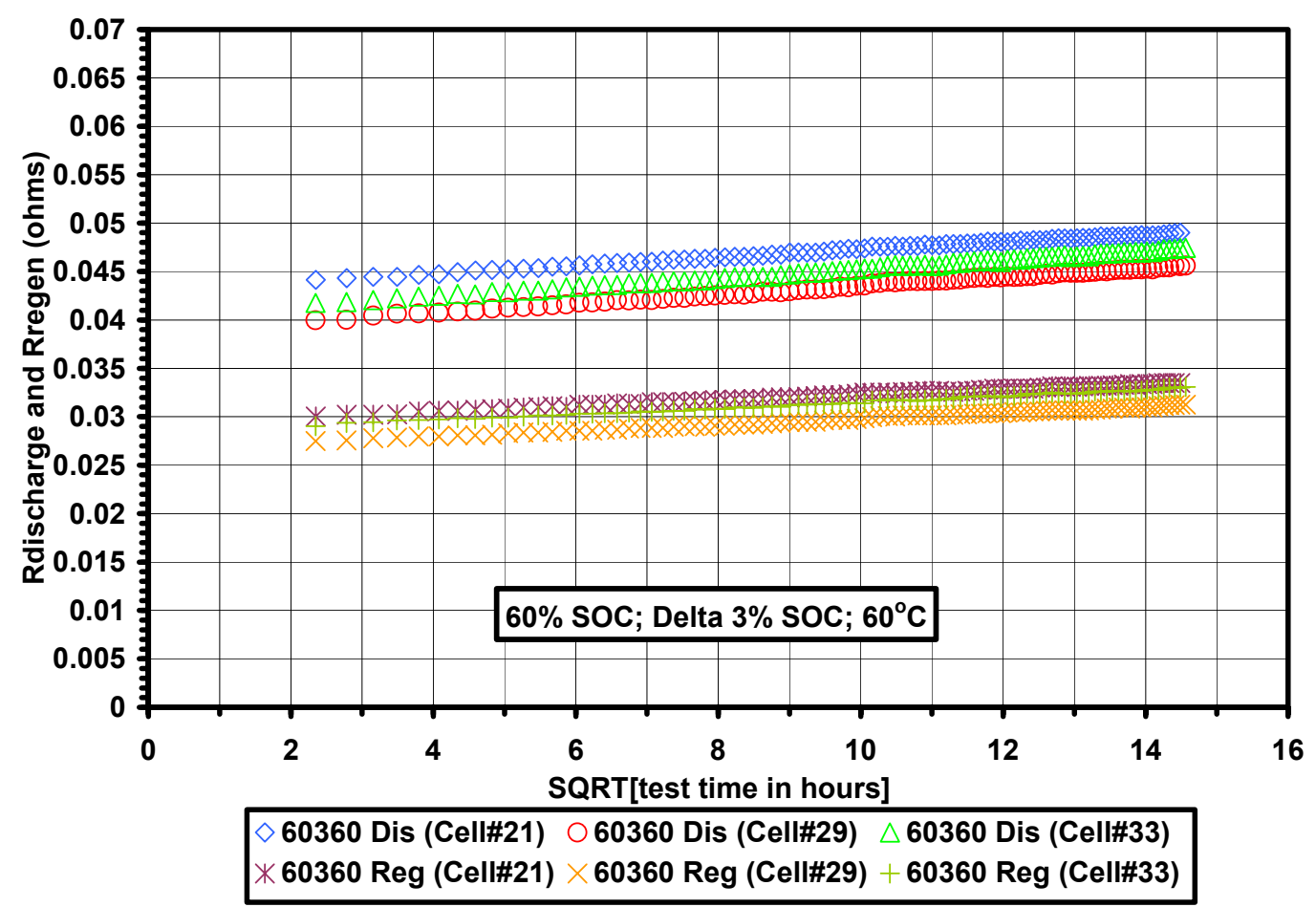

Figure 7. INEEL cycle-life discharge and regen resistance data for ATD Gen 1 (60360) cells.

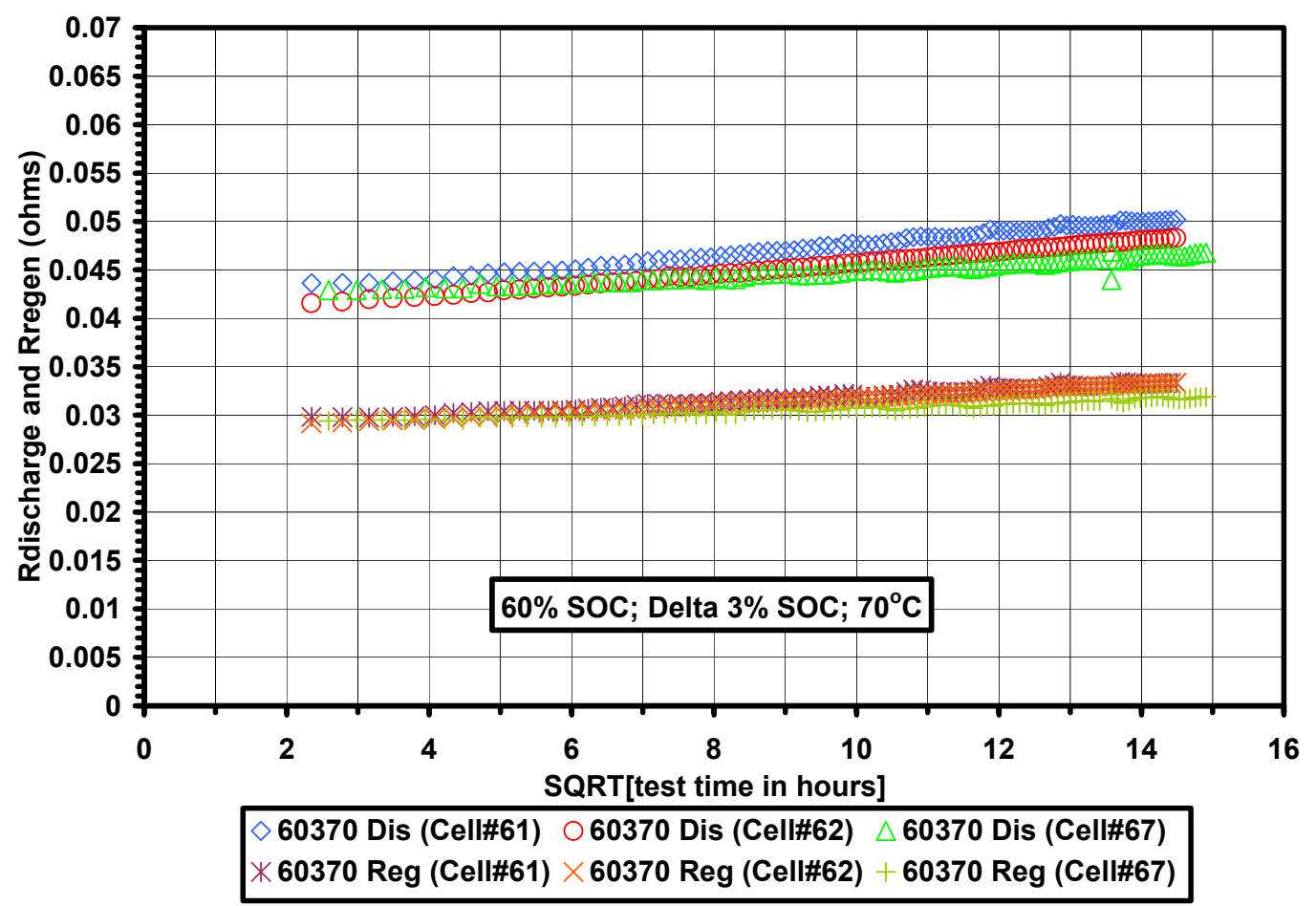

Figure 8. INEEL cycle-life discharge and regen resistance data for ATD Gen 1 (60370) cells. 


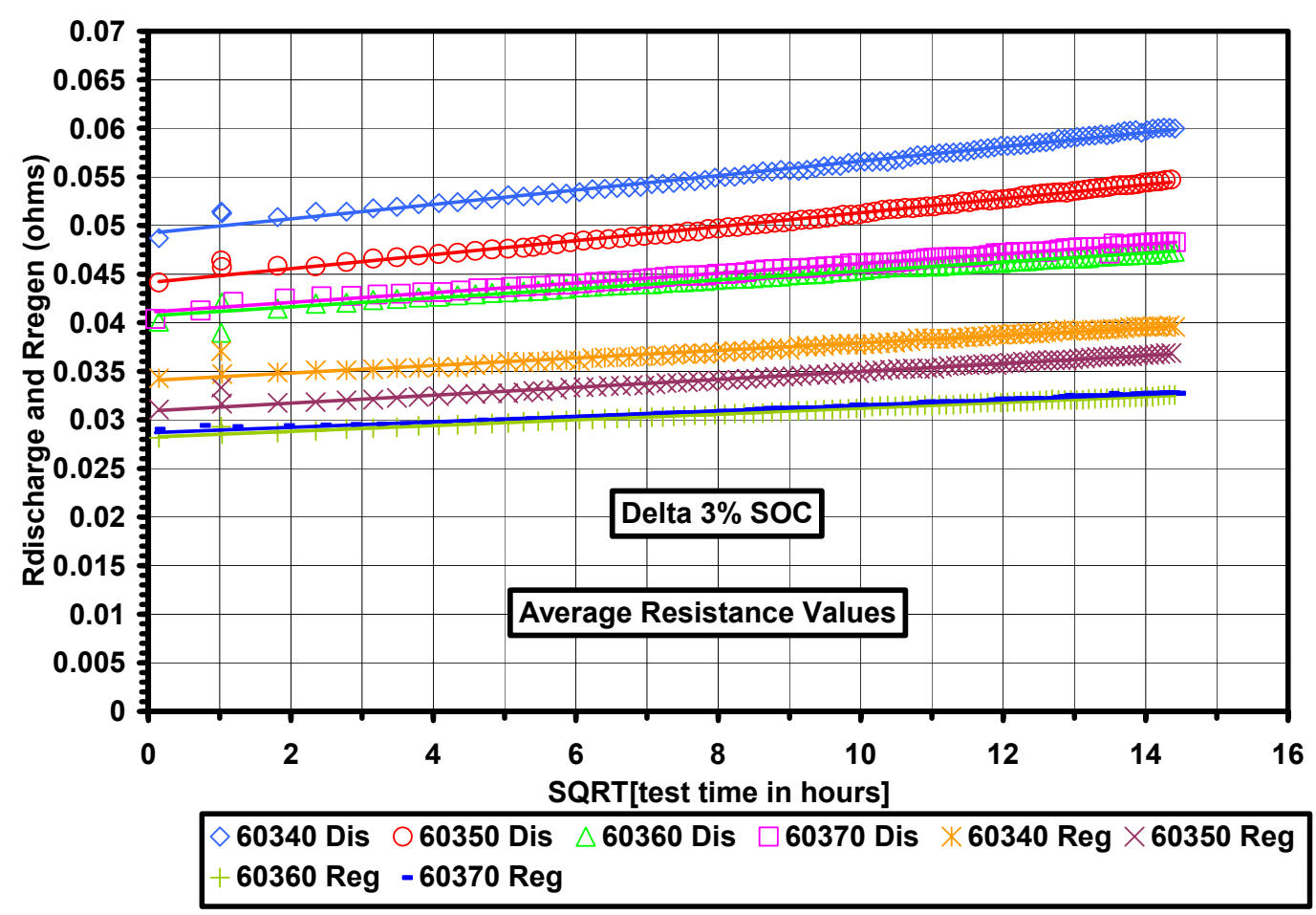

Figure 9. INEEL cycle-life discharge and regen resistance data for ATD Gen $1(603-40,50,60,70)$ cells.

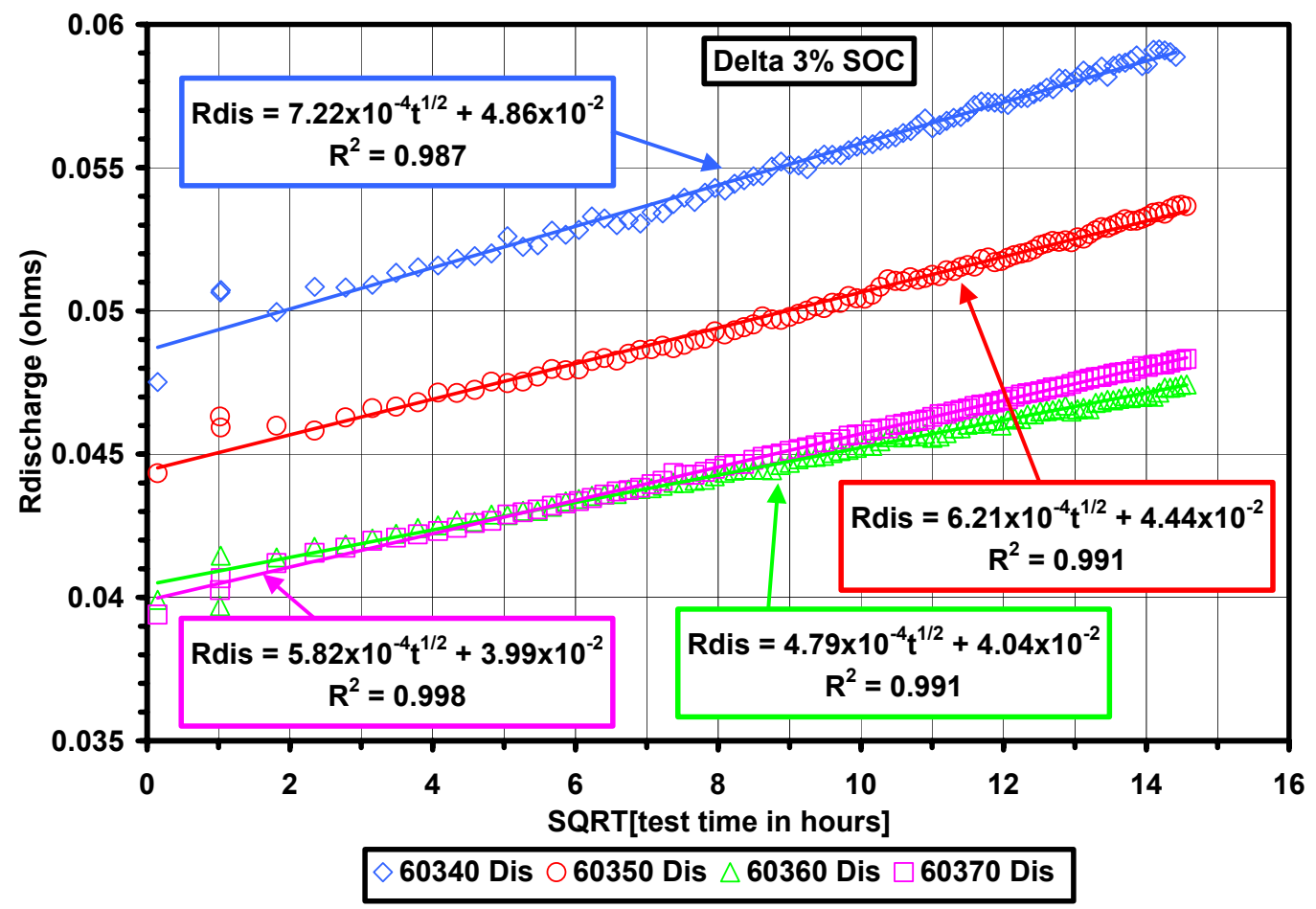

Figure 10. INEEL cycle-life discharge resistance data for ATD Gen $1(603-40,50,60,70)$ cells. 


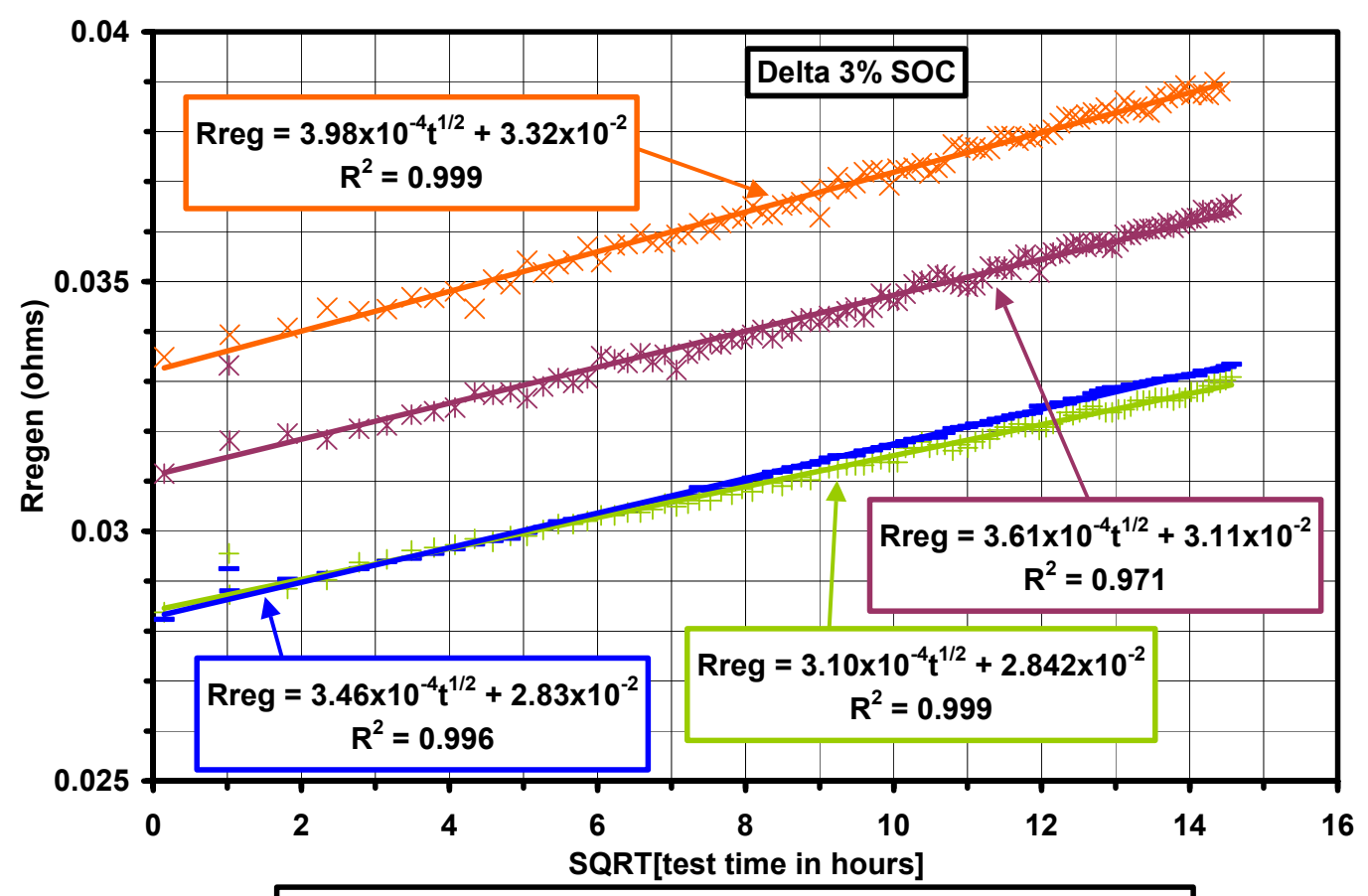

60340 Regen $* 60350$ Regen +69360 Regen -60370 Regen

Figure 11. INEEL cycle-life regen resistance data for ATD Gen $1(603-40,50,60,70)$ cells.

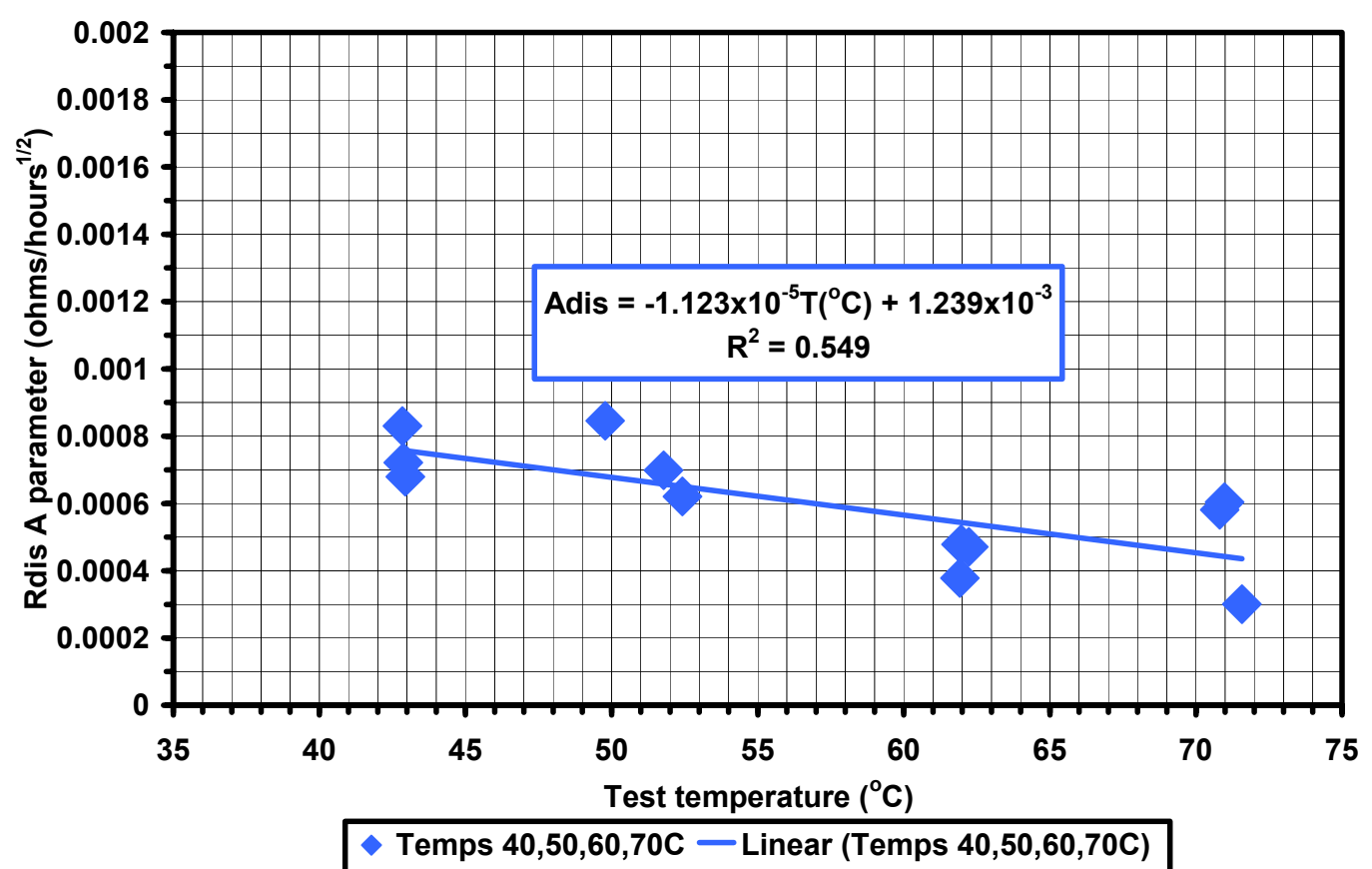

Figure 12. INEEL cycle-life discharge resistance data for ATD Gen $1(603-40,50,60,70)$ cells. Fit to equation: $\mathrm{R}(\mathrm{t}, \mathrm{T}, \mathrm{SOC})=\mathrm{A}(\mathrm{T}, \mathrm{SOC}) * \mathrm{SQRT}$ [test time in hours at temperature $+\mathrm{B}(\mathrm{T}, \mathrm{SOC})$. 


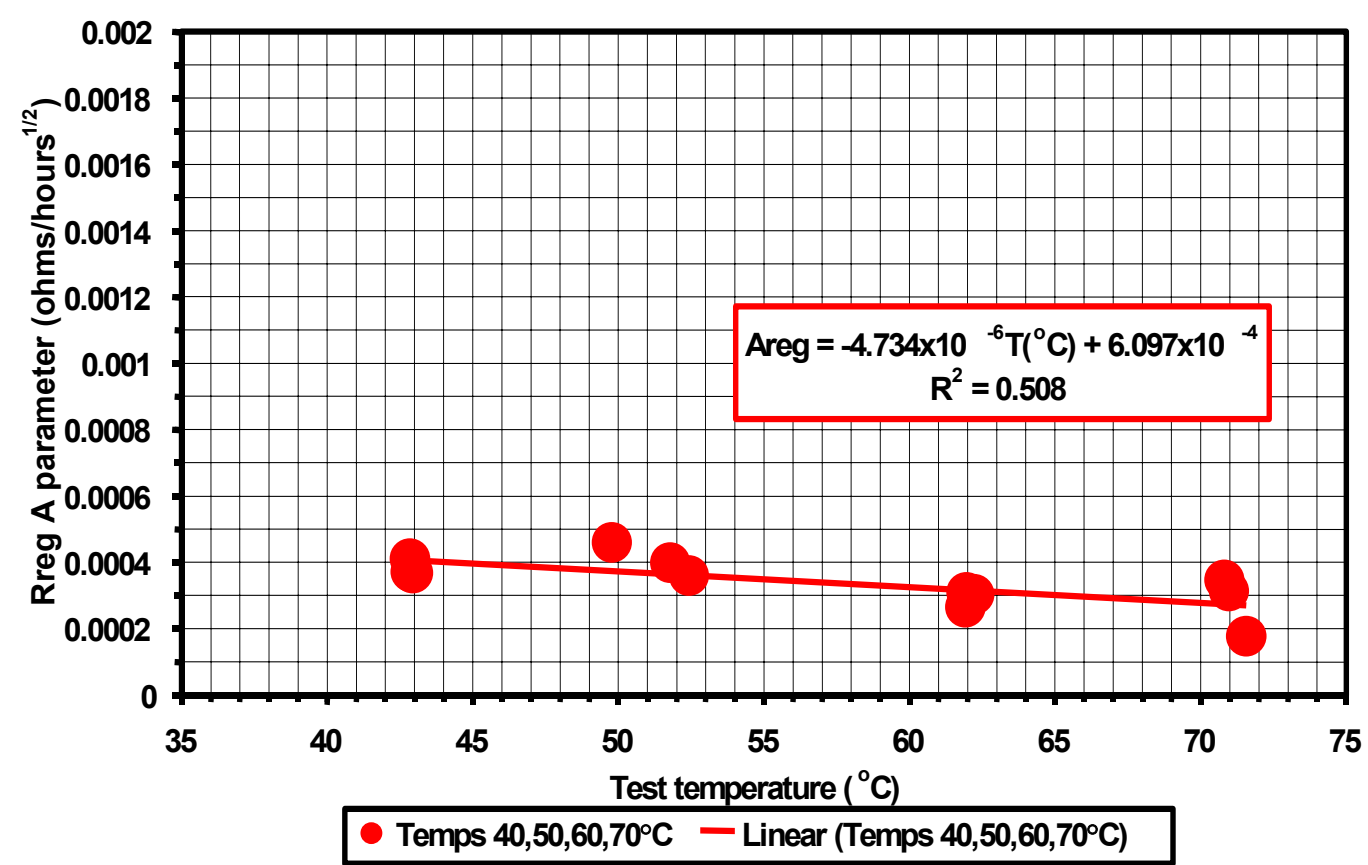

Figure 13. INEEL cycle-life regen resistance data for ATD Gen $1(603-40,50,60)$ cells. Fit to equation: $\mathrm{R}(\mathrm{t}, \mathrm{T}, \mathrm{SOC})=\mathrm{A}(\mathrm{T}, \mathrm{SOC}) * \mathrm{SQRT}[$ test time in hours at temperature $]+\mathrm{B}(\mathrm{T}, \mathrm{SOC})$.

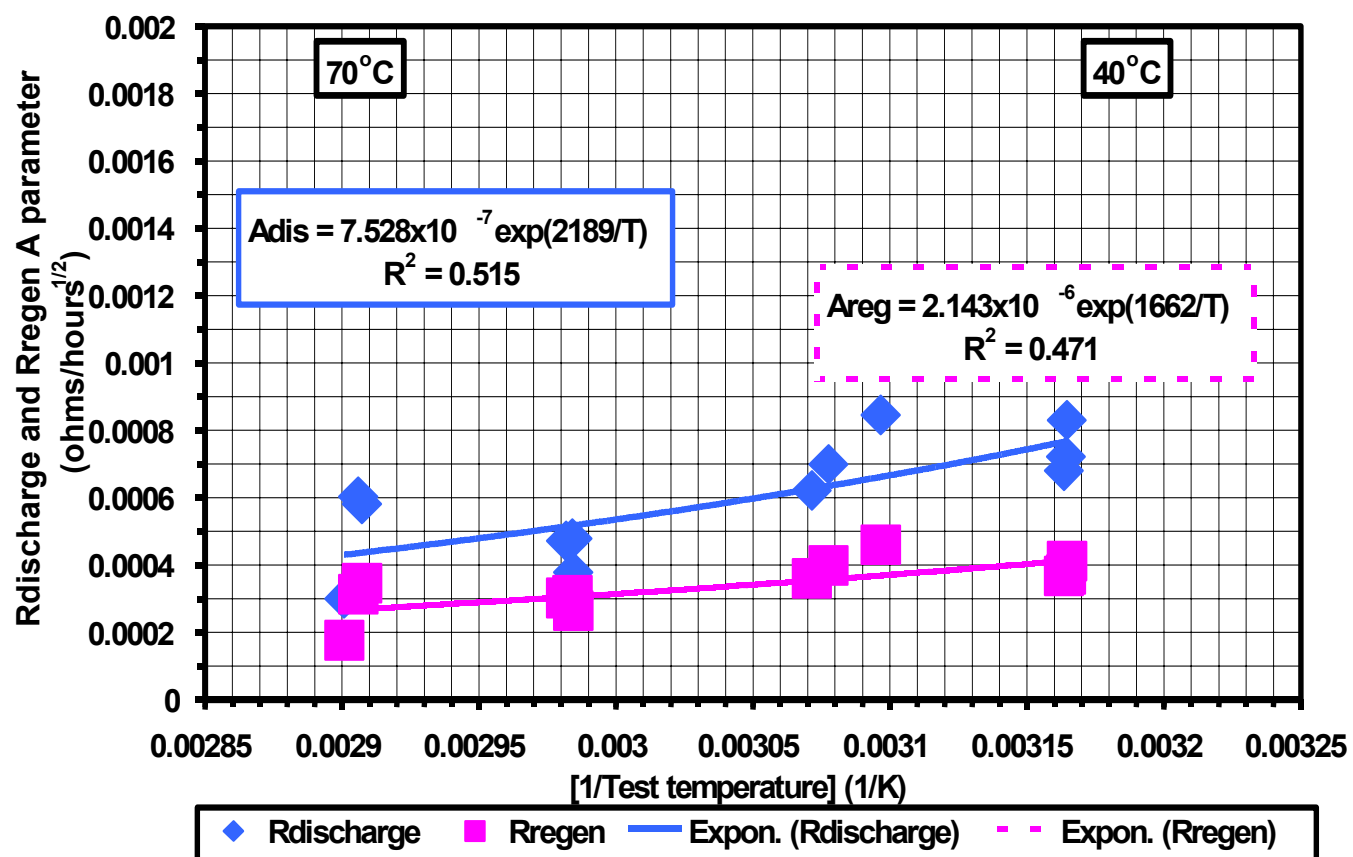

Figure 14. INEEL cycle-life discharge and regen resistance data for ATD Gen $1(603-40,50,60,70)$ cells. Fit to equation: $\mathrm{R}(\mathrm{t}, \mathrm{T}, \mathrm{SOC})=\mathrm{A}(\mathrm{T}, \mathrm{SOC}) * \mathrm{SQRT}[$ test time in hours at temperature] $+\mathrm{B}(\mathrm{T}, \mathrm{SOC})$. 


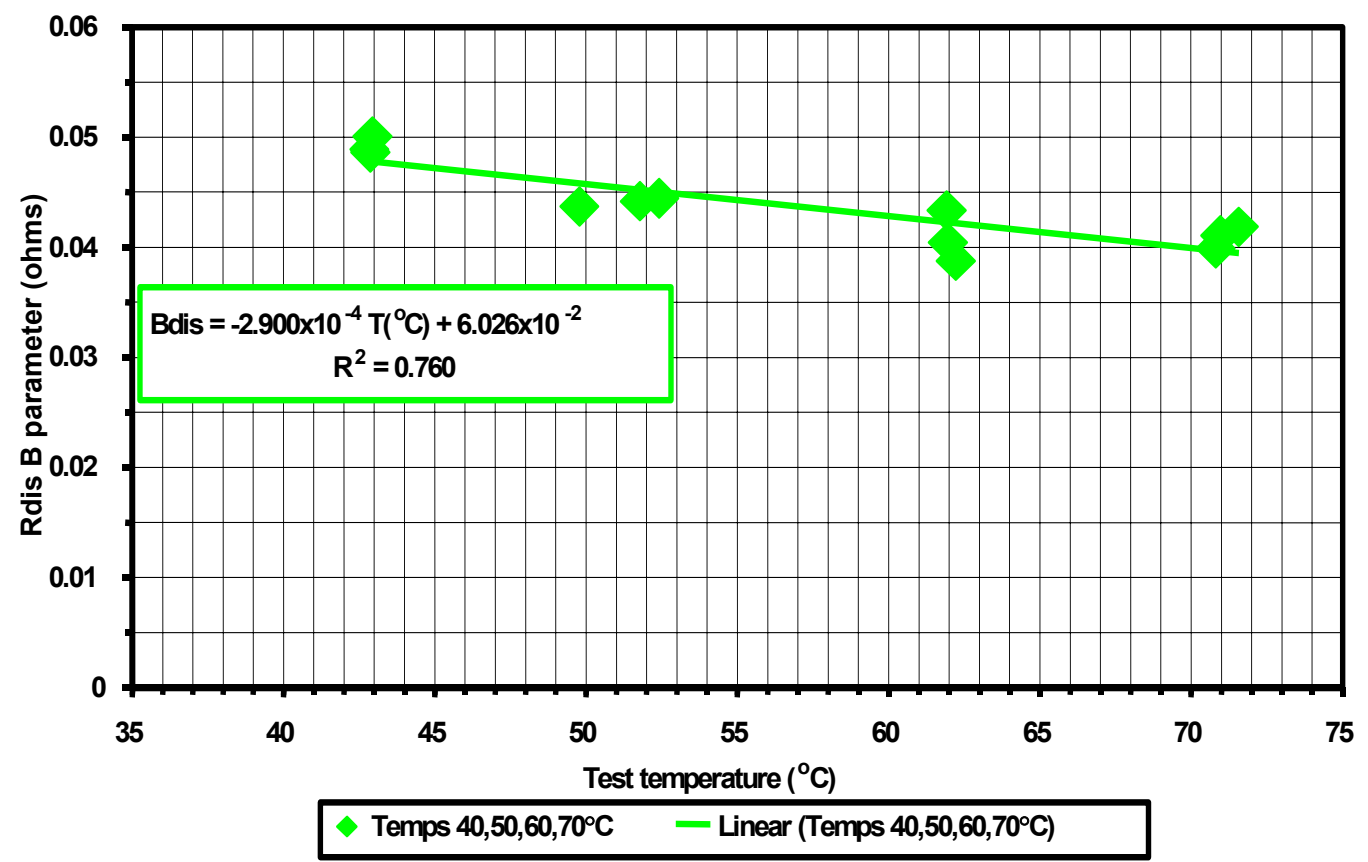

Figure 15. INEEL cycle-life discharge resistance data for ATD Gen $1(603-40,50,60,70)$ cells. Fit to equation: $\mathrm{R}(\mathrm{T}, \mathrm{SOC})=\mathrm{A}(\mathrm{T}, \mathrm{SOC})^{*} \mathrm{SQRT}[$ test time in hours at temperature $]+\mathrm{B}(\mathrm{T}, \mathrm{SOC})$.

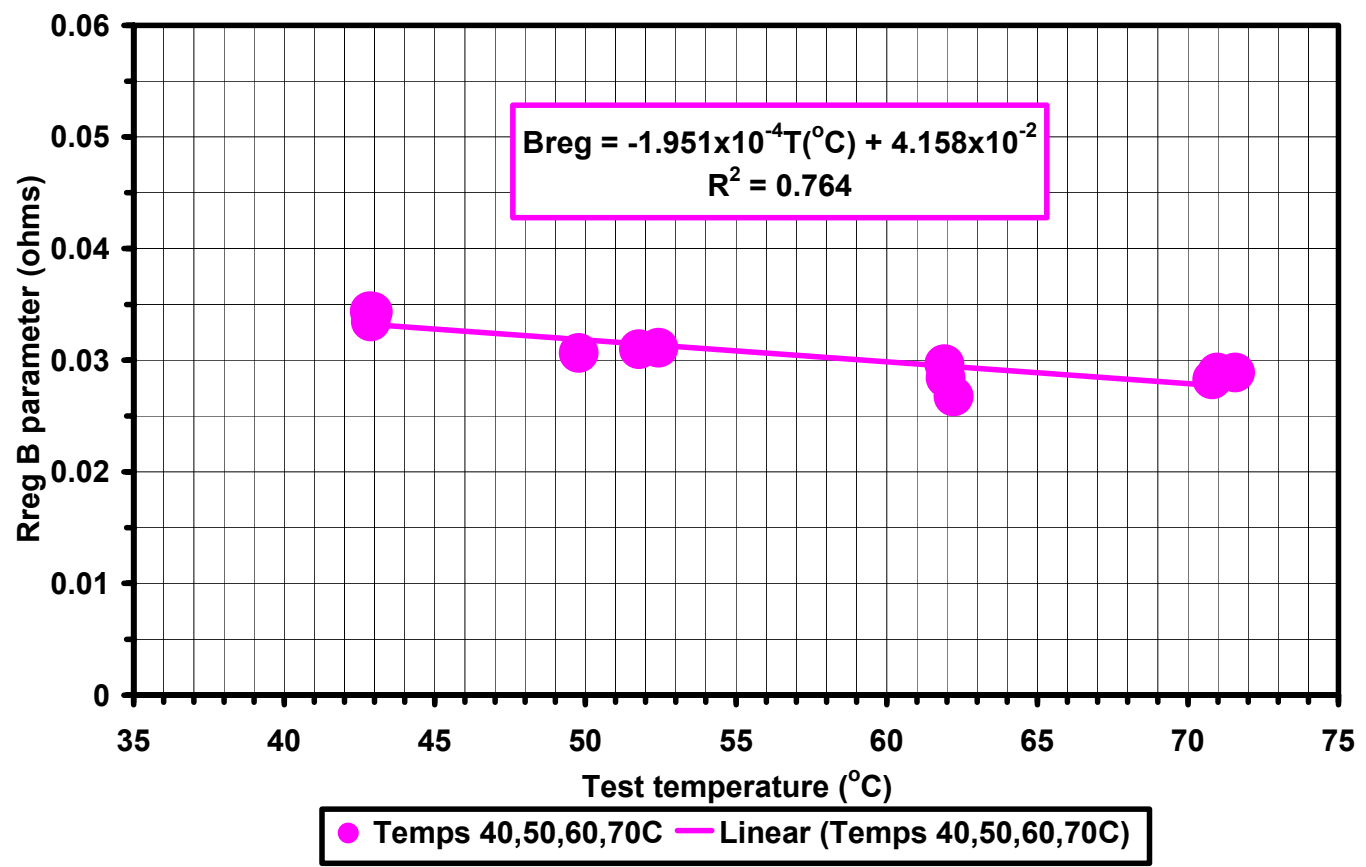

Figure 16. INEEL cycle-life regen resistance data for ATD Gen $1(603-40,50,60,70)$ cells. Fit to equation: $\mathrm{R}(\mathrm{t}, \mathrm{T}, \mathrm{SOC})=\mathrm{A}(\mathrm{T}, \mathrm{SOC}) * \mathrm{SQRT}[$ test time in hours at temperature $]+\mathrm{B}(\mathrm{T}, \mathrm{SOC})$. 


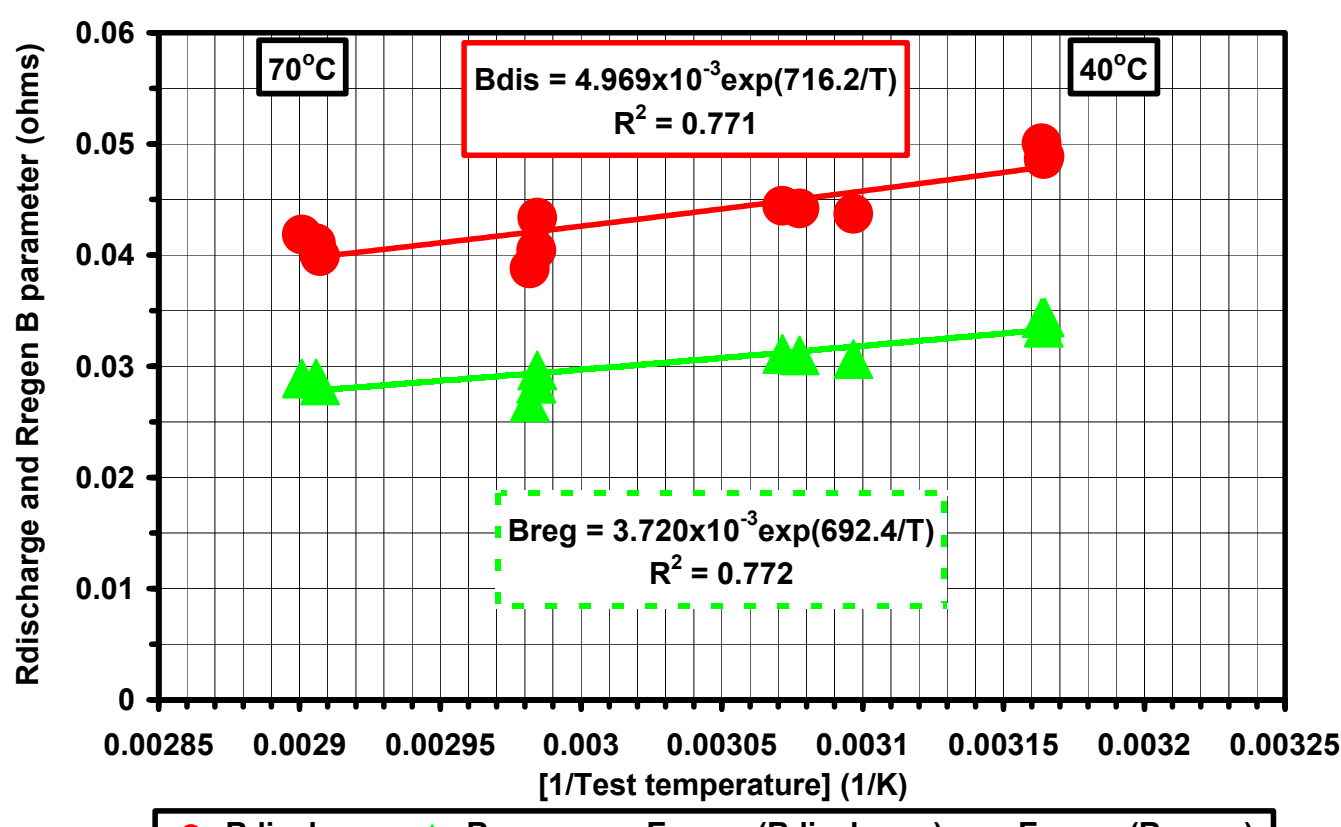

Rdischarge $\triangle$ Rregen —Expon. (Rdischarge) = - Expon. (Rregen)

Figure 17. INEEL cycle-life discharge and regen resistance data for ATD Gen $1(603-40,50,60,70)$ cells. Fit to equation: $\mathrm{R}(\mathrm{t}, \mathrm{T}, \mathrm{SOC})=\mathrm{A}(\mathrm{T}, \mathrm{SOC}) * \mathrm{SQRT}[$ test time in hours at temperature $]+\mathrm{B}(\mathrm{T}, \mathrm{SOC})$

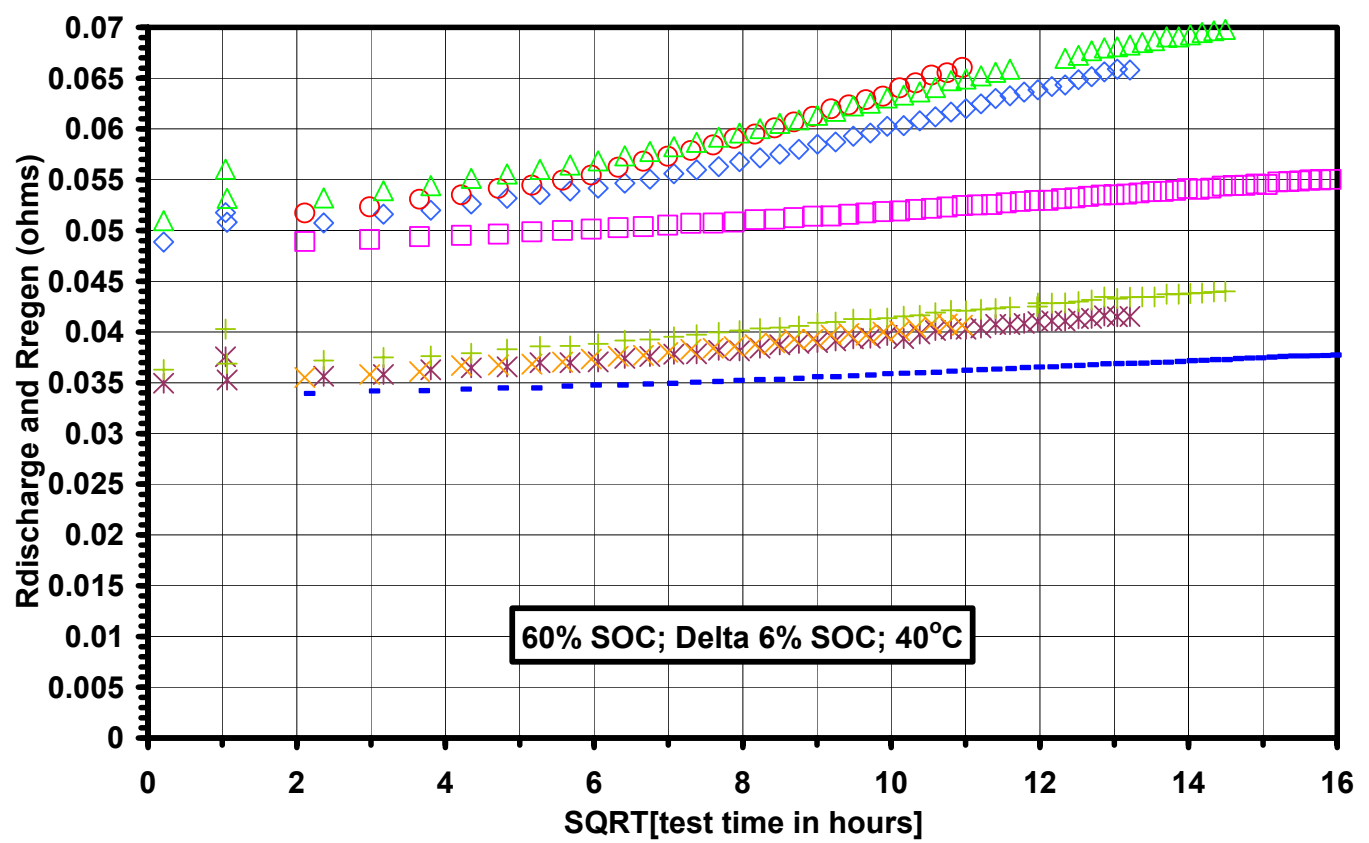

60640 Dis (Cell\#41) $\bigcirc 60640$ Dis (Cell\#42) $\triangle 60640$ Dis (Cell\#11) $\square 60640$ Dis (Cell\#70) *60640 Reg (Cell\#41) ×60640 Reg (Cell\#42) +60640 Reg (Cell\#11) - 60640 Reg (Cell\#70)

Figure 18. INEEL cycle-life discharge and regen resistance data for ATD Gen 1 (60640) cells. 


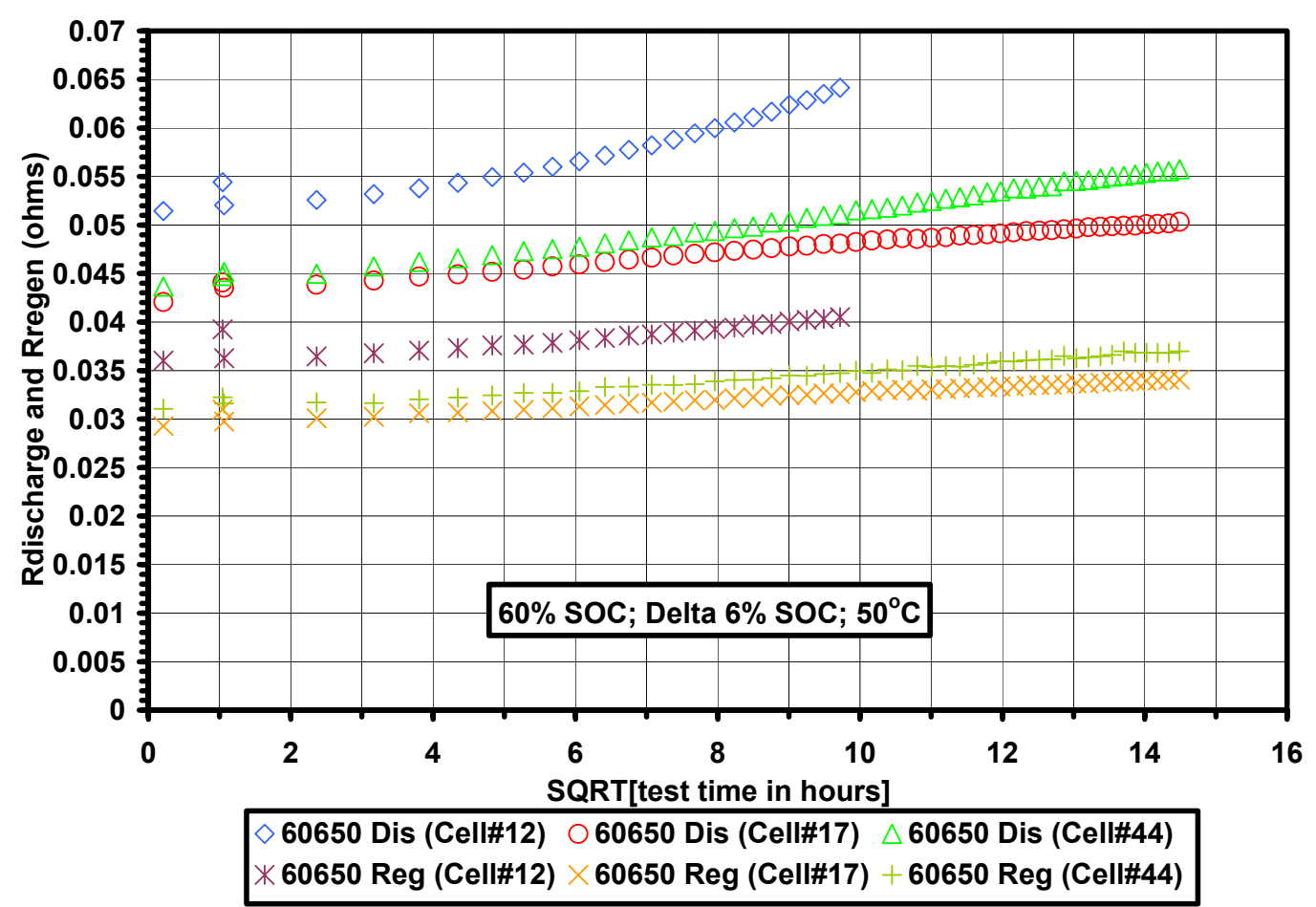

Figure 19. INEEL cycle-life discharge and regen resistance data for ATD Gen 1 (60650) cells.

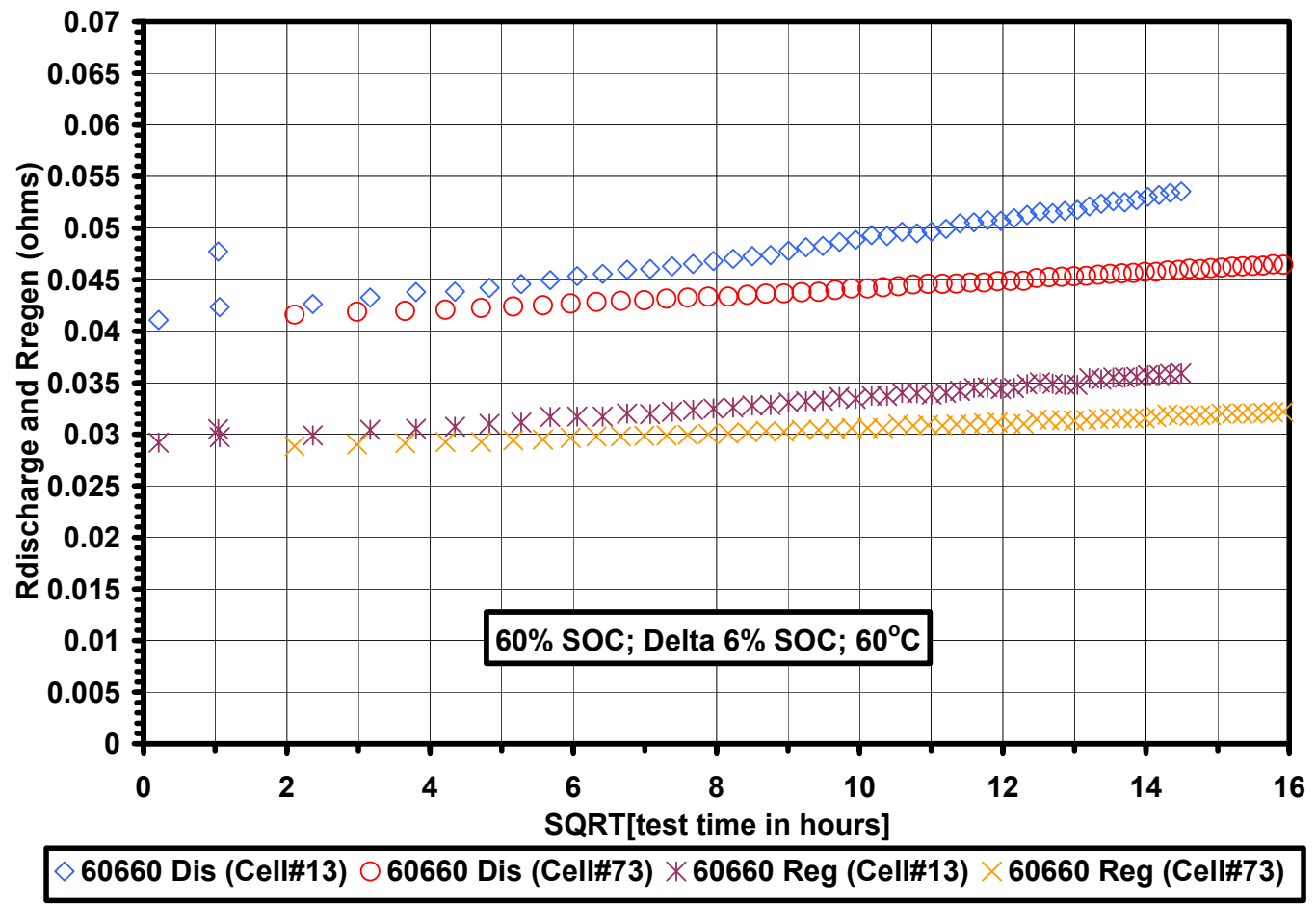

Figure 20. INEEL cycle-life discharge and regen resistance data for ATD Gen 1 (60660) cells. 


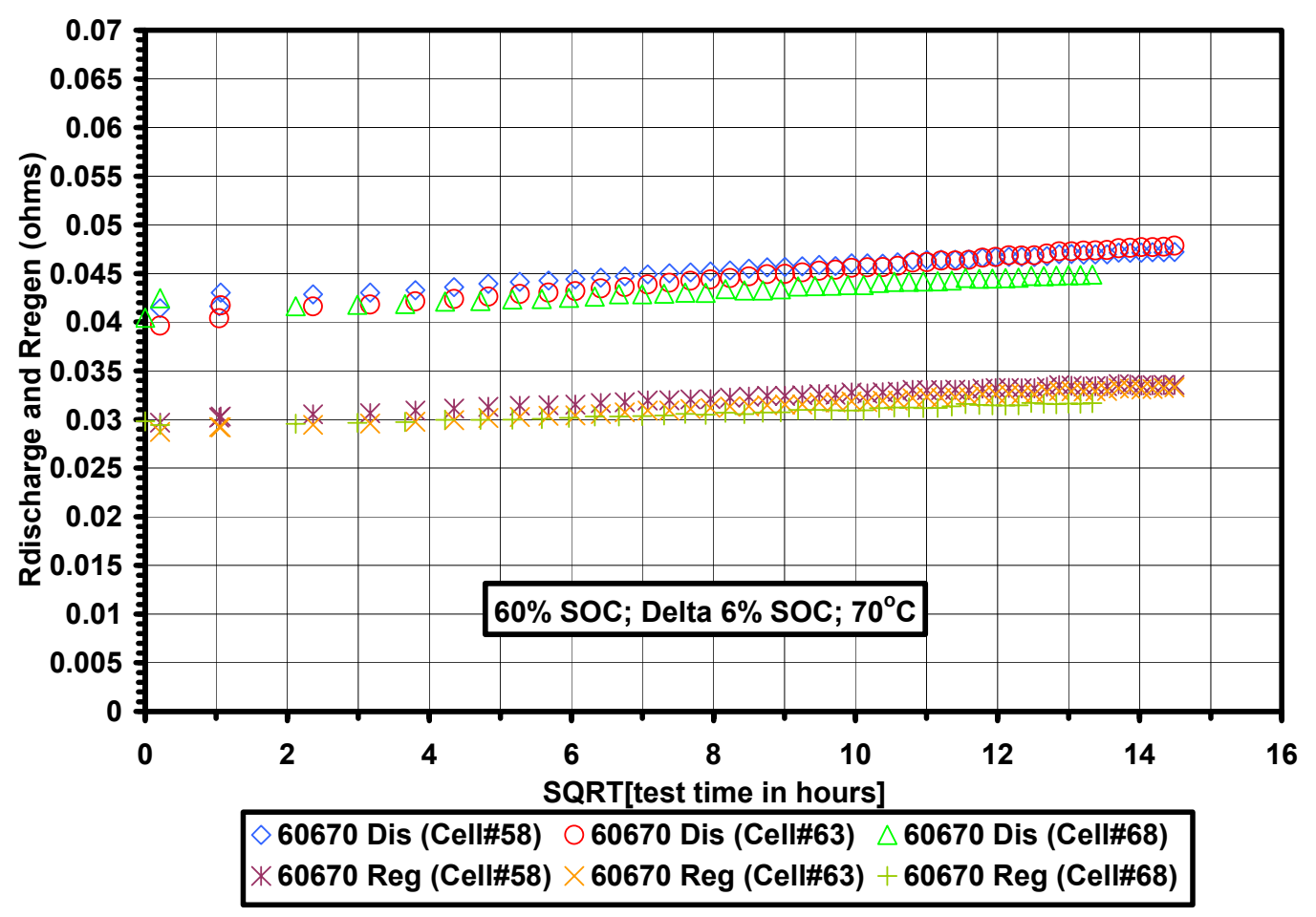

Figure 21. INEEL cycle-life discharge and regen resistance data for ATD Gen 1 (60670) cells.

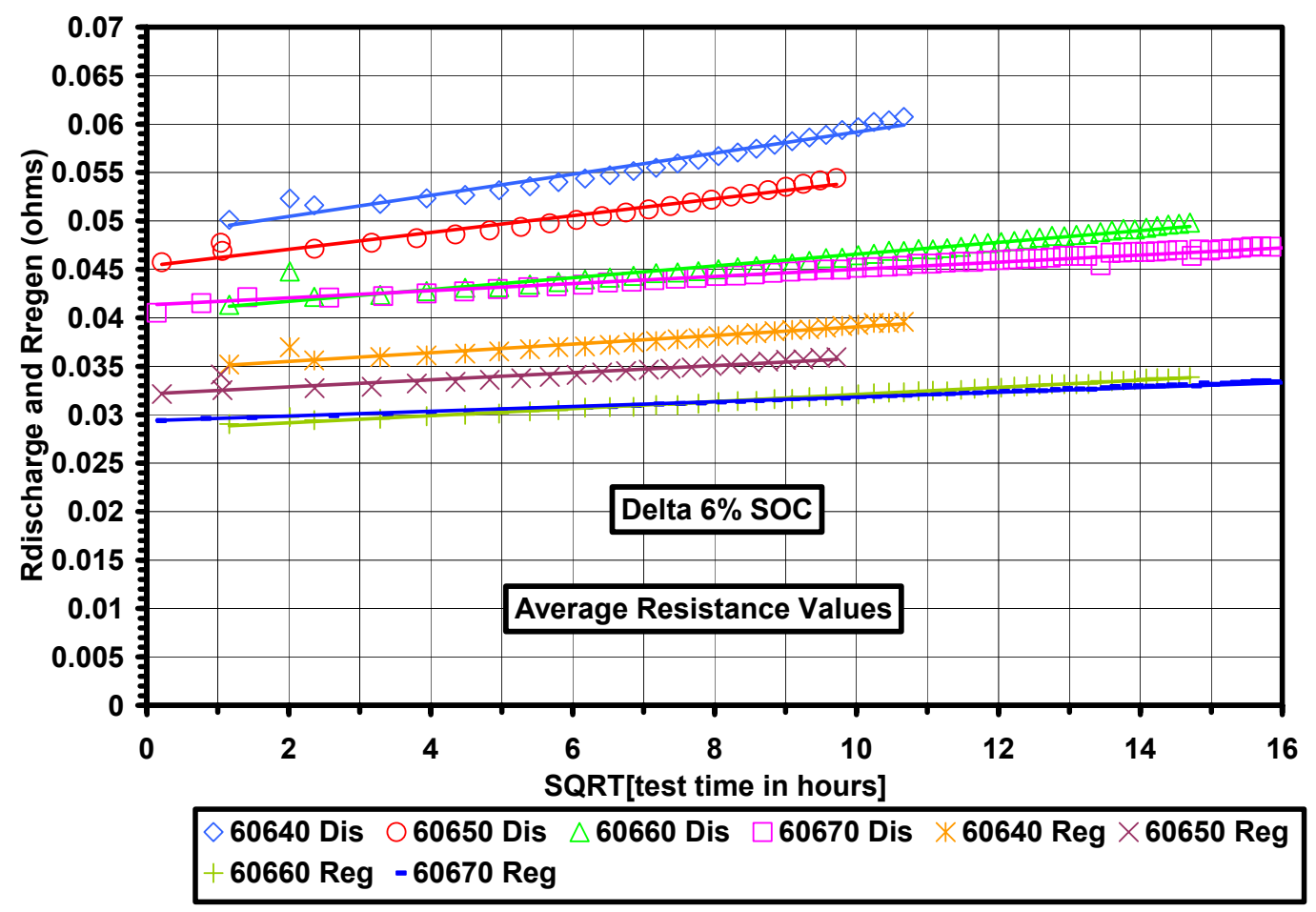

Figure 22. INEEL cycle-life discharge and regen resistance data for ATD Gen $1(606-40,50,60,70)$ cells. 


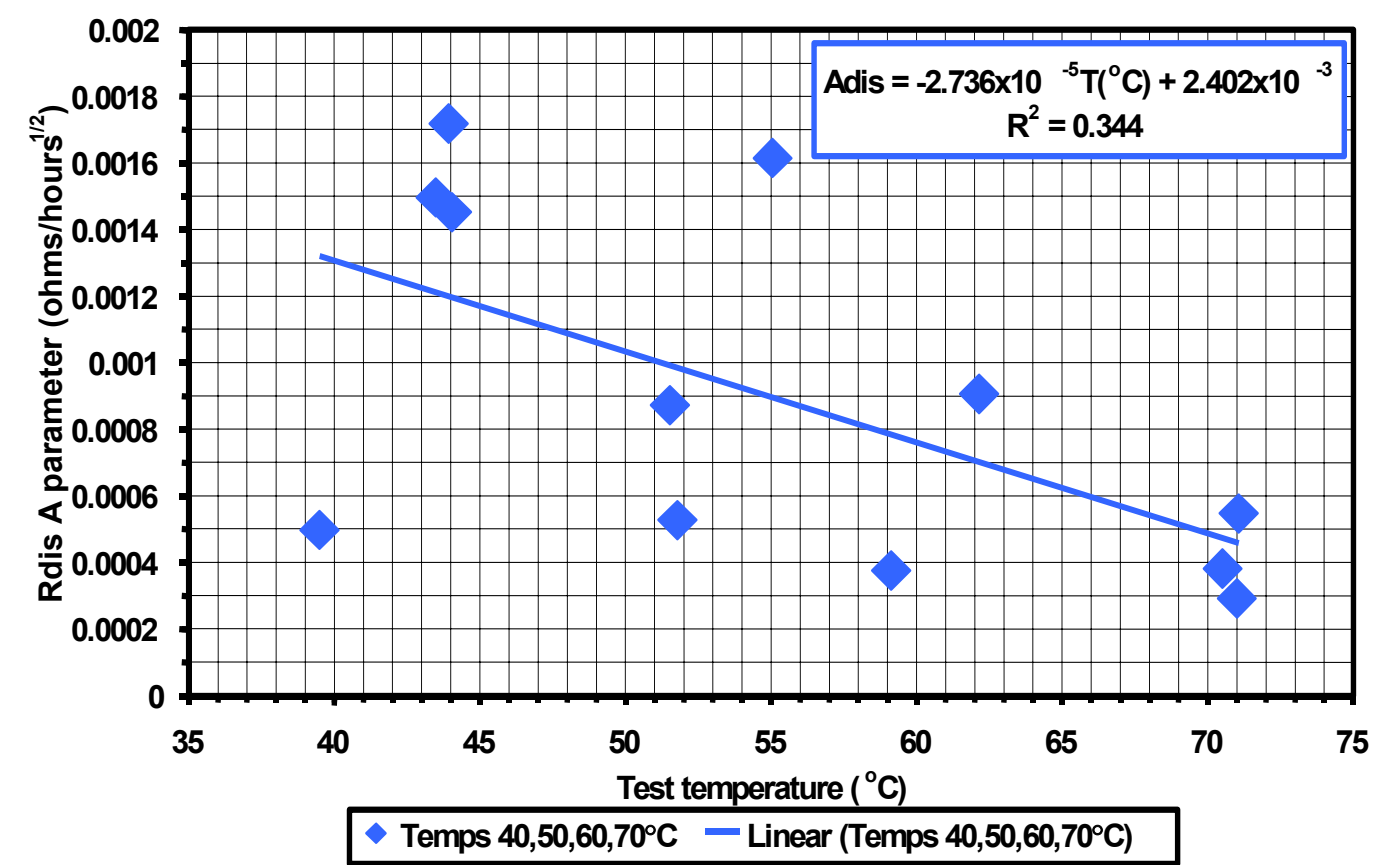

Figure 23. INEEL cycle-life discharge resistance data for ATD Gen $1(606-40,50,60,70)$ cells. Fit to equation: $\mathrm{R}(\mathrm{t}, \mathrm{T}, \mathrm{SOC})=\mathrm{A}(\mathrm{T}, \mathrm{SOC}) * \mathrm{SQRT}$ [test time in hours at temperature $]+\mathrm{B}(\mathrm{T}, \mathrm{SOC})$.

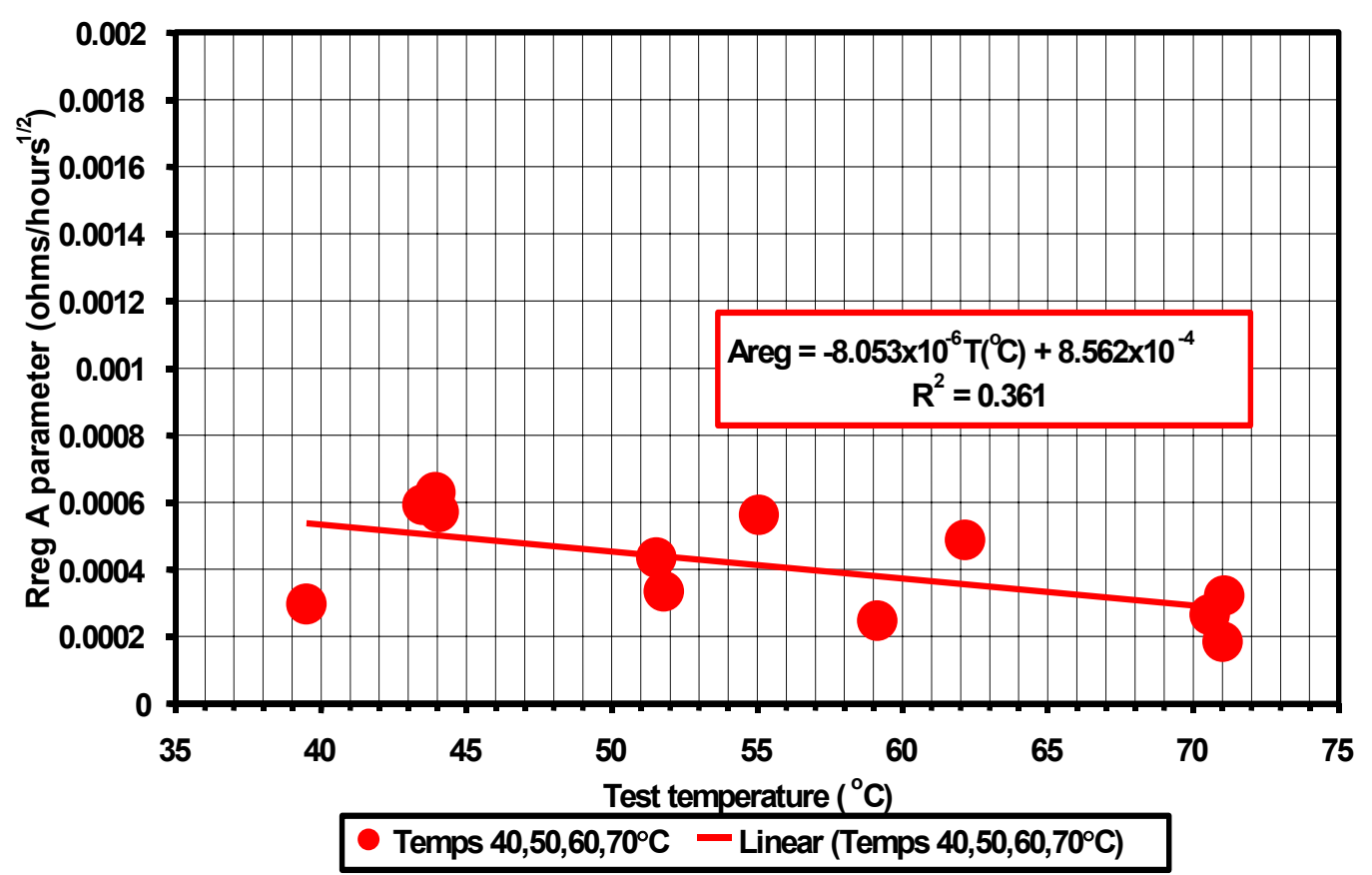

Figure 24. INEEL cycle-life regen resistance data for ATD Gen $1(606-40,50,60,70)$ cells. Fit to equation: $\mathrm{R}(\mathrm{t}, \mathrm{T}, \mathrm{SOC})=\mathrm{A}(\mathrm{T}, \mathrm{SOC}) * \mathrm{SQRT}$ [test time in hours at temperature] $+\mathrm{B}(\mathrm{T}, \mathrm{SOC})$. 


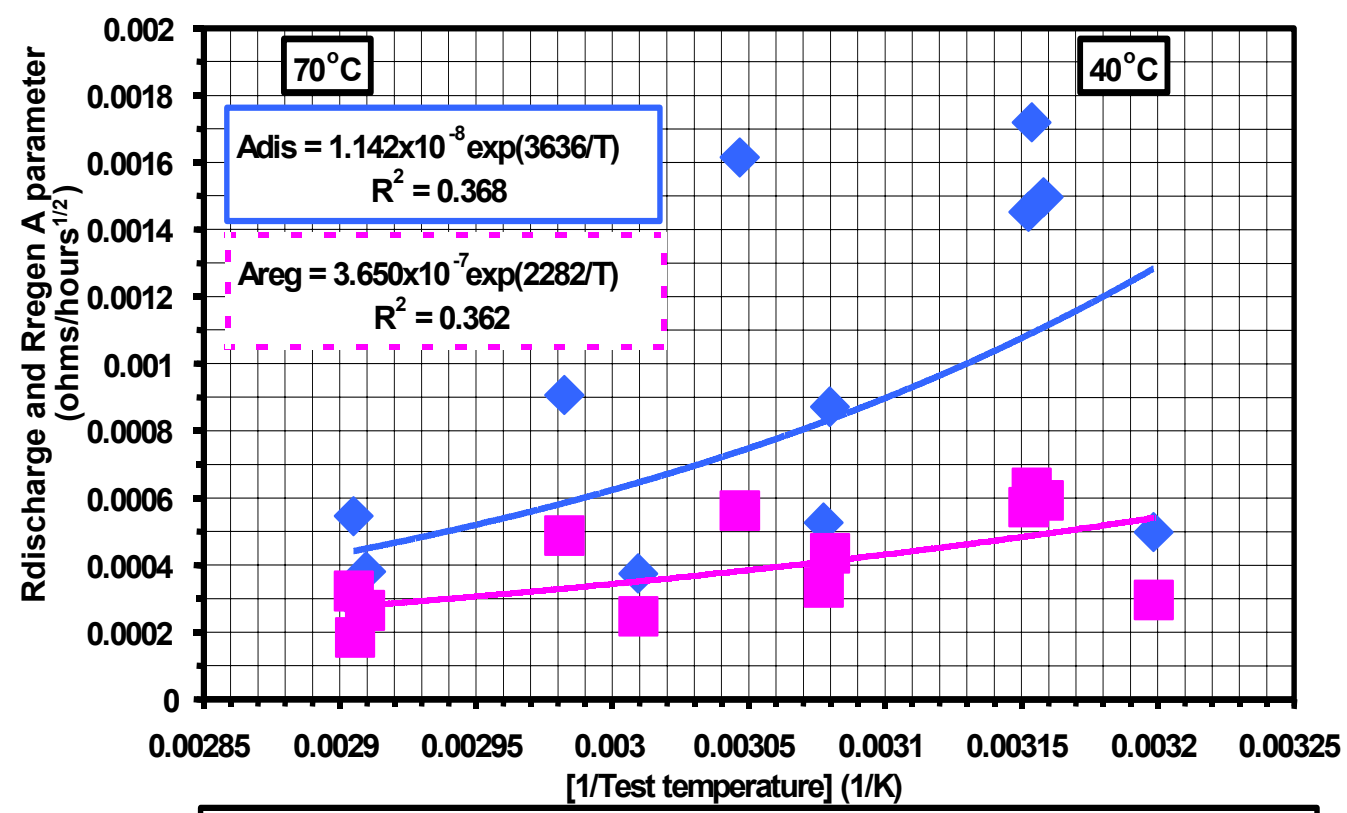

$\diamond$ Rdischarge $\square$ Rregen - Expon. (Rdischarge) - - Expon. (Rregen)

Figure 25. INEEL cycle-life discharge and regen resistance data for ATD Gen $1(606-40,50,60,70)$ cells. Fit to equation: $\mathrm{R}(\mathrm{t}, \mathrm{T}, \mathrm{SOC})=\mathrm{A}(\mathrm{T}, \mathrm{SOC}) * \mathrm{SQRT}$ [test time in hours at temperature] $+\mathrm{B}(\mathrm{T}, \mathrm{SOC})$.

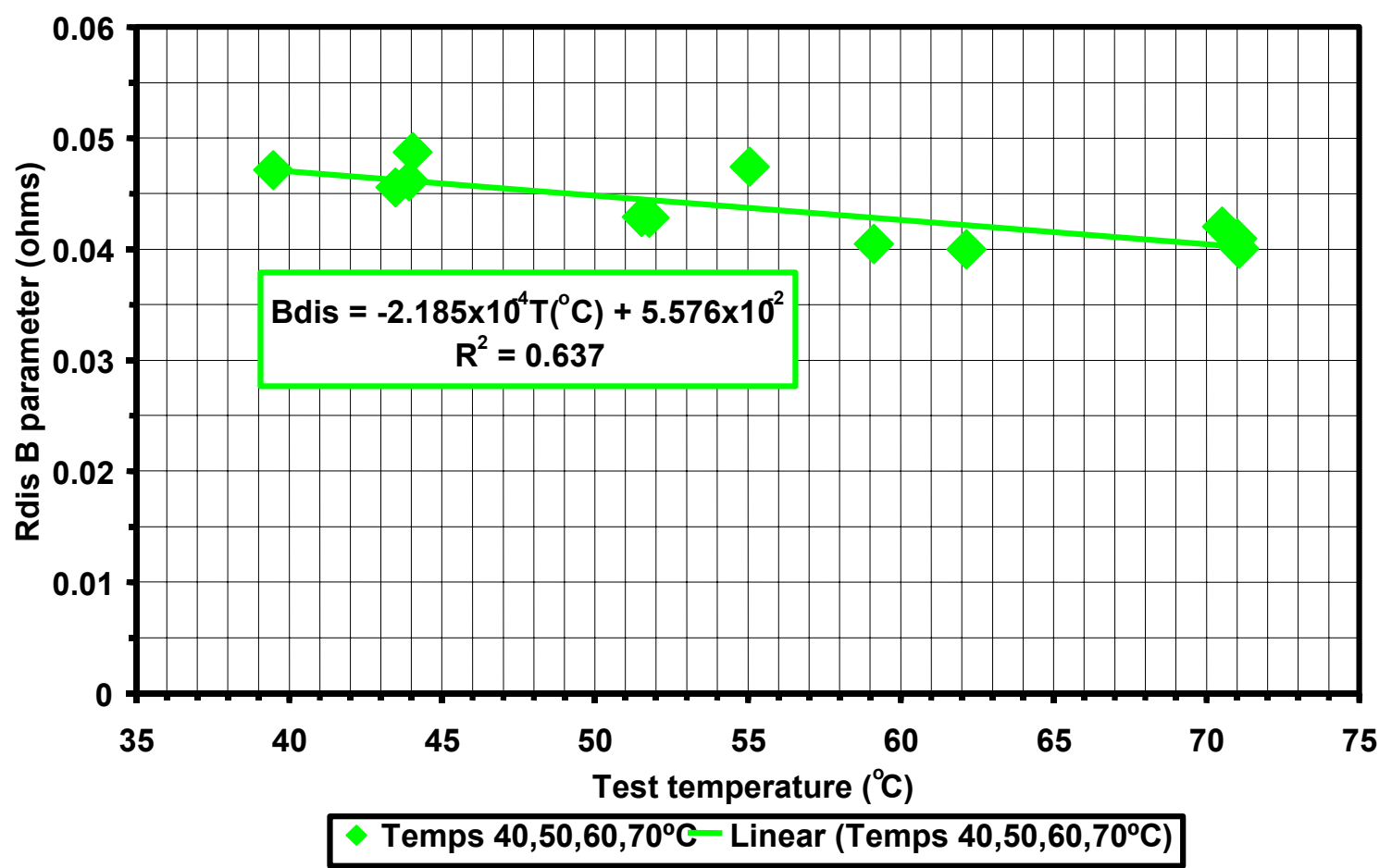

Figure 26. INEEL cycle-life discharge resistance data for ATD Gen $1(606-40,50,60,70)$ cells. Fit to equation: $\mathrm{R}(\mathrm{t}, \mathrm{T}, \mathrm{SOC})=\mathrm{A}(\mathrm{T}, \mathrm{SOC}) * \mathrm{SQRT}$ [test time in hours at temperature] $+\mathrm{B}(\mathrm{T}, \mathrm{SOC})$. 


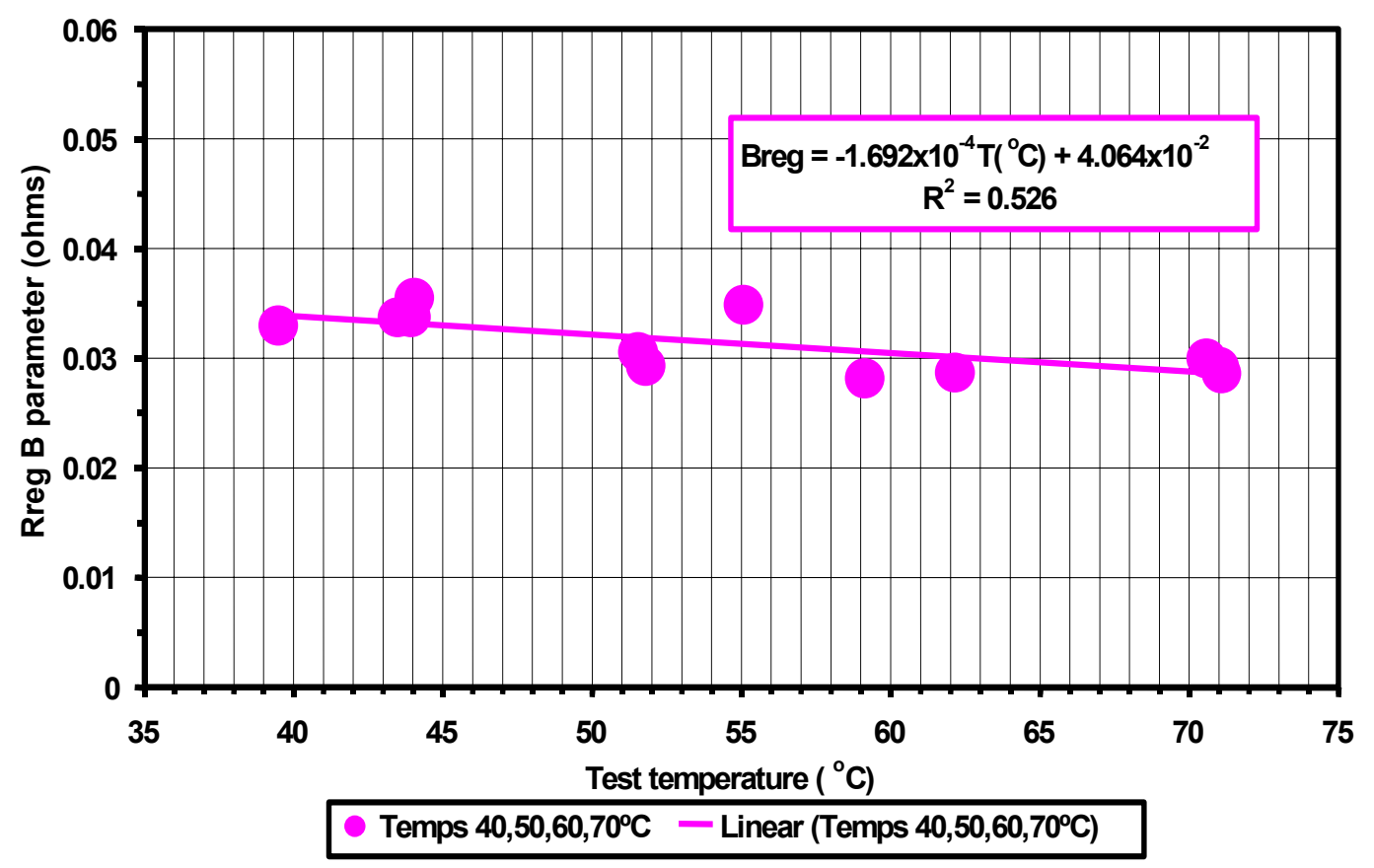

Figure 27. INEEL cycle-life regen resistance data for ATD Gen $1(606-40,50,60)$ cells. Fit to equation: $\mathrm{R}(\mathrm{t}, \mathrm{T}, \mathrm{SOC})=\mathrm{A}(\mathrm{T}, \mathrm{SOC}) * \mathrm{SQRT}[$ test time in hours at temperature $]+\mathrm{B}(\mathrm{T}, \mathrm{SOC})$.

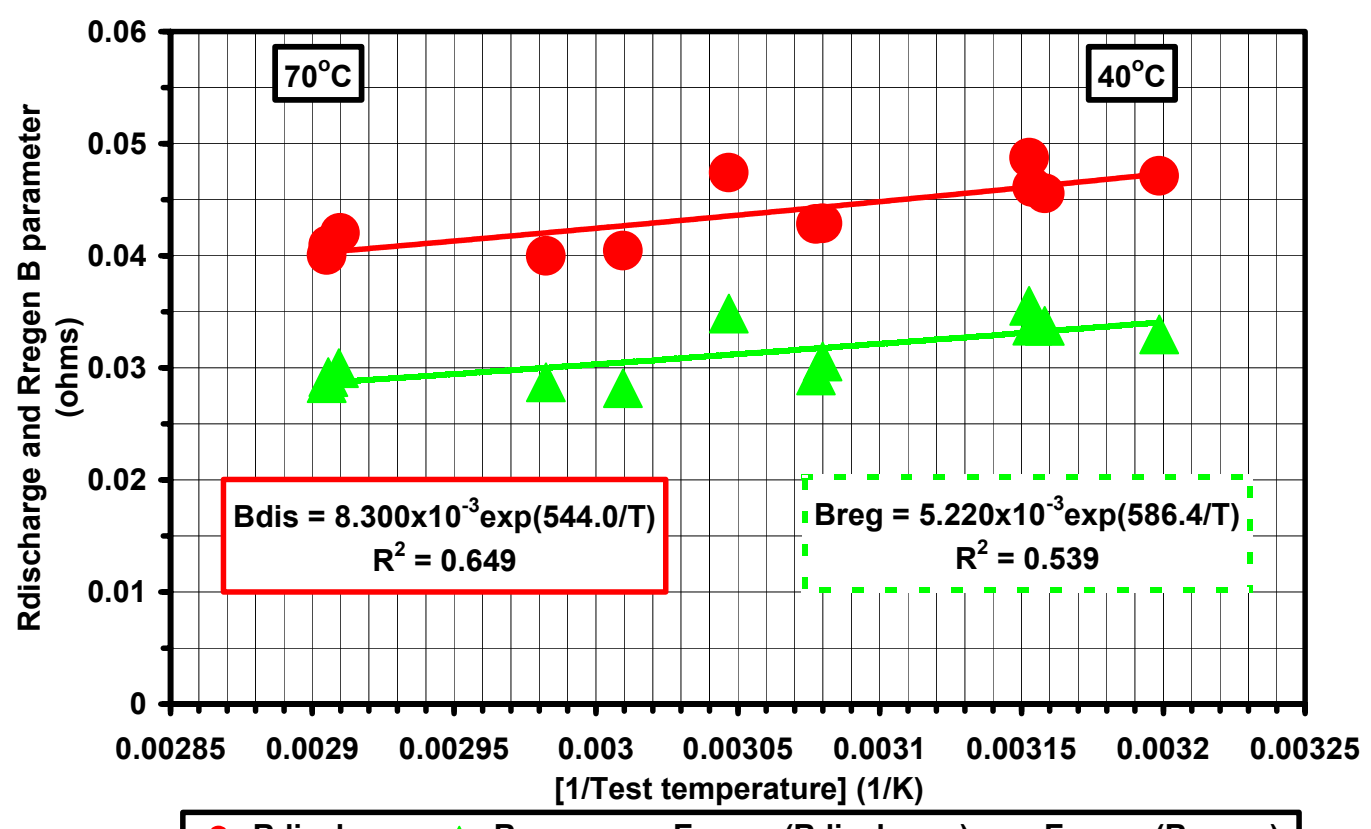

Rdischarge $\Delta$ Rregen —Expon. (Rdischarge) - - Expon. (Rregen)

Figure 28. INEEL cycle-life discharge and regen resistance data for ATD Gen $1(606-40,50,60,70)$ cells. Fit to equation: $\mathrm{R}(\mathrm{t}, \mathrm{T}, \mathrm{SOC})=\mathrm{A}(\mathrm{T}, \mathrm{SOC}) * \mathrm{SQRT}[$ test time in hours at temperature $]+\mathrm{B}(\mathrm{T}, \mathrm{SOC})$. 


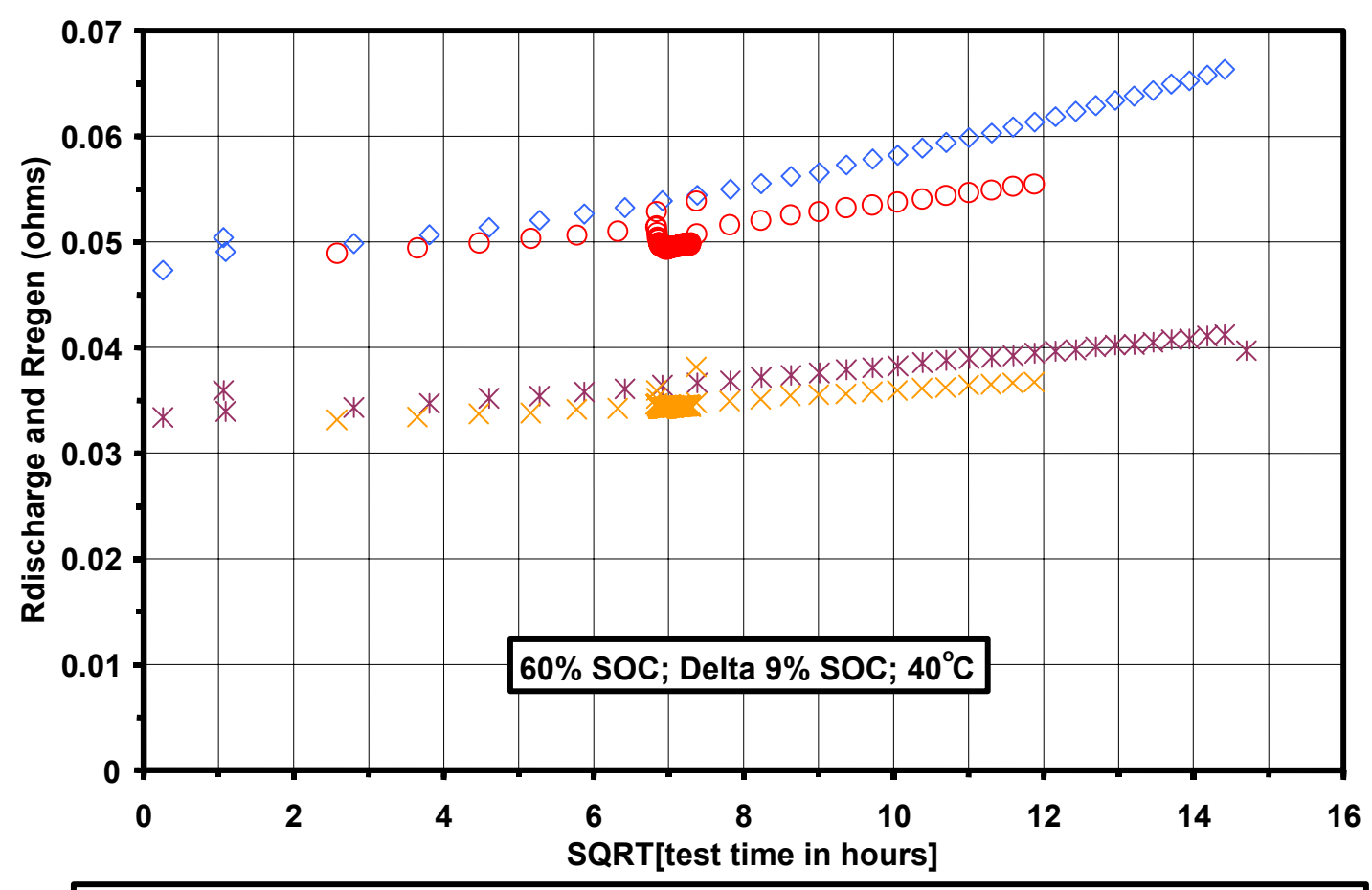

$\diamond 60940$ Dis (Cell\#16)○60940 Dis (Cell\#22) $* 60940$ Reg (Cell\#16) $\times 60940$ Reg (Cell\#22)

Figure 29. INEEL cycle-life discharge and regen resistance data for ATD Gen 1 (60940) cells.

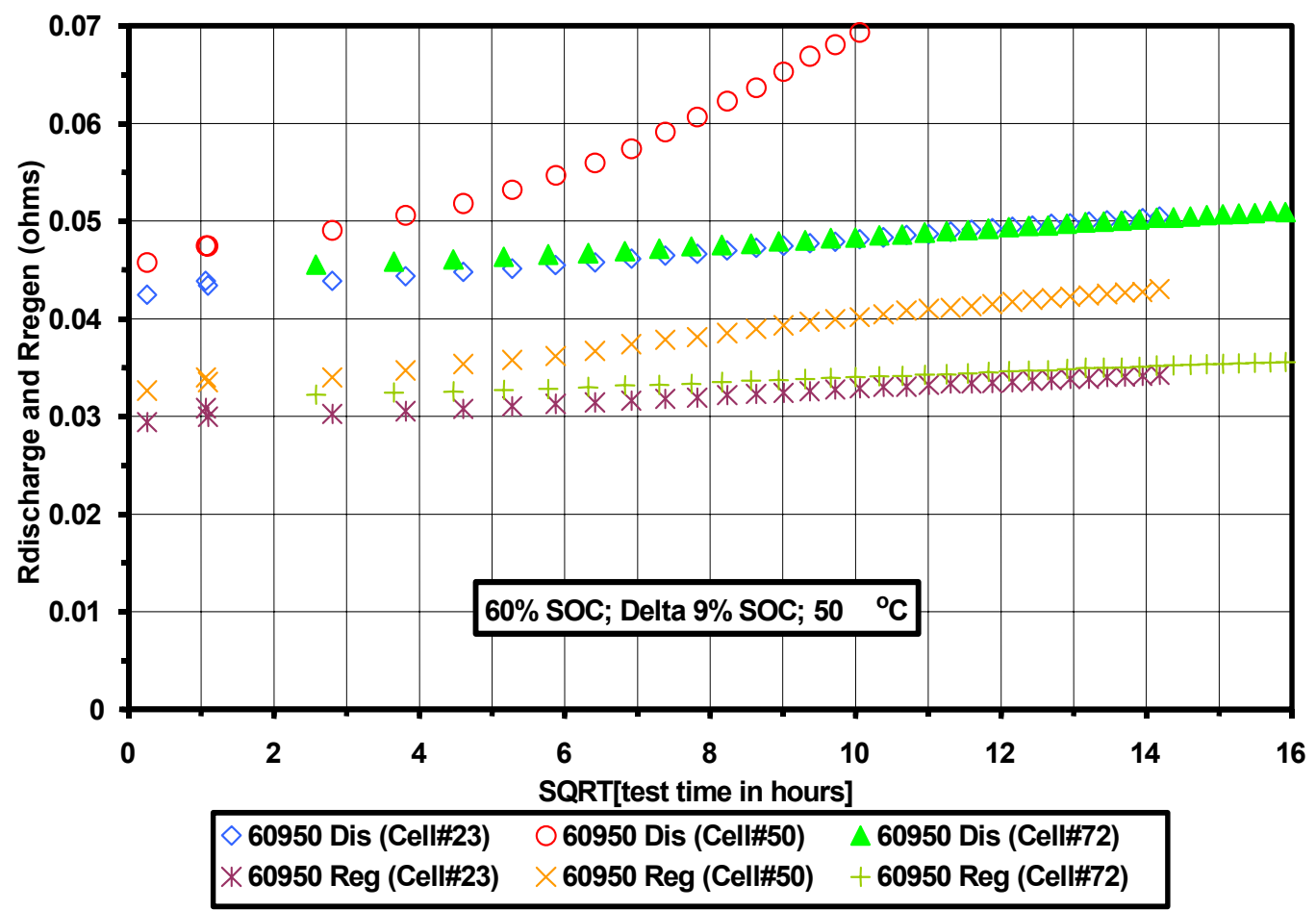

Figure 30. INEEL cycle-life discharge and regen resistance data for ATD Gen 1 (60950) cells. 


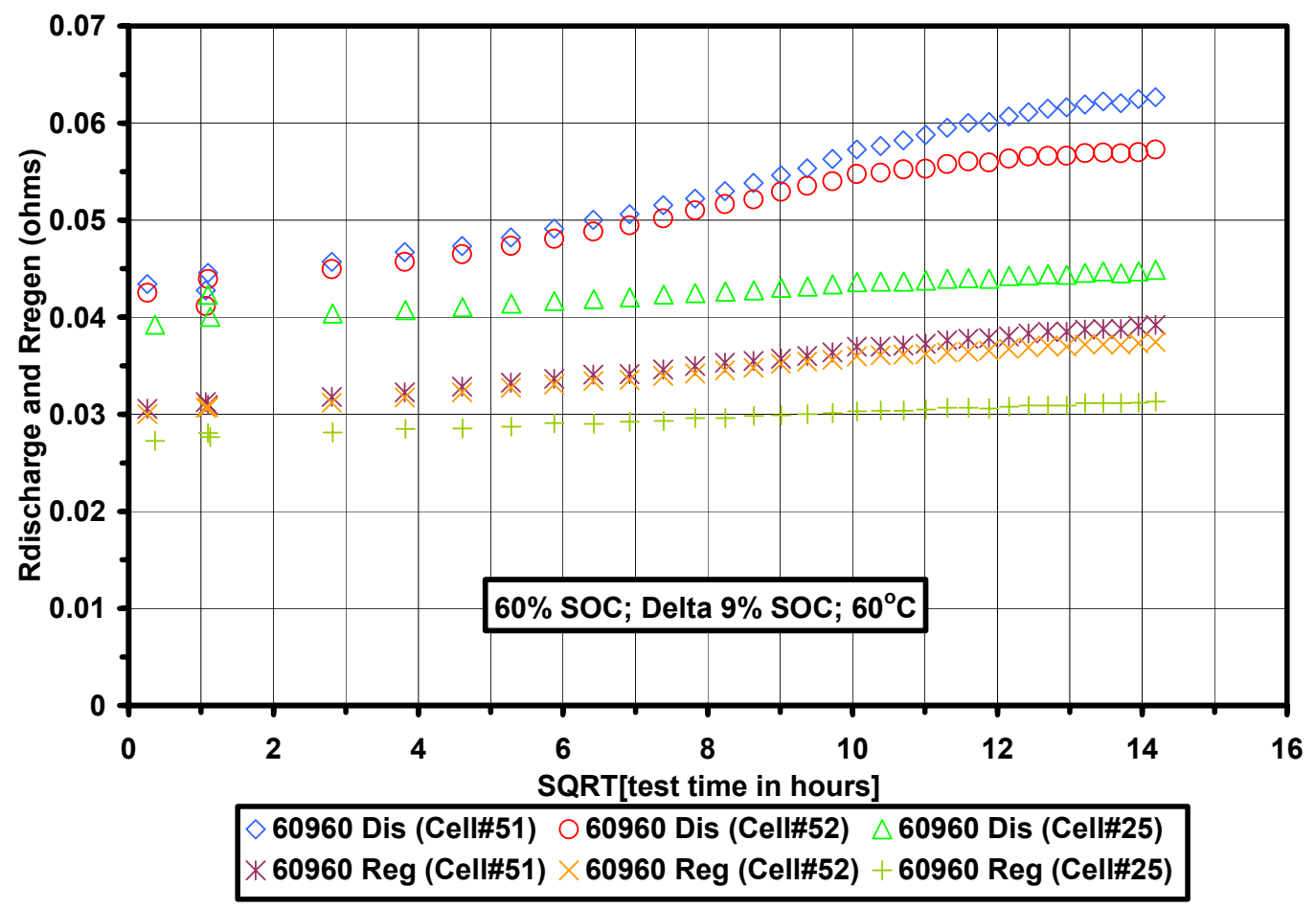

Figure 31. INEEL cycle-life discharge and regen resistance data for ATD Gen 1 (60960) cells.

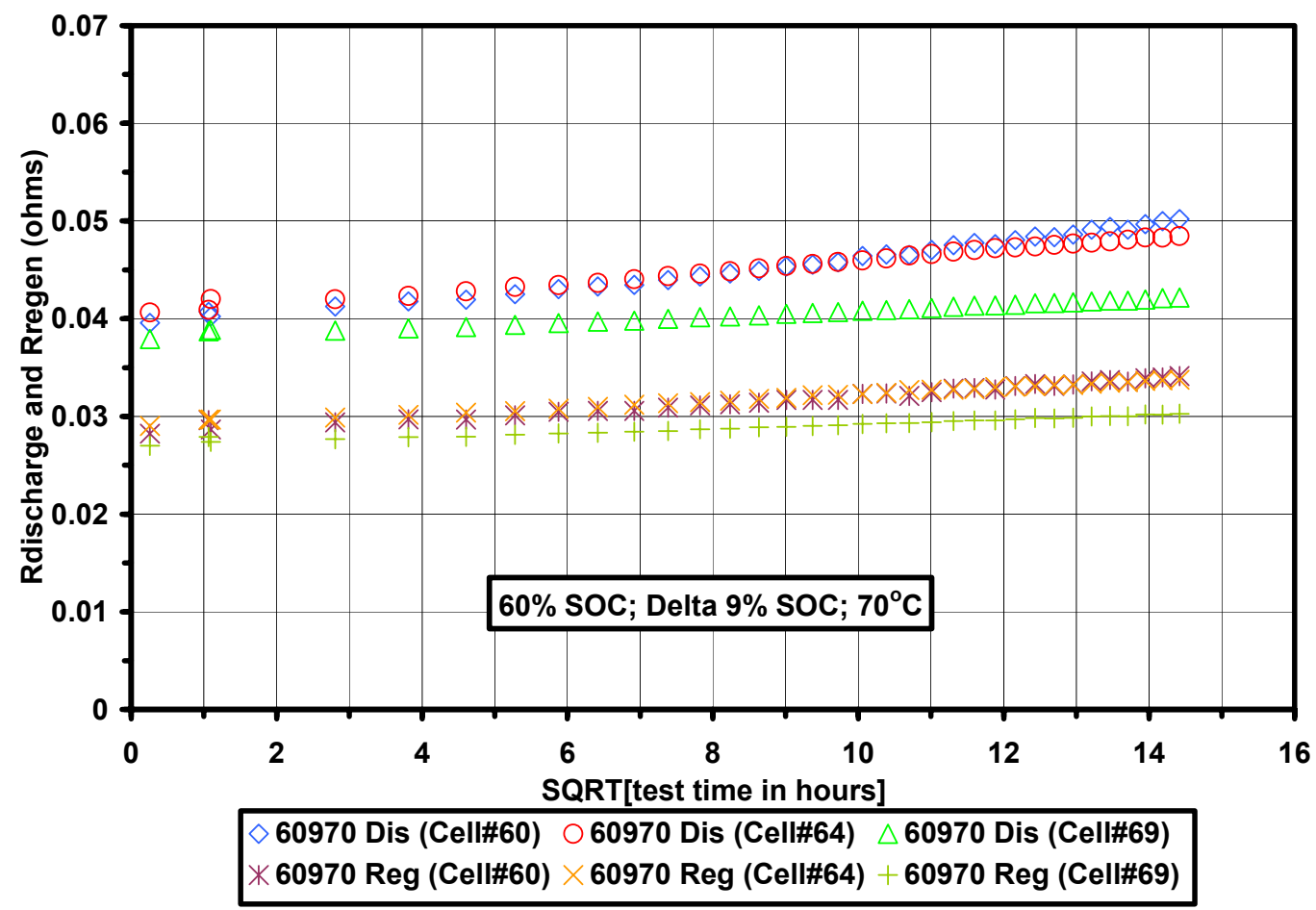

Figure 32. INEEL cycle-life discharge and regen resistance data for ATD Gen 1 (60970) cells. 


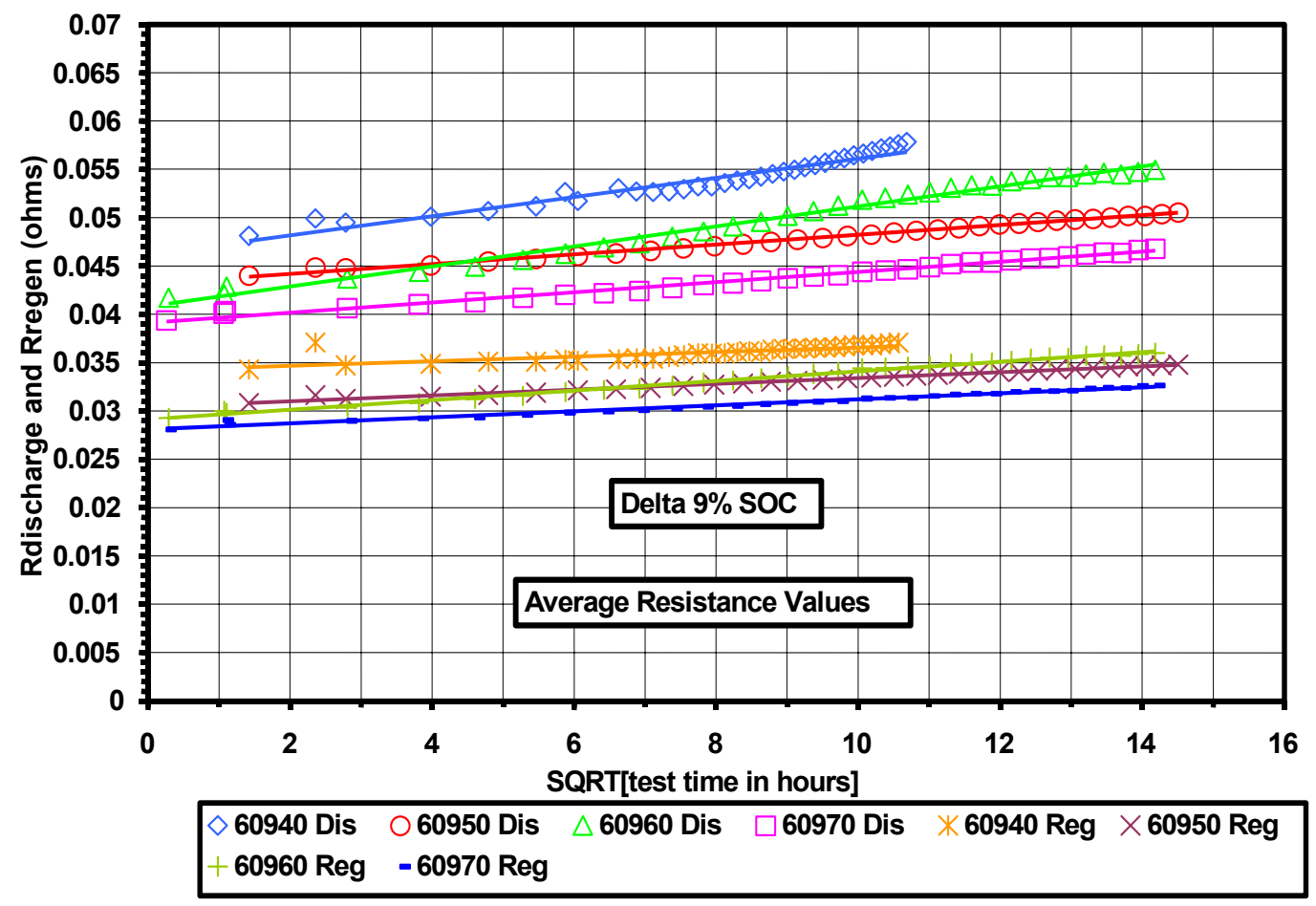

Figure 33. INEEL cycle-life discharge and regen resistance data for ATD Gen $1(609-40,50,60,70)$ cells.

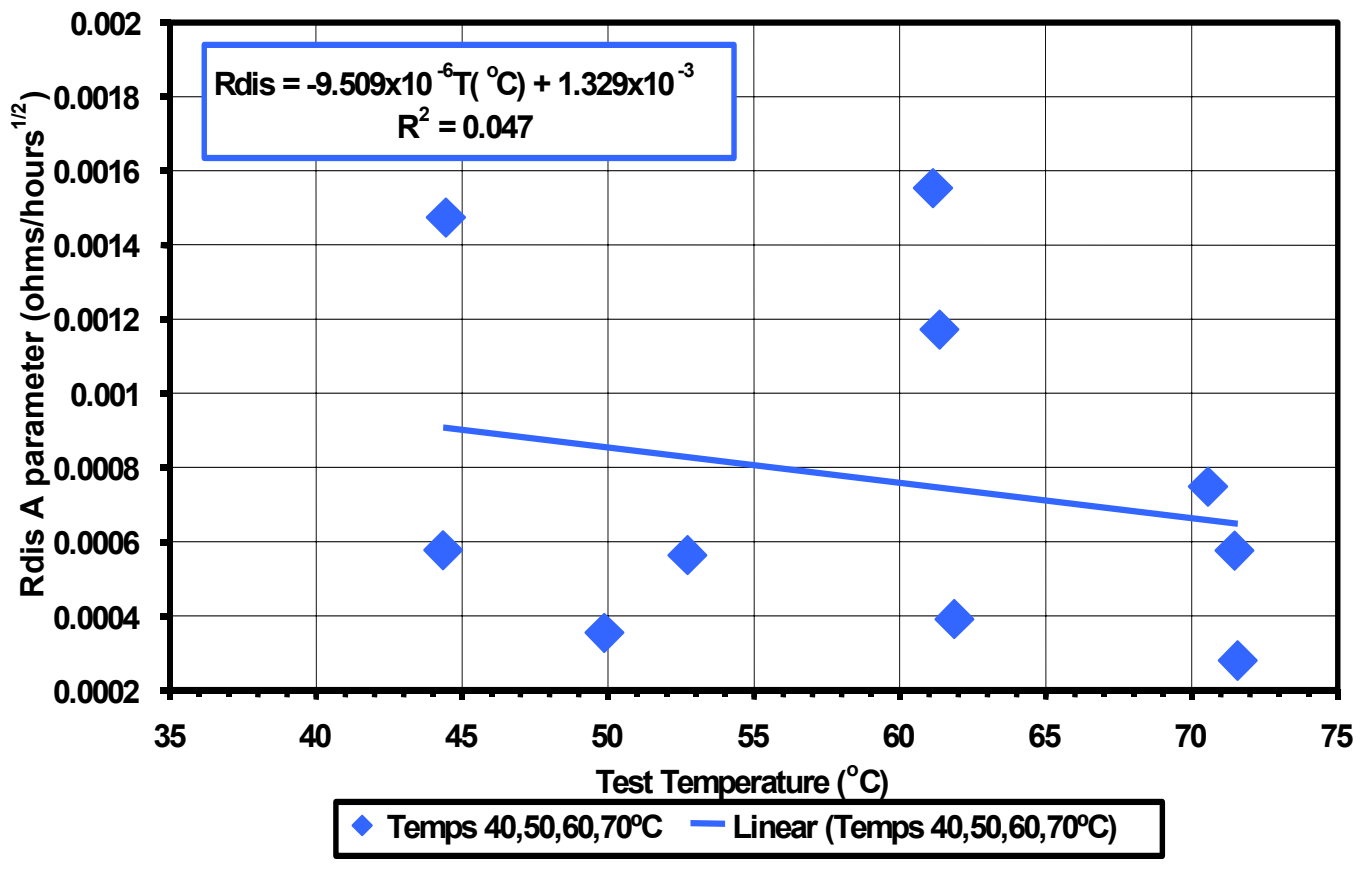

Figure 34. INEEL cycle-life discharge resistance data for ATD Gen $1(609-40,50,60,70)$ cells. Fit to equation: $\mathrm{R}(\mathrm{t}, \mathrm{T}, \mathrm{SOC})=\mathrm{A}(\mathrm{T}, \mathrm{SOC}) * \mathrm{SQRT}[$ test time in hours at temperature $]+\mathrm{B}(\mathrm{T}, \mathrm{SOC})$. 


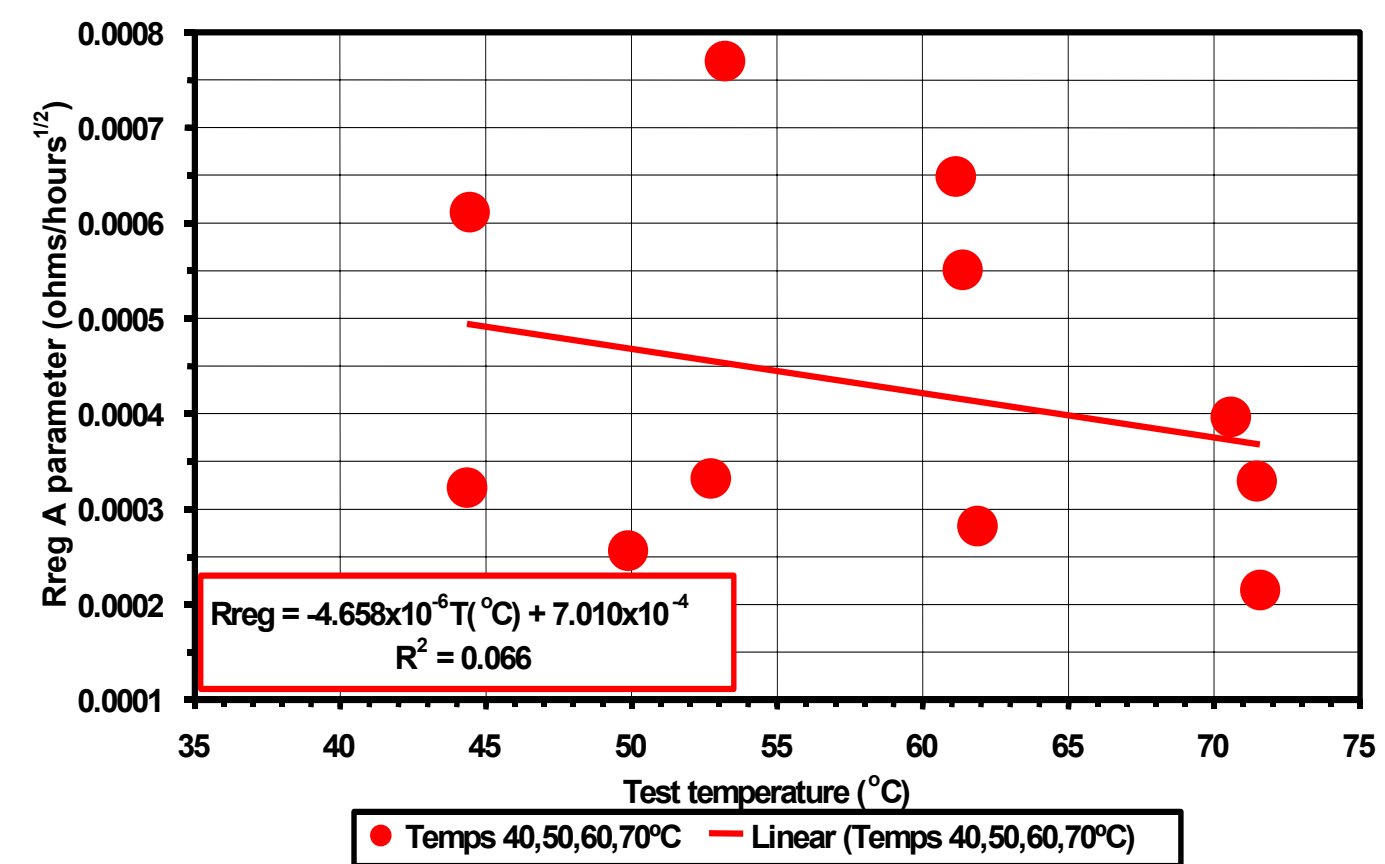

Figure 35. INEEL cycle-life regen resistance data for ATD Gen $1(609-40,50,60,70)$ cells. Fit to equation: $\mathrm{R}(\mathrm{t}, \mathrm{T}, \mathrm{SOC})=\mathrm{A}(\mathrm{T}, \mathrm{SOC}) * \mathrm{SQRT}$ [test time in hours at temperature $]+\mathrm{B}(\mathrm{T}, \mathrm{SOC})$.

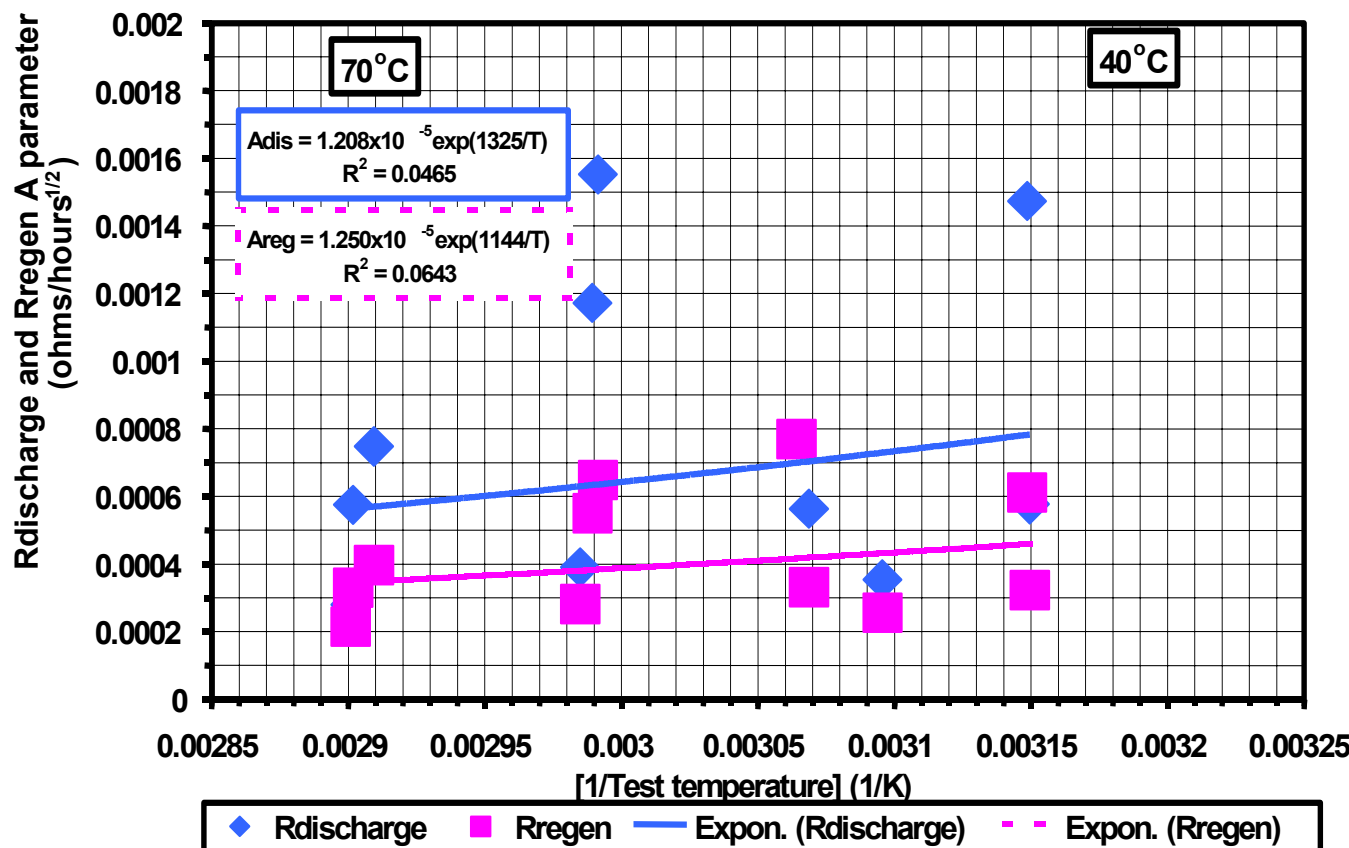

Figure 36. INEEL cycle-life discharge and regen resistance data for ATD Gen $1(609-40,50,60,70)$ cells. Fit to equation: $\mathrm{R}(\mathrm{t}, \mathrm{T}, \mathrm{SOC})=\mathrm{A}(\mathrm{T}, \mathrm{SOC}) * \mathrm{SQRT}$ [test time in hours at temperature] $+\mathrm{B}(\mathrm{T}, \mathrm{SOC})$. 


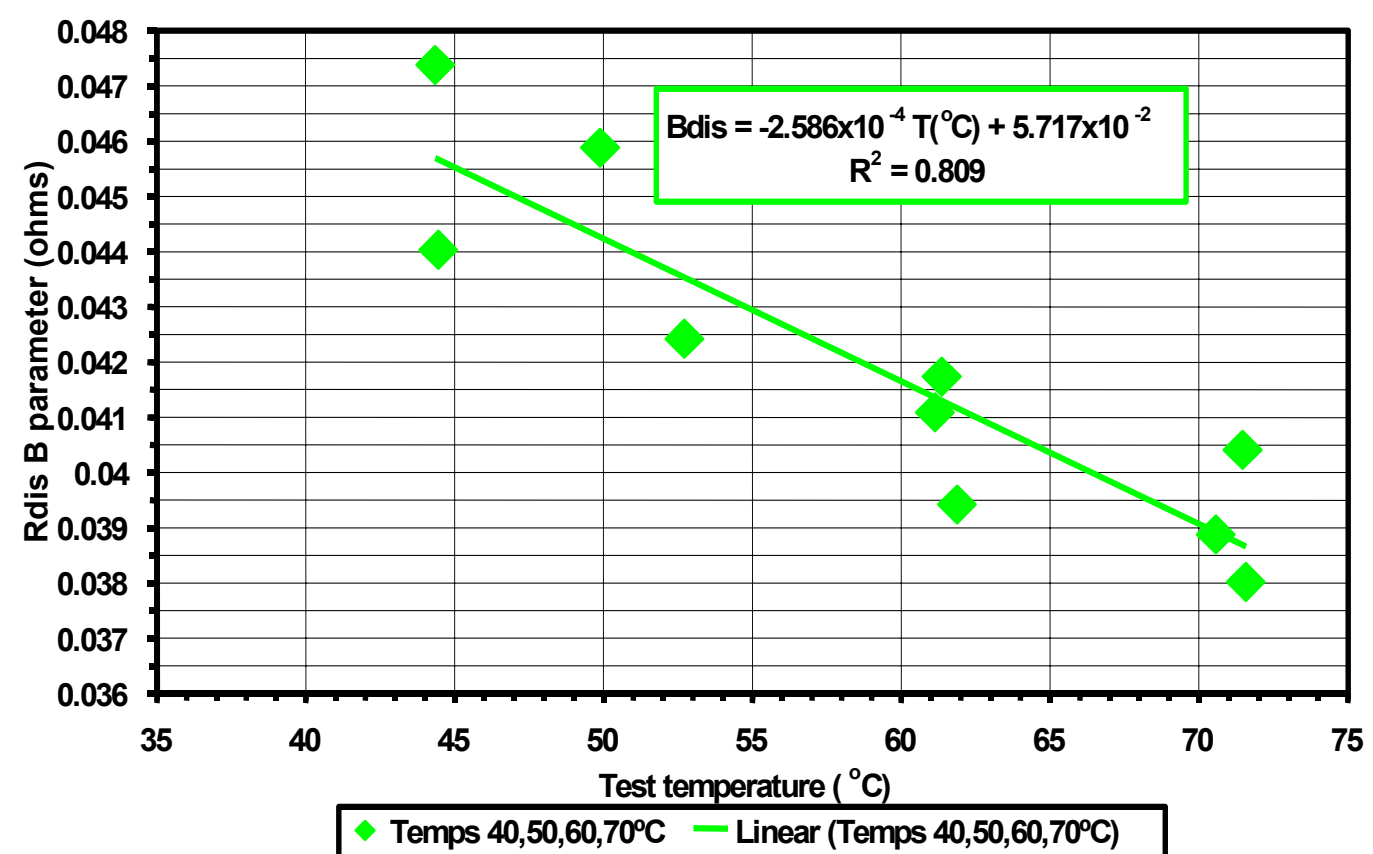

Figure 37. INEEL cycle-life discharge resistance data for ATD Gen $1(609-40,50,60,70)$ cells. Fit to equation: $\mathrm{R}(\mathrm{t}, \mathrm{T}, \mathrm{SOC})=\mathrm{A}(\mathrm{T}, \mathrm{SOC}) * \mathrm{SQRT}$ [test time in hours at temperature $]+\mathrm{B}(\mathrm{T}, \mathrm{SOC})$.

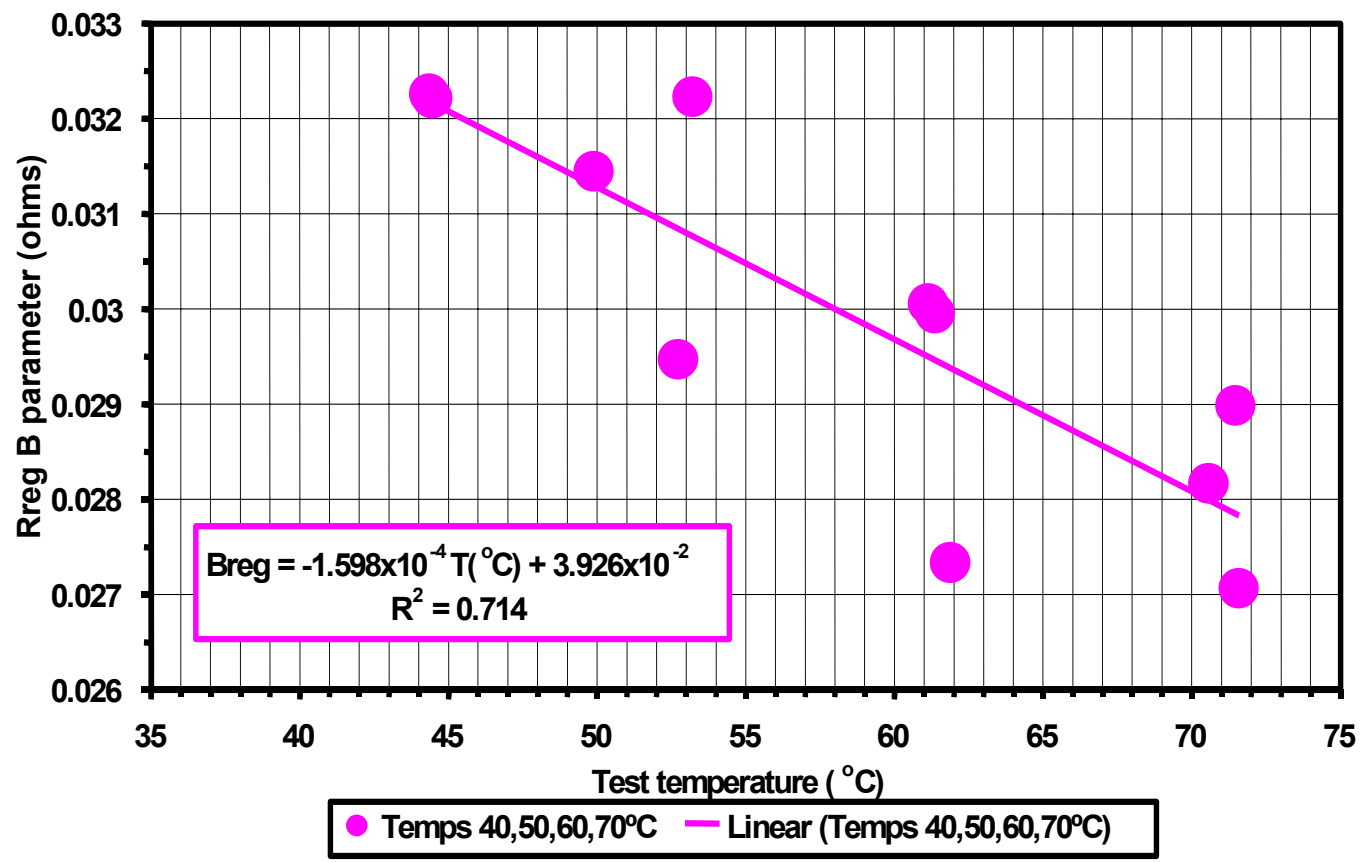

Figure 38. INEEL cycle-life regen resistance data for ATD Gen $1(609-40,50,60,70)$ cells. Fit to equation: $\mathrm{R}(\mathrm{t}, \mathrm{T}, \mathrm{SOC})=\mathrm{A}(\mathrm{T}, \mathrm{SOC}) * \mathrm{SQRT}$ [test time in hours at temperature] $+\mathrm{B}(\mathrm{T}, \mathrm{SOC})$. 


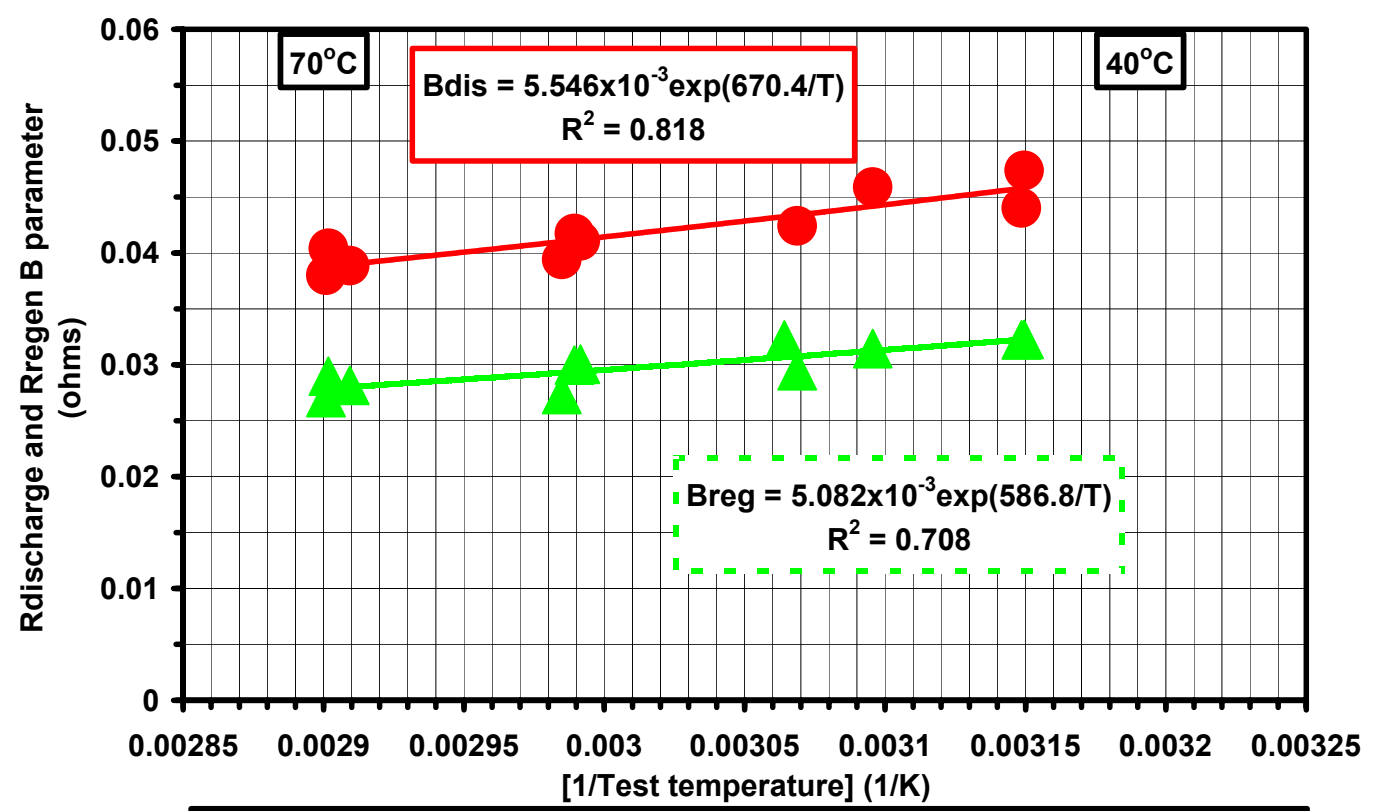

- Rdischarge $\triangle$ Rregen —Expon. (Rdischarge) = = Expon. (Rregen)

Figure 39. INEEL cycle-life discharge and regen resistance data for ATD Gen $1(609-40,50,60,70)$ cells. Fit to equation: $\mathrm{R}(\mathrm{t}, \mathrm{T}, \mathrm{SOC})=\mathrm{A}(\mathrm{T}, \mathrm{SOC}) * \mathrm{SQRT}[$ test time in hours at temperature] $+\mathrm{B}(\mathrm{T}, \mathrm{SOC})$.

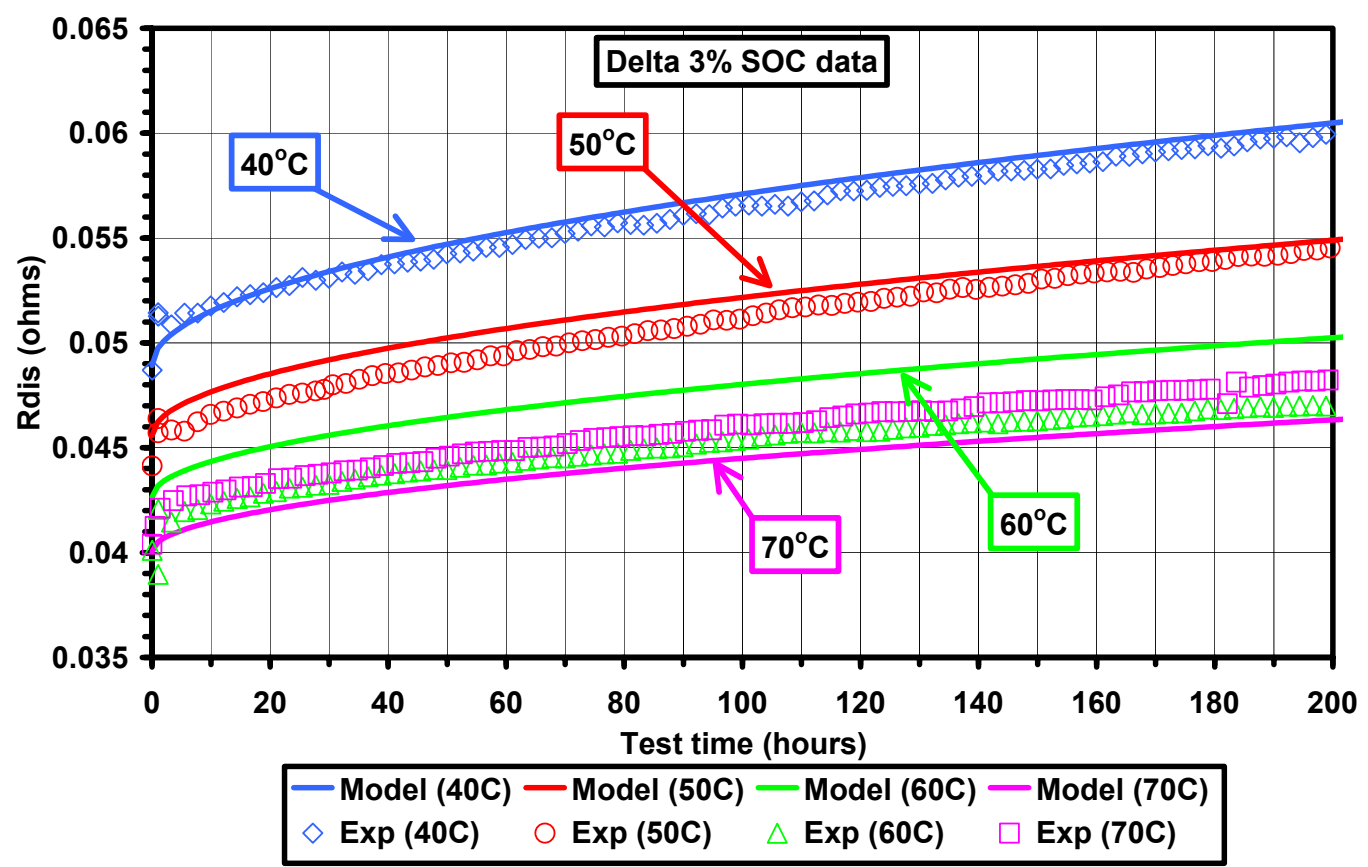

Figure 40. Selected INEEL cycle-life discharge resistance data for ATD Gen 1 [603-40,50,60,70] cells. Fit to equation: $\mathrm{R}(\mathrm{t}, \mathrm{T}, \mathrm{SOC})=\mathrm{A}(\mathrm{T}, \mathrm{SOC}) * \mathrm{SQRT}[$ test time in hours at temperature $]+\mathrm{B}(\mathrm{T}, \mathrm{SOC})$. 


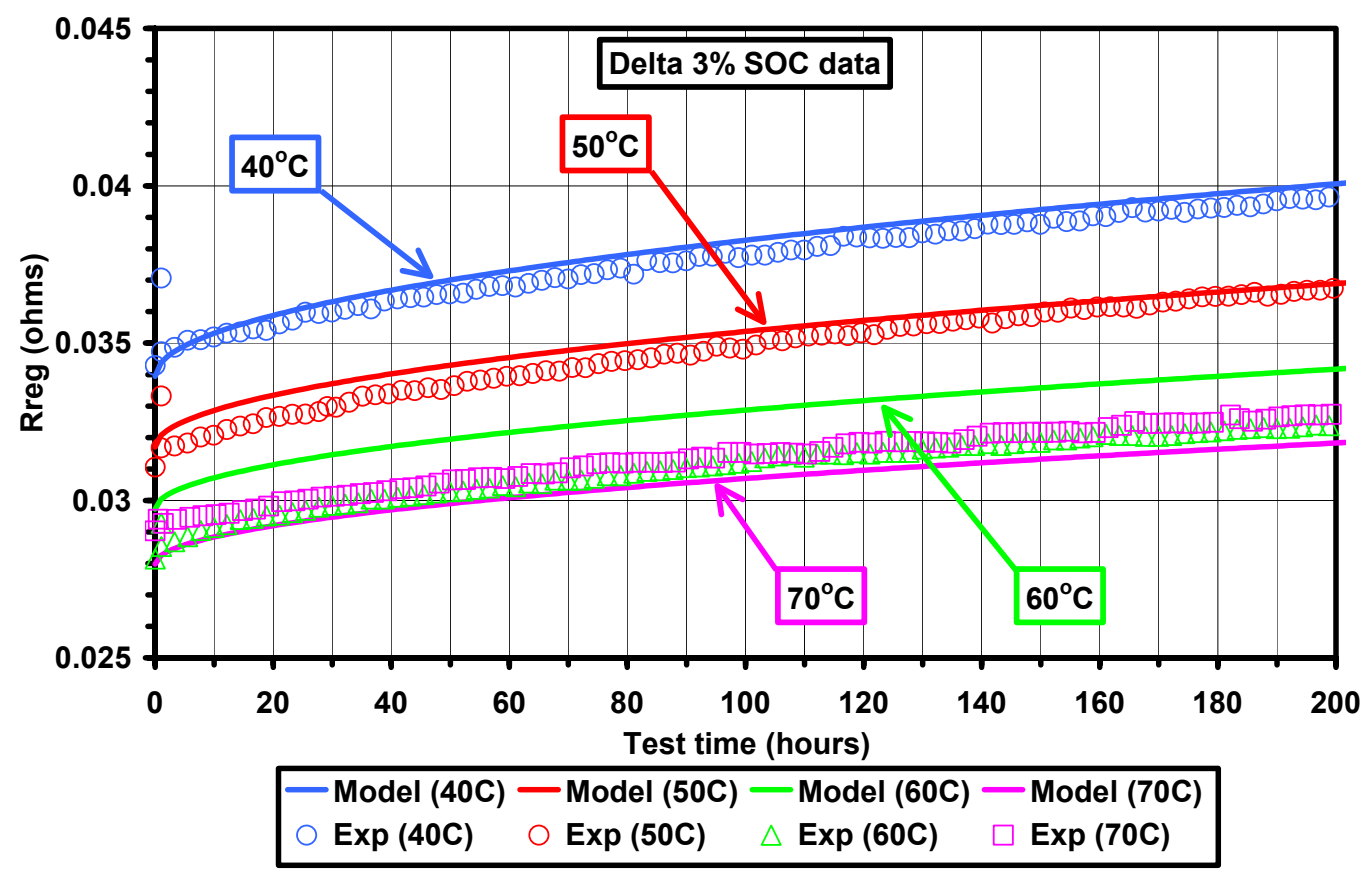

Figure 41. Selected INEEL cycle-life regen resistance data for ATD Gen 1 [603-40,50,60,70] cells. Fit to equation: $\mathrm{R}(\mathrm{t}, \mathrm{T}, \mathrm{SOC})=\mathrm{A}(\mathrm{T}, \mathrm{SOC})^{*} \mathrm{SQRT}$ [test time in hours at temperature] $+\mathrm{B}(\mathrm{T}, \mathrm{SOC})$.

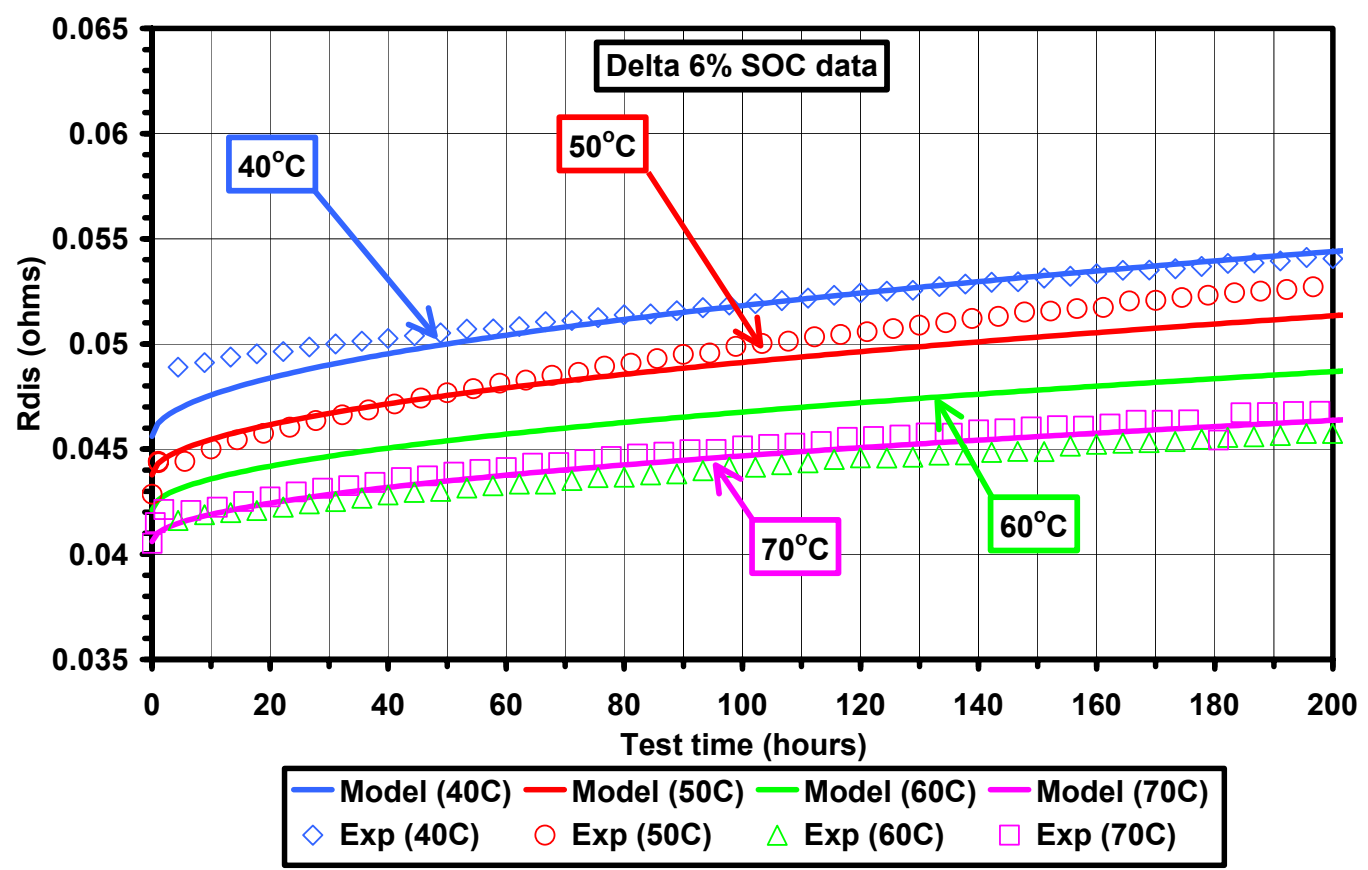

Figure 42. Selected INEEL cycle-life discharge resistance data for ATD Gen 1 [606-40,50,60,70] cells. Fit to equation: $\mathrm{R}(\mathrm{t}, \mathrm{T}, \mathrm{SOC})=\mathrm{A}(\mathrm{T}, \mathrm{SOC}) * \mathrm{SQRT}[$ test time in hours at temperature $]+\mathrm{B}(\mathrm{T}, \mathrm{SOC})$. 


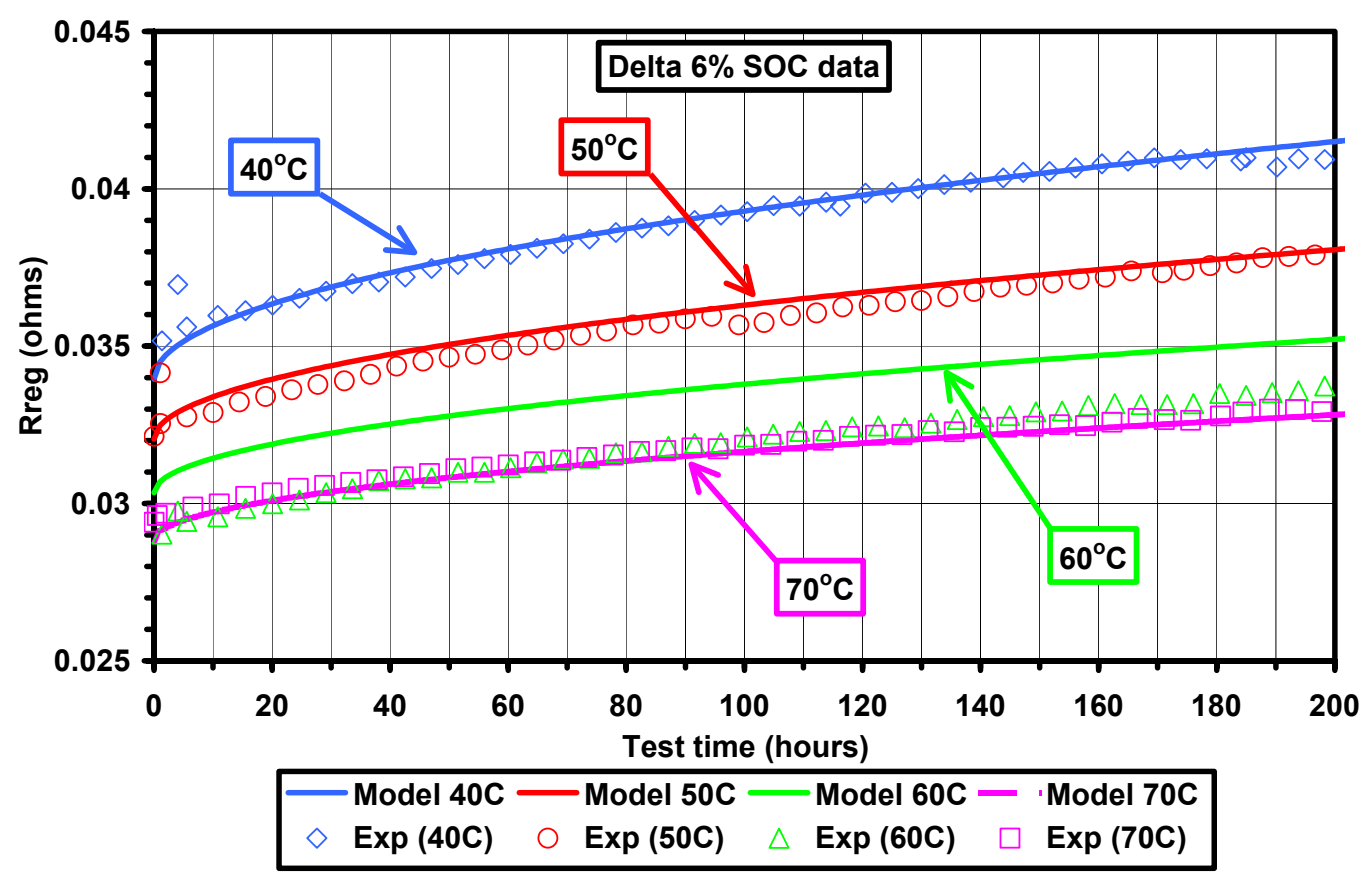

Figure 43. INEEL cycle-life regen resistance data for ATD Gen 1 [606-40,50,60,70] cells. Fit to equation: $\mathrm{R}(\mathrm{t}, \mathrm{T}, \mathrm{SOC})=\mathrm{A}(\mathrm{T}, \mathrm{SOC}) * \mathrm{SQRT}[$ test time in hours at temperature $]+\mathrm{B}(\mathrm{T}, \mathrm{SOC})$.

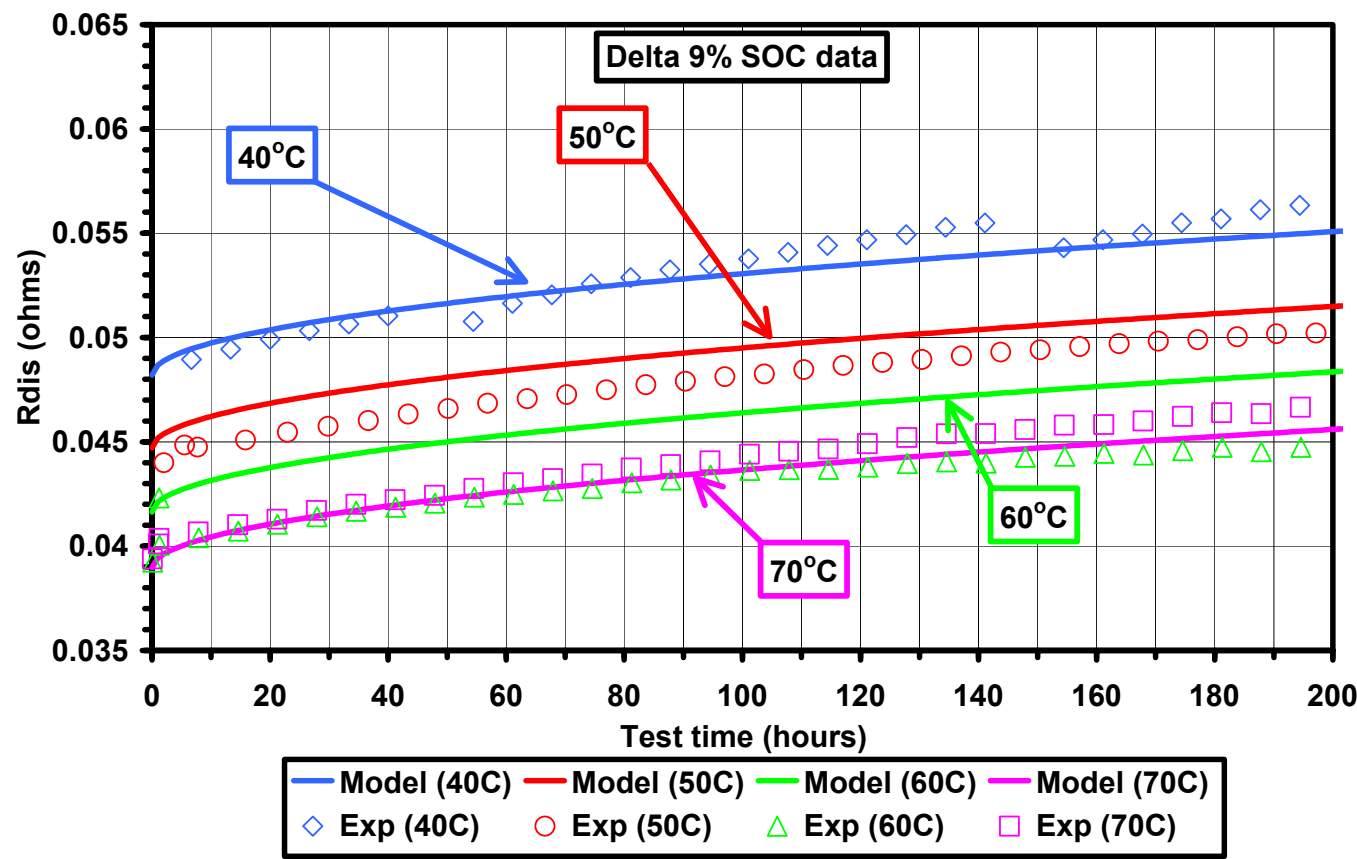

Figure 44. Selected INEEL cycle-life discharge resistance data for ATD Gen 1 [609-40,50,60,70] cells. Fit to equation: $\mathrm{R}(\mathrm{t}, \mathrm{T}, \mathrm{SOC})=\mathrm{A}(\mathrm{T}, \mathrm{SOC}) * \mathrm{SQRT}[$ test time in hours at temperature $]+\mathrm{B}(\mathrm{T}, \mathrm{SOC})$. 


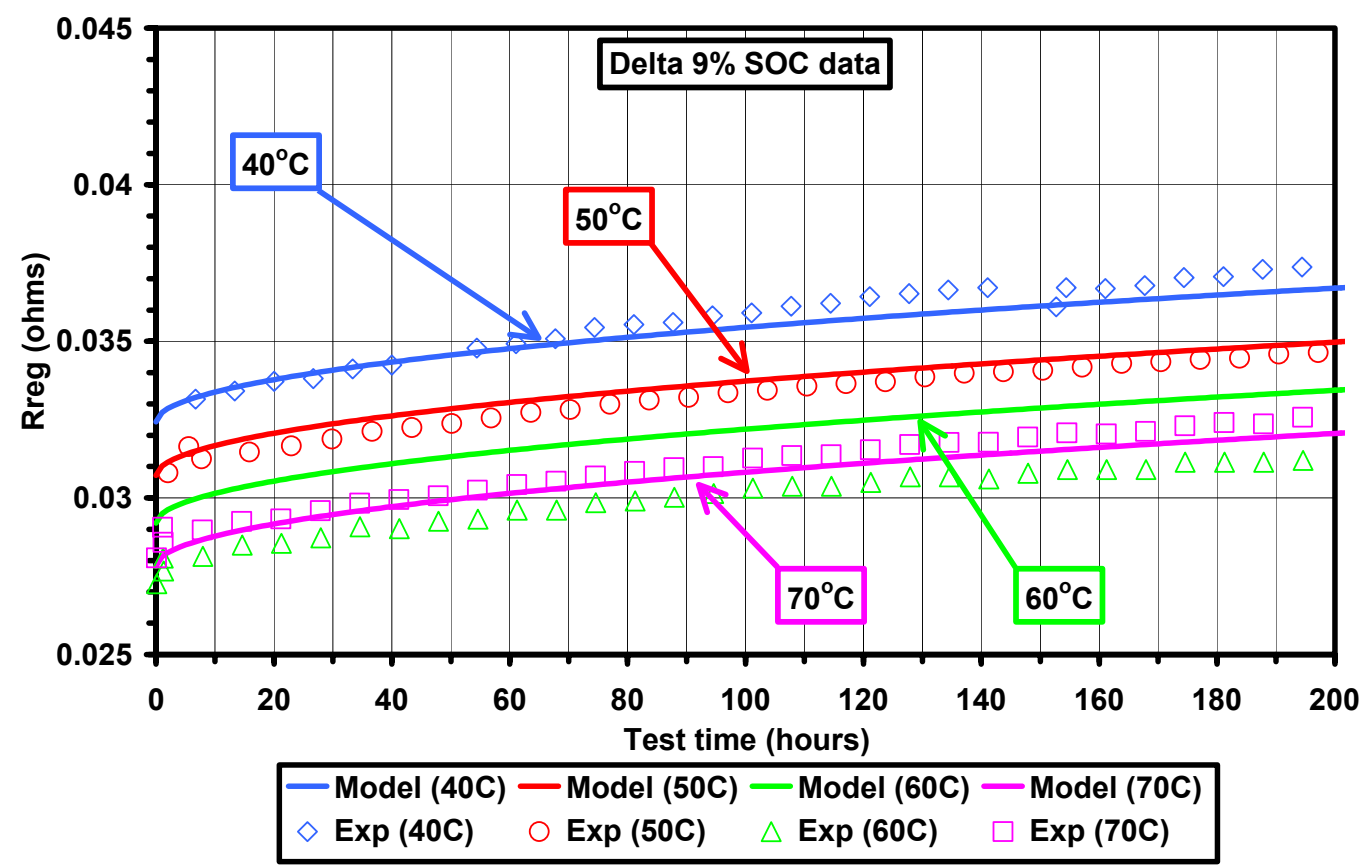

Figure 45. Selected INEEL cycle-life regen resistance data for ATD Gen 1 [609-40,50,60,70] cells. Fit to equation: $\mathrm{R}(\mathrm{t}, \mathrm{T}, \mathrm{SOC})=\mathrm{A}(\mathrm{T}, \mathrm{SOC})^{*} \mathrm{SQRT}[$ test time in hours at temperature $]+\mathrm{B}(\mathrm{T}, \mathrm{SOC})$.

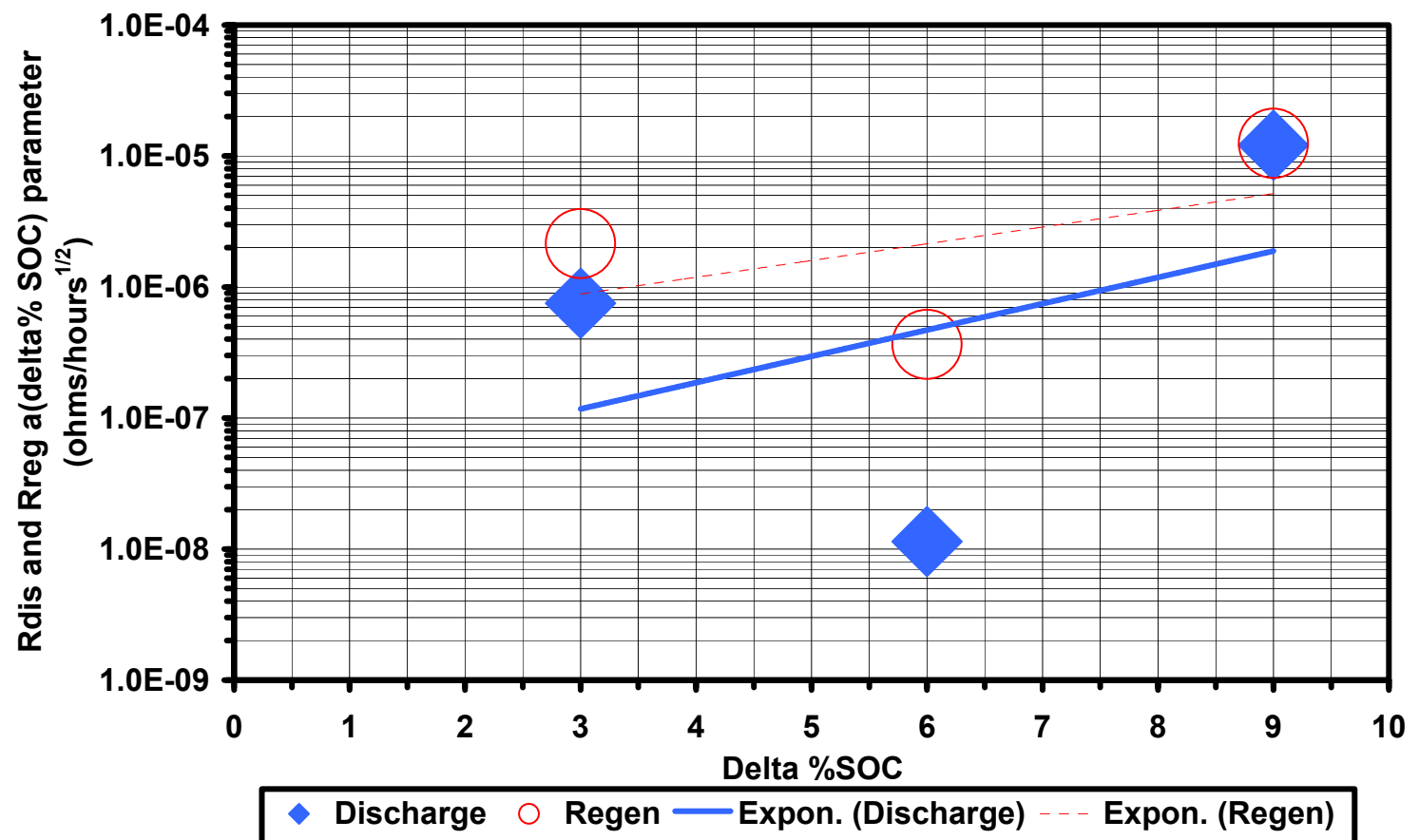

Figure 46. INEEL cycle-life discharge and regen resistance data for ATD Gen 1 [60(3,6,9)-40,50,60,70] cells. Fit to equation: $\mathrm{R}(\mathrm{t}, \mathrm{T}$, delta $\% \mathrm{SOC})=\mathrm{A}(\mathrm{T}, \mathrm{SOC}) * \mathrm{SQRT}$ [test time in hours] $+\mathrm{B}(\mathrm{T}, \mathrm{SOC}) \mathrm{A}(\mathrm{SOC})=$ $\mathrm{a}(\mathrm{SOC})[\exp [\mathrm{b}(\mathrm{SOC}) / \mathrm{T}]] ; \mathrm{B}=\mathrm{c}(\mathrm{SOC})[\exp [\mathrm{d}(\mathrm{SOC}) / \mathrm{T}]]$. 


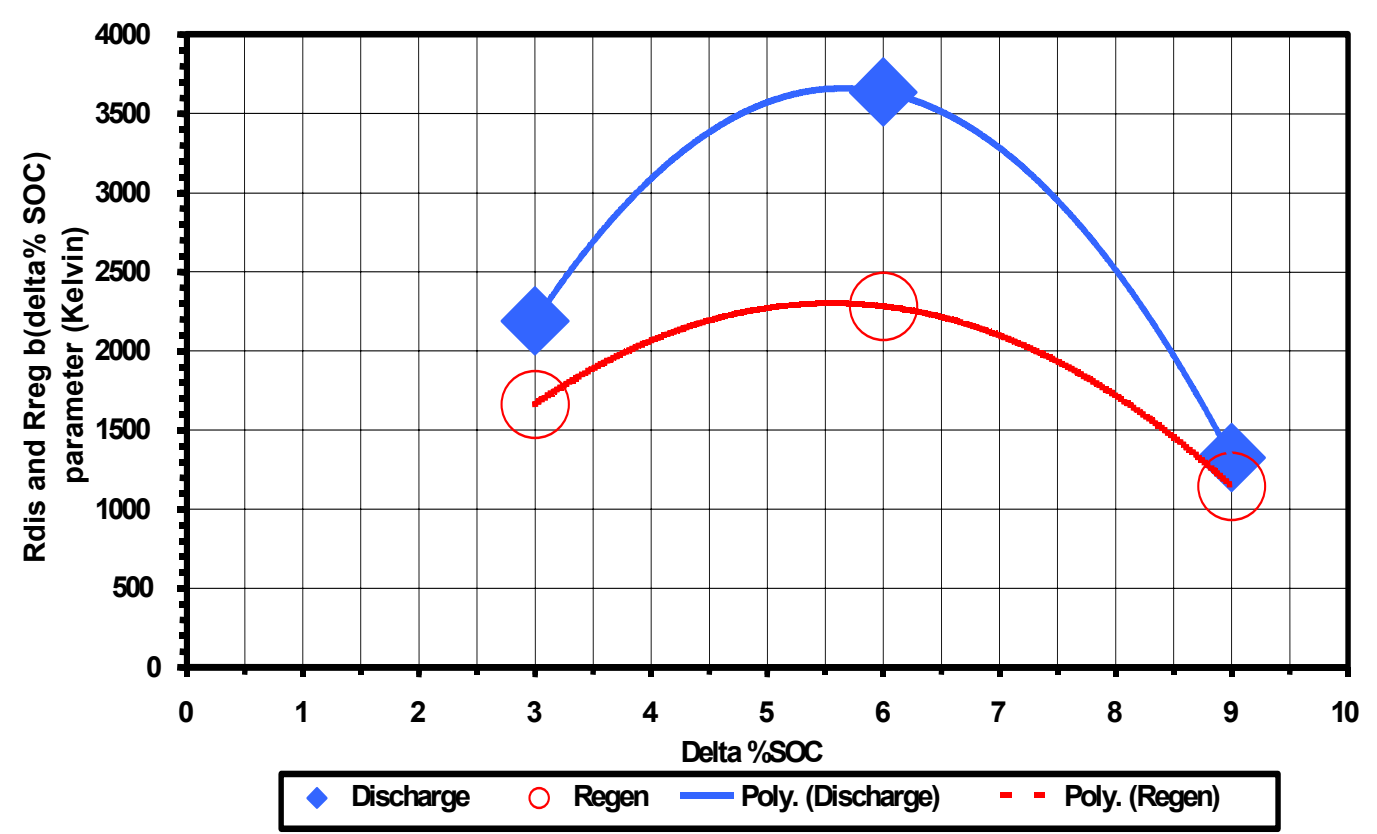

Figure 47. INEEL cycle-life discharge and regen resistance data for ATD Gen $1[60(0,3,6,9)$ $40,50,60,70$ ] cells. Fit to equation: $\mathrm{R}(\mathrm{t}, \mathrm{T}, \mathrm{SOC})=\mathrm{A}(\mathrm{T}, \mathrm{SOC}) * \mathrm{SQRT}$ [test time in hours] $+\mathrm{B}(\mathrm{T}, \mathrm{SOC})$ $\mathrm{A}(\mathrm{T}, \mathrm{SOC})=\mathrm{a}(\mathrm{SOC})[\exp [\mathrm{b}(\mathrm{SOC}) / \mathrm{T}]] ; \mathrm{B}(\mathrm{T}, \mathrm{SOC})=\mathrm{c}(\mathrm{SOC})[\exp [\mathrm{d}(\mathrm{SOC}) / \mathrm{T}]]$.

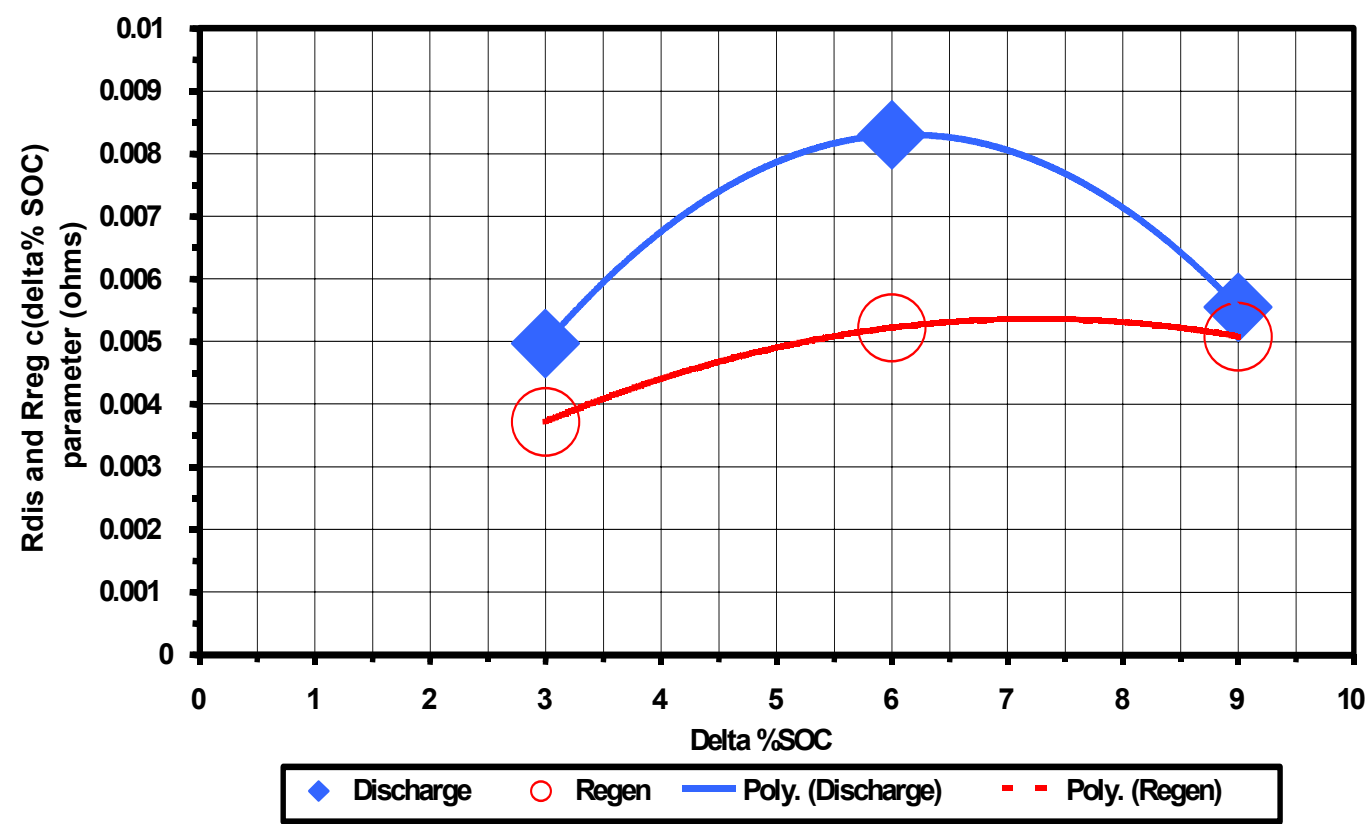

Figure 48. INEEL cycle-life discharge and regen resistance data for ATD Gen $1[60(0,3,6,9)$ $40,50,60,70]$ cells. Fit to equation: $\mathrm{R}(\mathrm{t}, \mathrm{T}, \mathrm{SOC})=\mathrm{A}(\mathrm{T}, \mathrm{SOC}) * \mathrm{SQRT}$ [test time in hours] $+\mathrm{B}(\mathrm{T}, \mathrm{SOC})$ $\mathrm{A}(\mathrm{T}, \mathrm{SOC})=\mathrm{a}(\mathrm{SOC})[\exp [\mathrm{b}(\mathrm{SOC}) / \mathrm{T}]] ; \mathrm{B}(\mathrm{T}, \mathrm{SOC})=\mathrm{c}(\mathrm{SOC})[\exp [\mathrm{d}(\mathrm{SOC}) / \mathrm{T}]]$. 


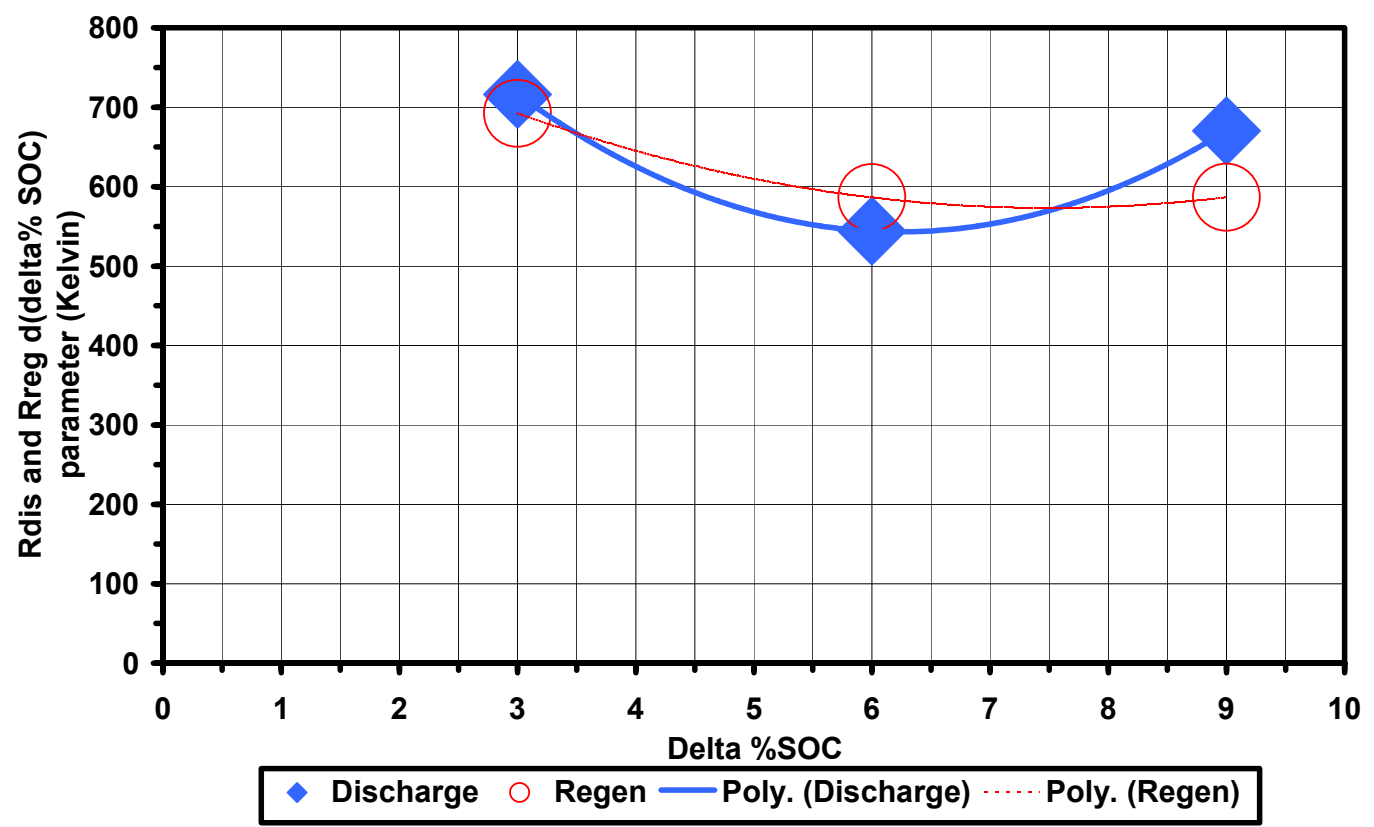

Figure 49. INEEL cycle-life discharge and regen resistance data for ATD Gen $1[60(0,3,6,9)$ $40,50,60,70]$ cells. Fit to equation: $\mathrm{R}(\mathrm{t}, \mathrm{T}, \mathrm{SOC})=\mathrm{A}(\mathrm{T}, \mathrm{SOC}) * \mathrm{SQRT}[$ test time in hours] $+\mathrm{B}(\mathrm{t}, \mathrm{SOC})$ $\mathrm{A}(\mathrm{T}, \mathrm{SOC})=\mathrm{a}(\mathrm{SOC})[\exp [\mathrm{b}(\mathrm{SOC}) / \mathrm{T}]] ; \mathrm{B}(\mathrm{T}, \mathrm{SOC})=\mathrm{c}(\mathrm{SOC})[\exp [\mathrm{d}(\mathrm{SOC}) / \mathrm{T}]]$. 


\section{Appendix C}

Figures for Cycle-Life Discharge and Regen Resistance Tests on ATD GEN 1 Li-ION Batteries:

Leakage Current, Leakage Resistance, and Differential Capacity 



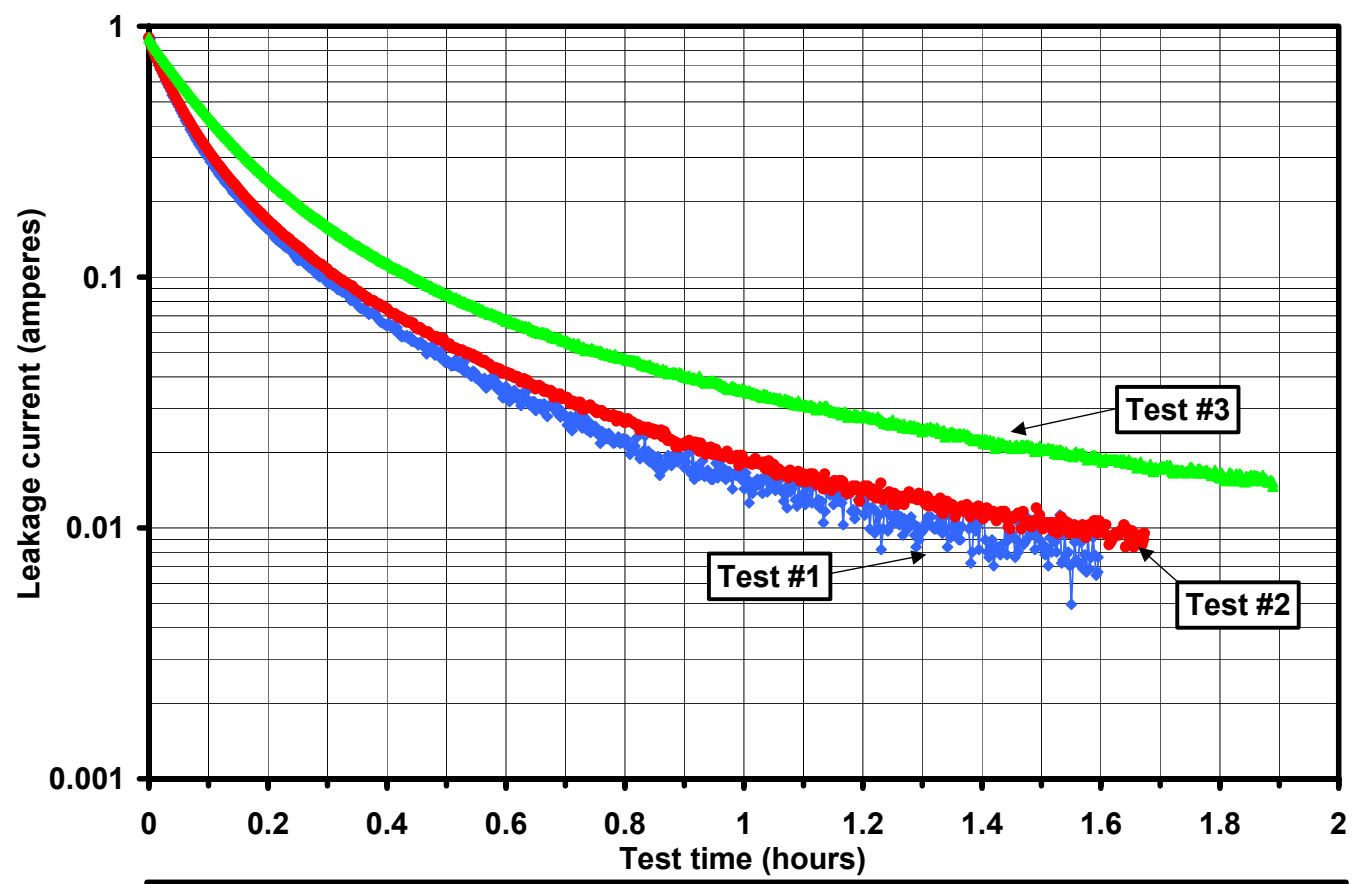

- Test \#1: 4 C/1 - Test \#2: 4 C/1 + RPT $₫$ Test \#3: 4 C/1 + RPT + LC70delta9\%

Figure 50. Leakage current following constant current C/1 charge on ATD GEN I cell test (60970).

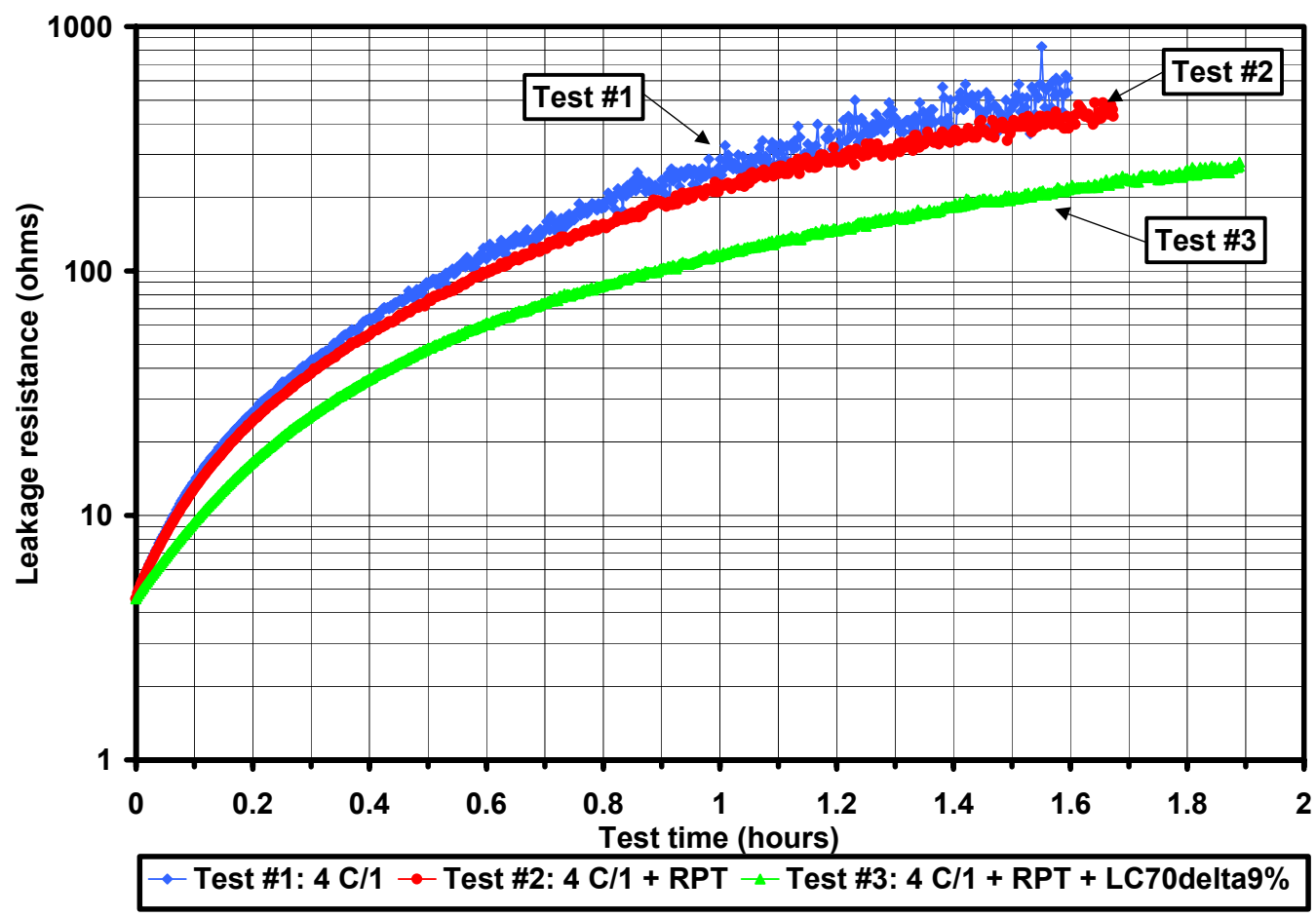

Figure 51. Leakage resistance following constant current C/1 charge on ATD GEN I cell test (60970). 


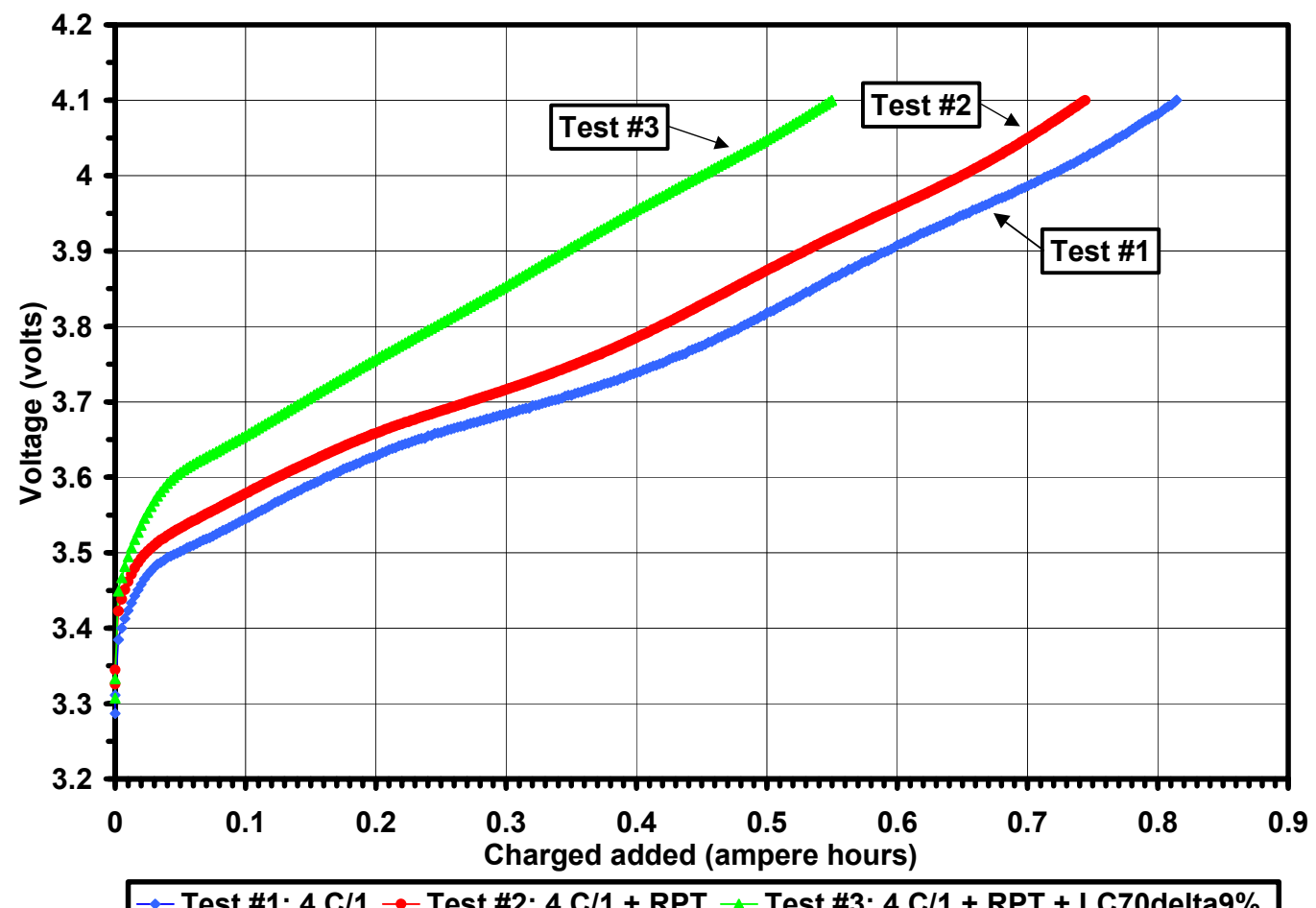

Test \#1: 4 C/1 - - Test \#2: 4 C/1 + RPT $₫$ - Test \#3: 4 C/1 + RPT + LC70delta9\%

Figure 52. Constant current C/1 charge on ATD GEN I cell test (60970).

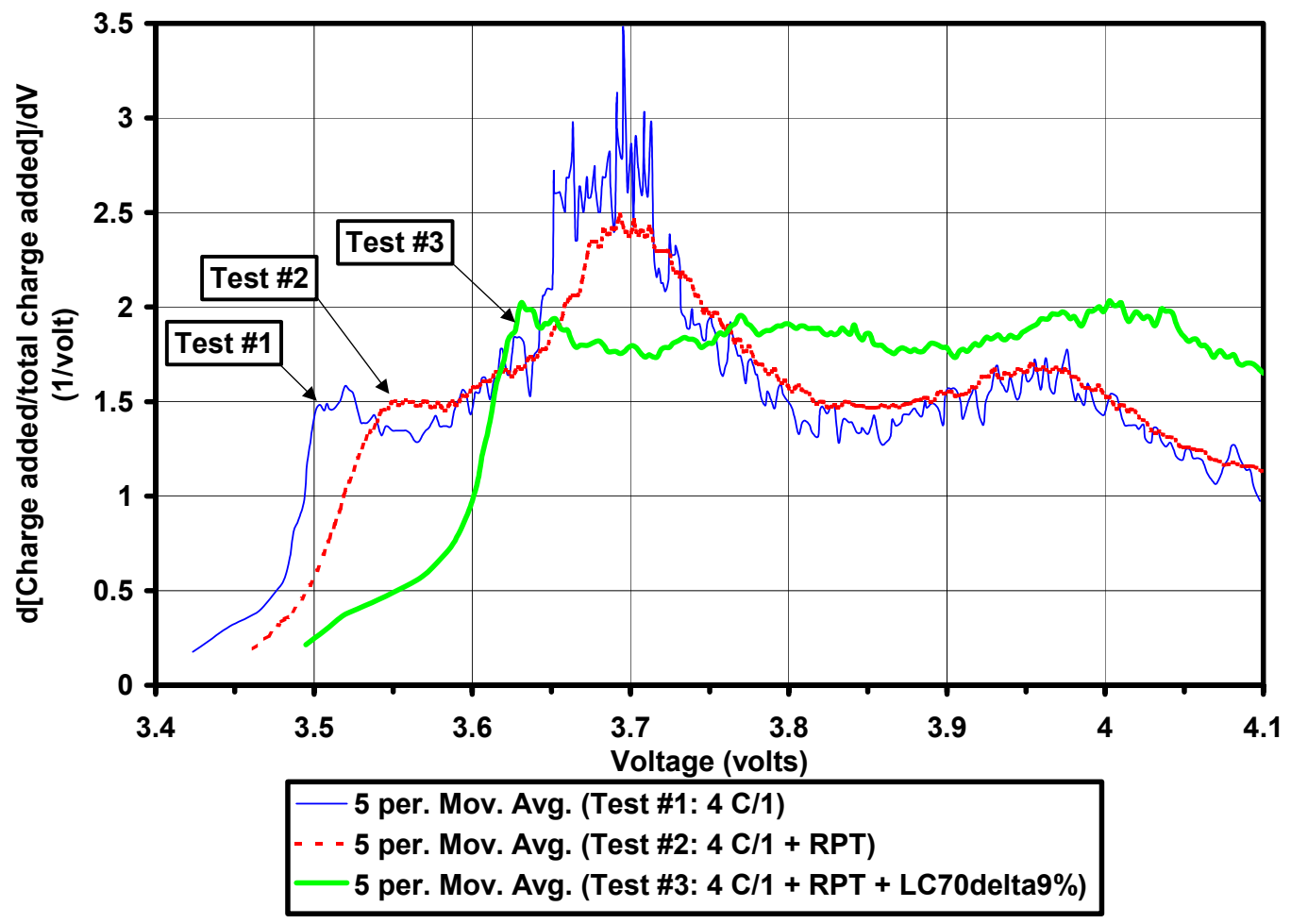

Figure 53. Constant current C/1 charge on ATD GEN I cell test (60970). 


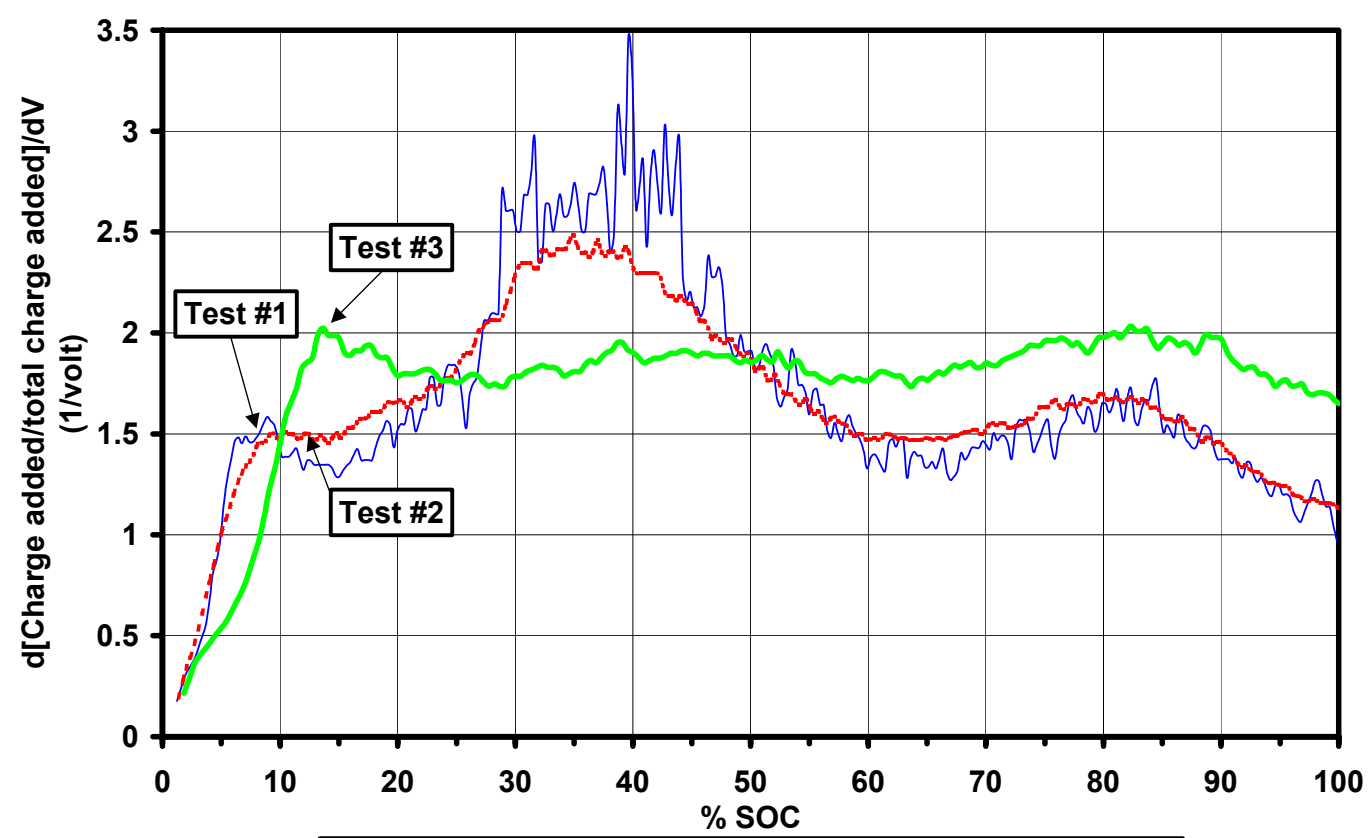

5 per. Mov. Avg. (Test \#1: $4 \mathrm{C} / 1)$

- - 5 per. Mov. Avg. (Test \#2: $4 \mathrm{C} / 1+\mathrm{RPT})$

5 per. Mov. Avg. (Test \#3: 4 C/1 + RPT + LC70delta9\%)

Figure 54. Constant current C/1 charge on ATD GEN I cell test (60970).

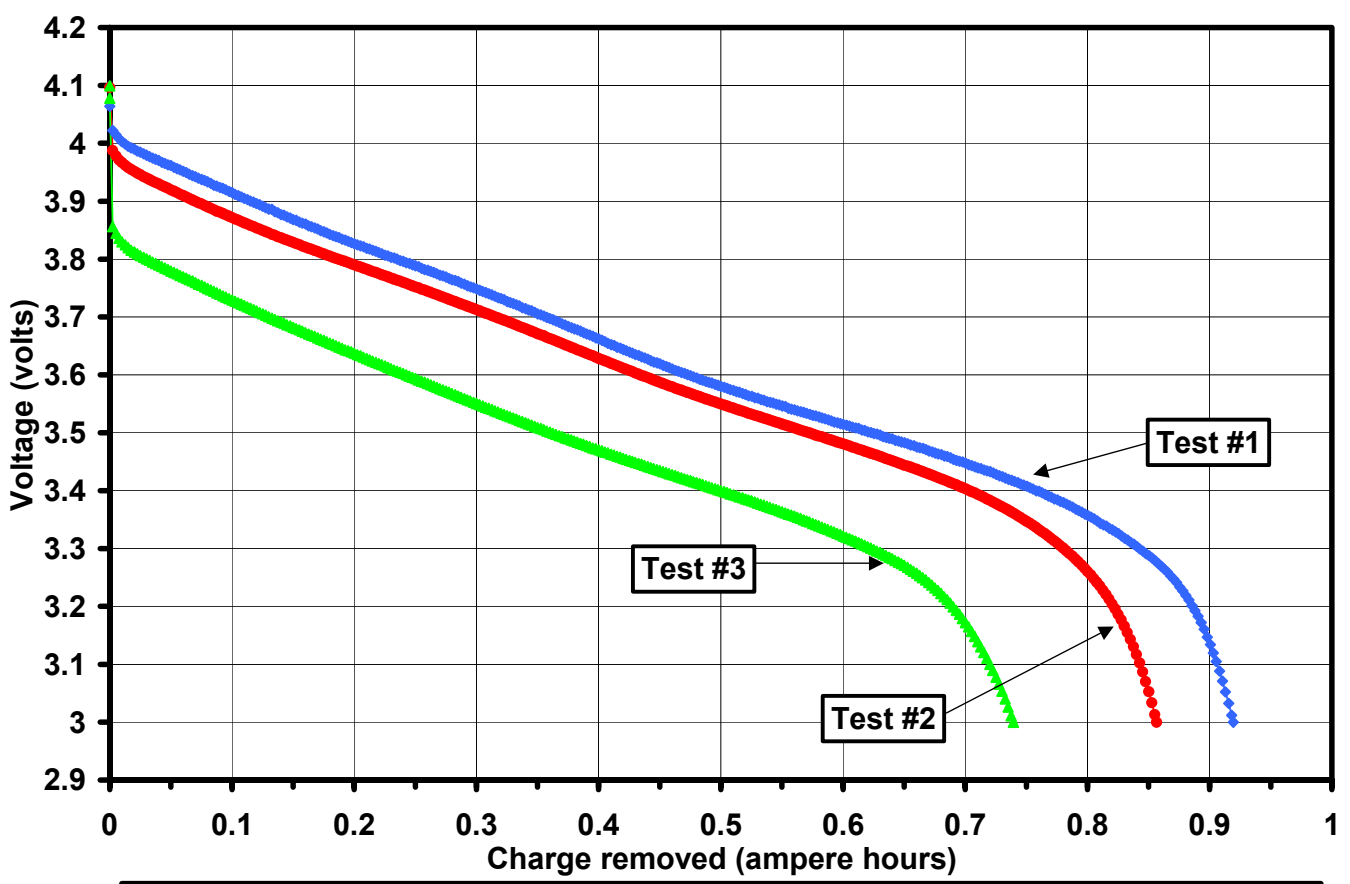

$\rightarrow-$ Test \#1: 3 C/1 $\rightarrow$ - Test \#2: 3 C/1 + RPT $\leadsto$ Test \#3: 3 C/1 + RPT + LC70delta9\%

Figure 55. Constant current C/1 discharge on ATD GEN I cell test (60970). 


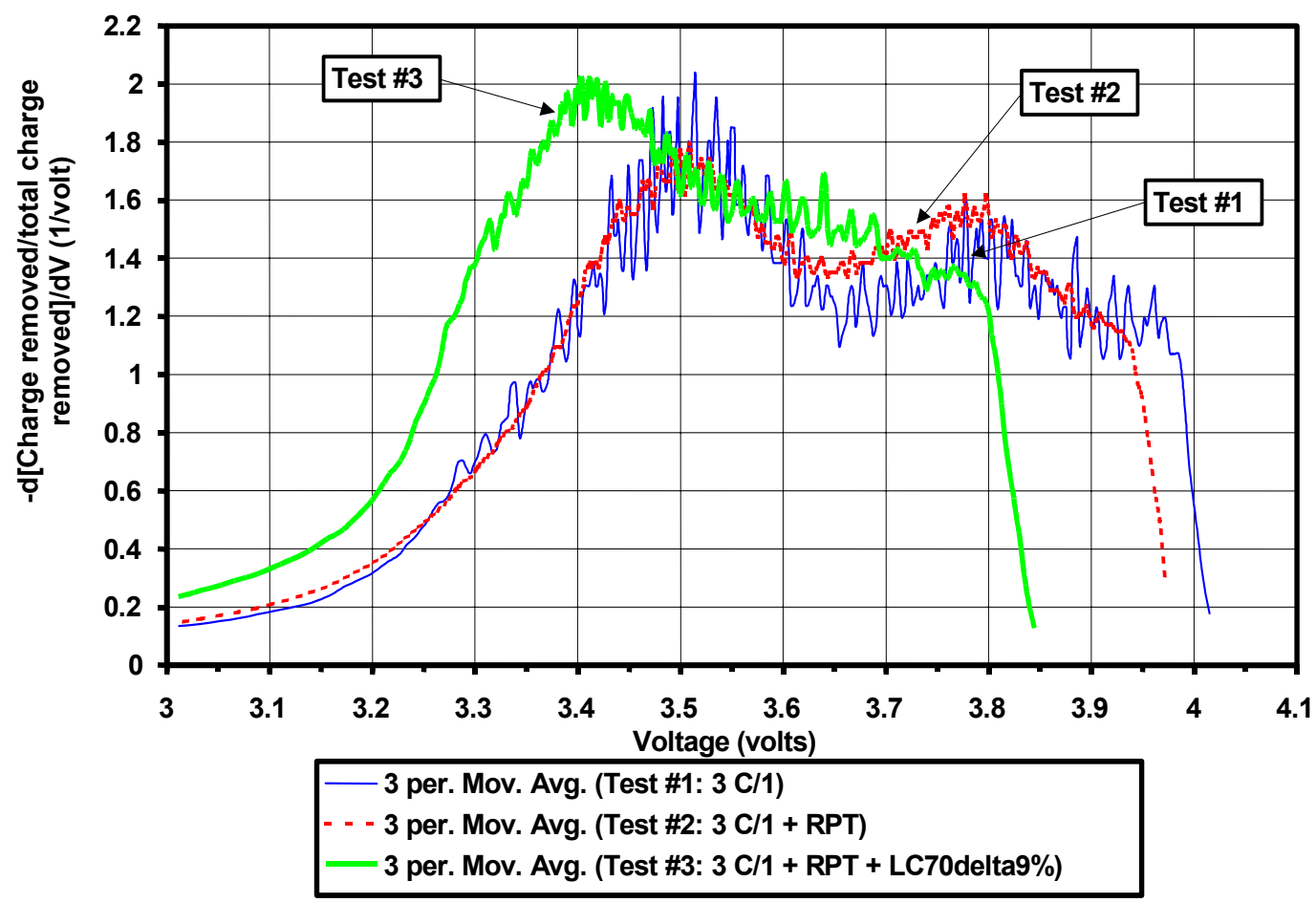

Figure 56. Constant current C/1 discharge on ATD GEN I cell test (60970).

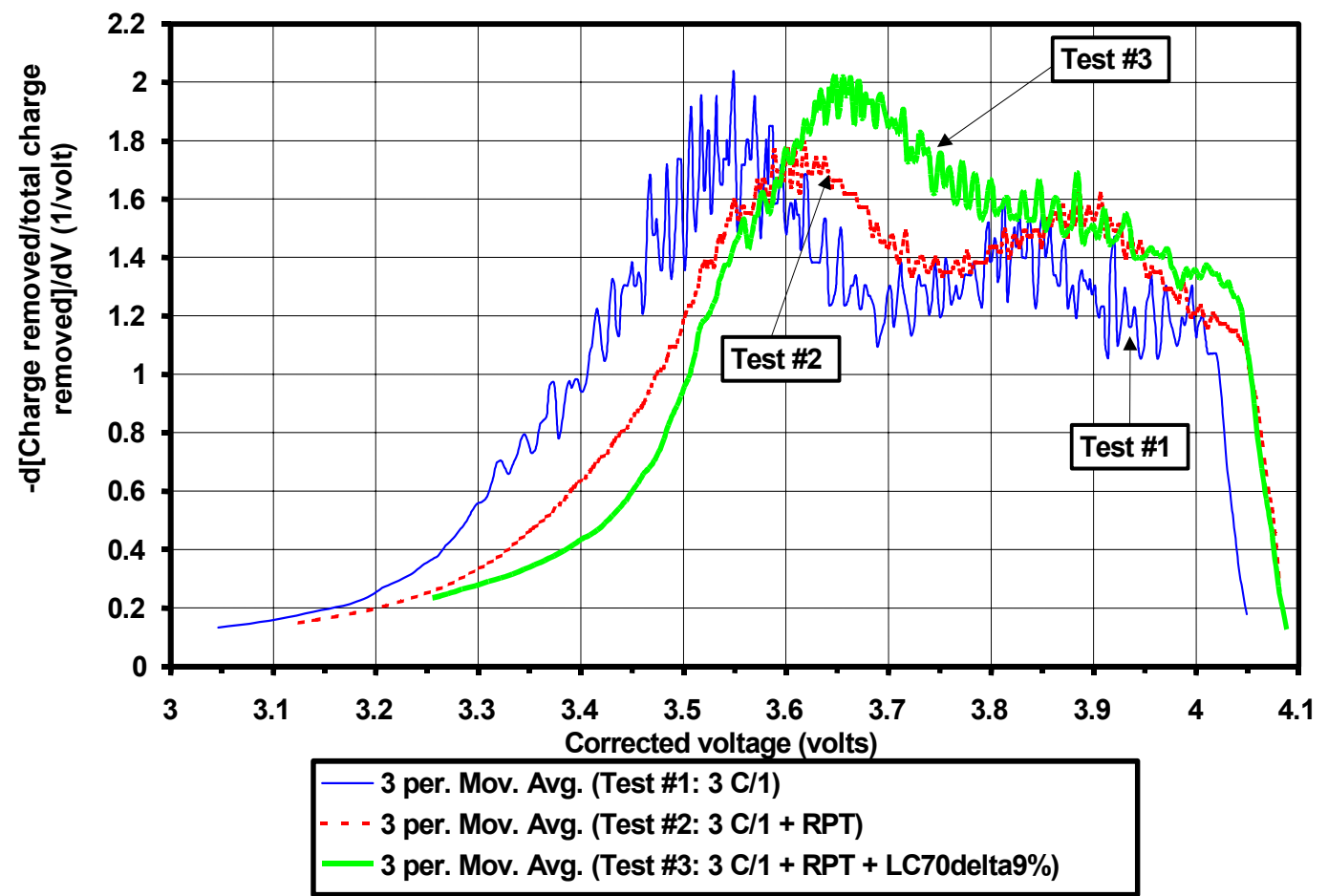

Figure 57. Constant current C/1 discharge on ATD GEN I cell test (60970). 


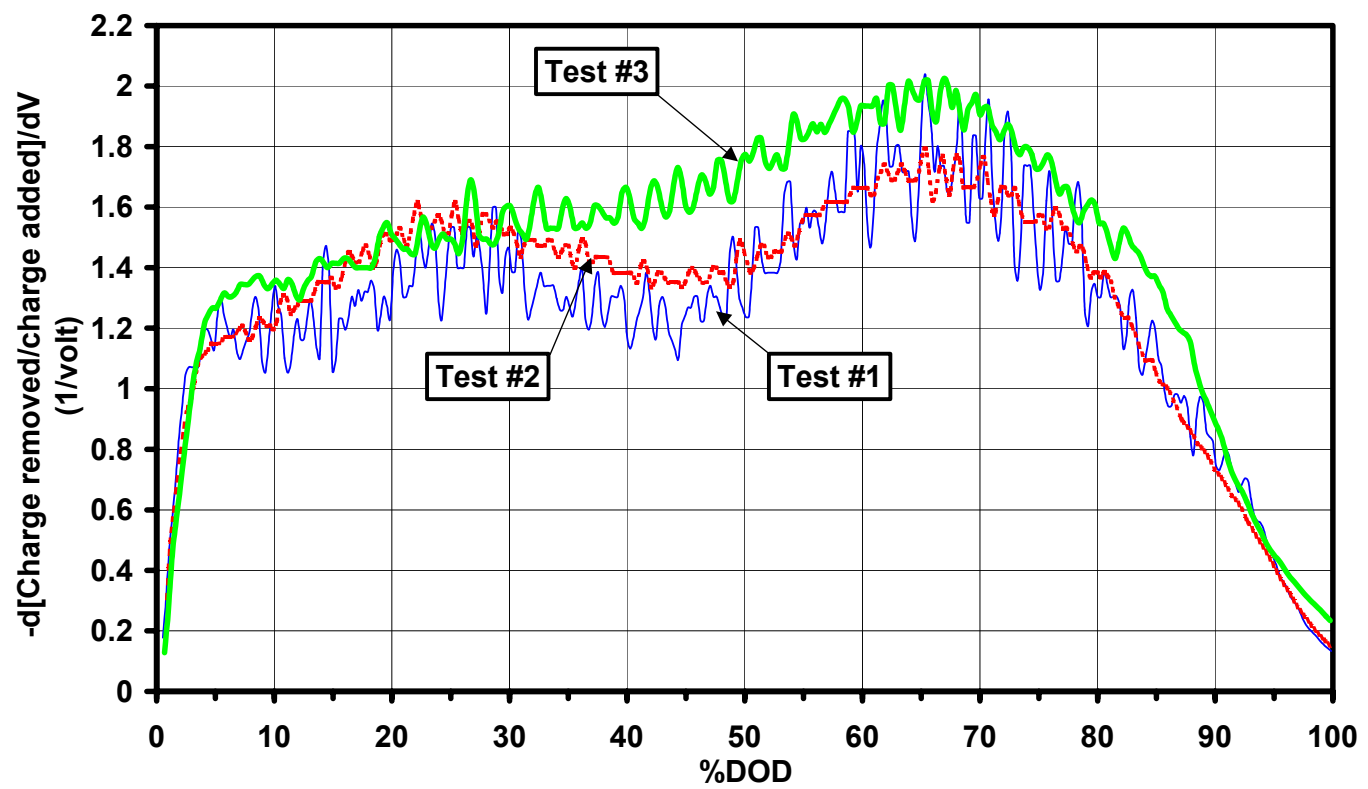

3 per. Mov. Avg. (Test \#1: $3 \mathrm{C} / 1$ )

- - 3 per. Mov. Avg. (Test \#2: 3 C/1 + RPT)

3 per. Mov. Avg. (Test \#3: 3 C/1 + RPT + LCdelta9\%)

Figure 58. Constant current C/1 discharge tests on ATD GEN I cell test (60970).

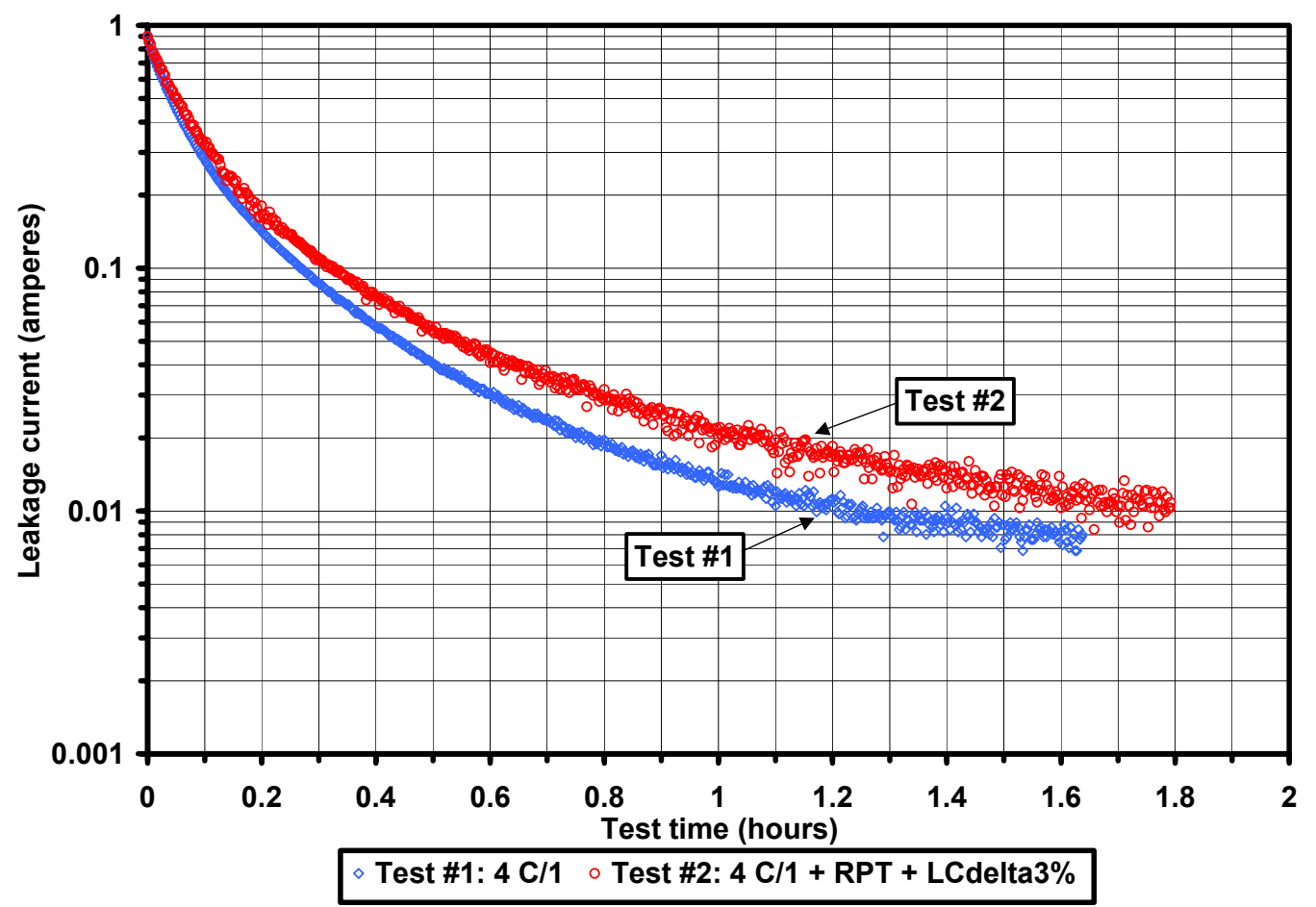

Figure 59. Leakage current following constant current C/1 charge on ATD GEN I cell test (60340). 


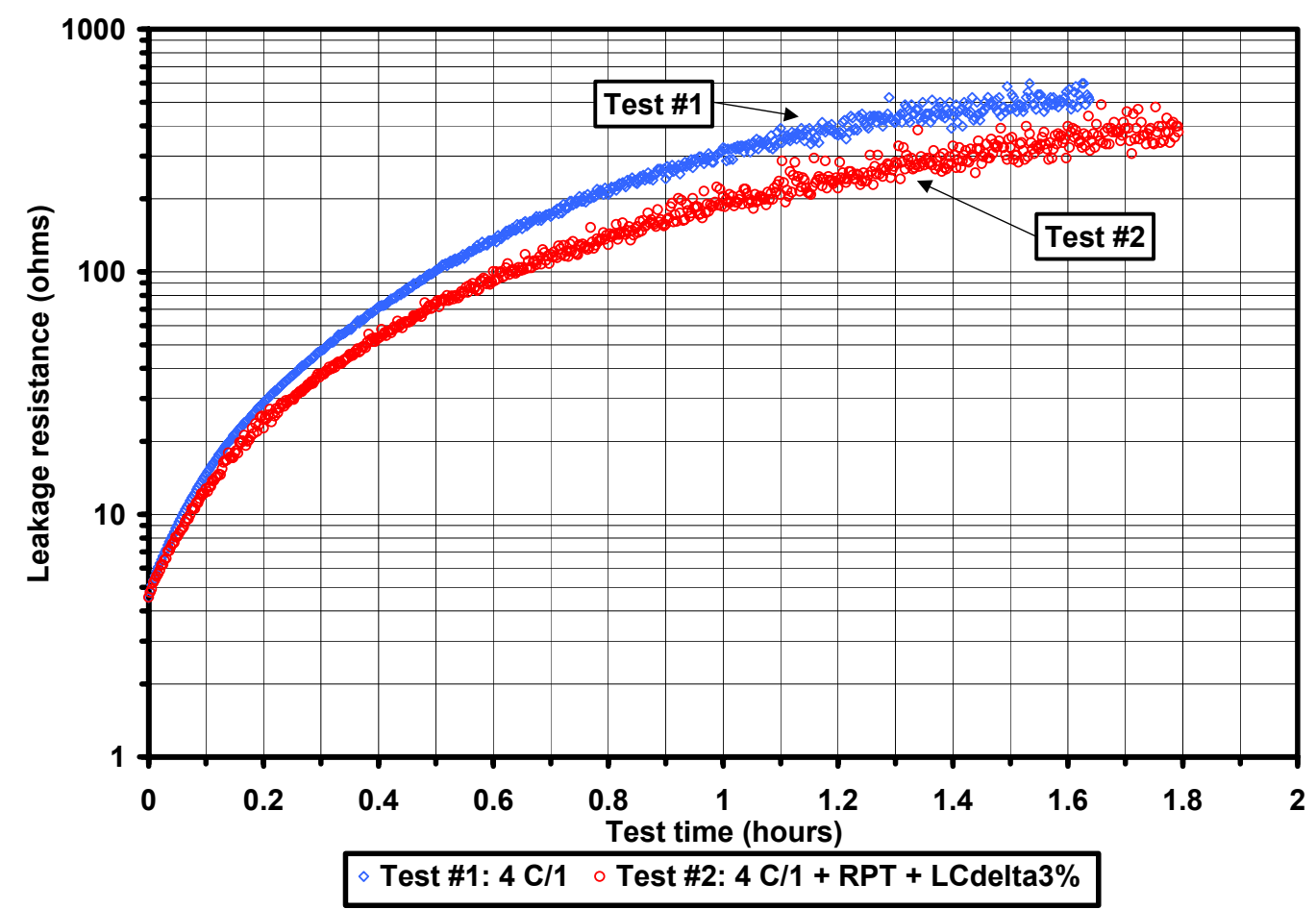

Figure 60. Leakage resistance following constant current C/1 charge on ATD GEN I cell test (60340).

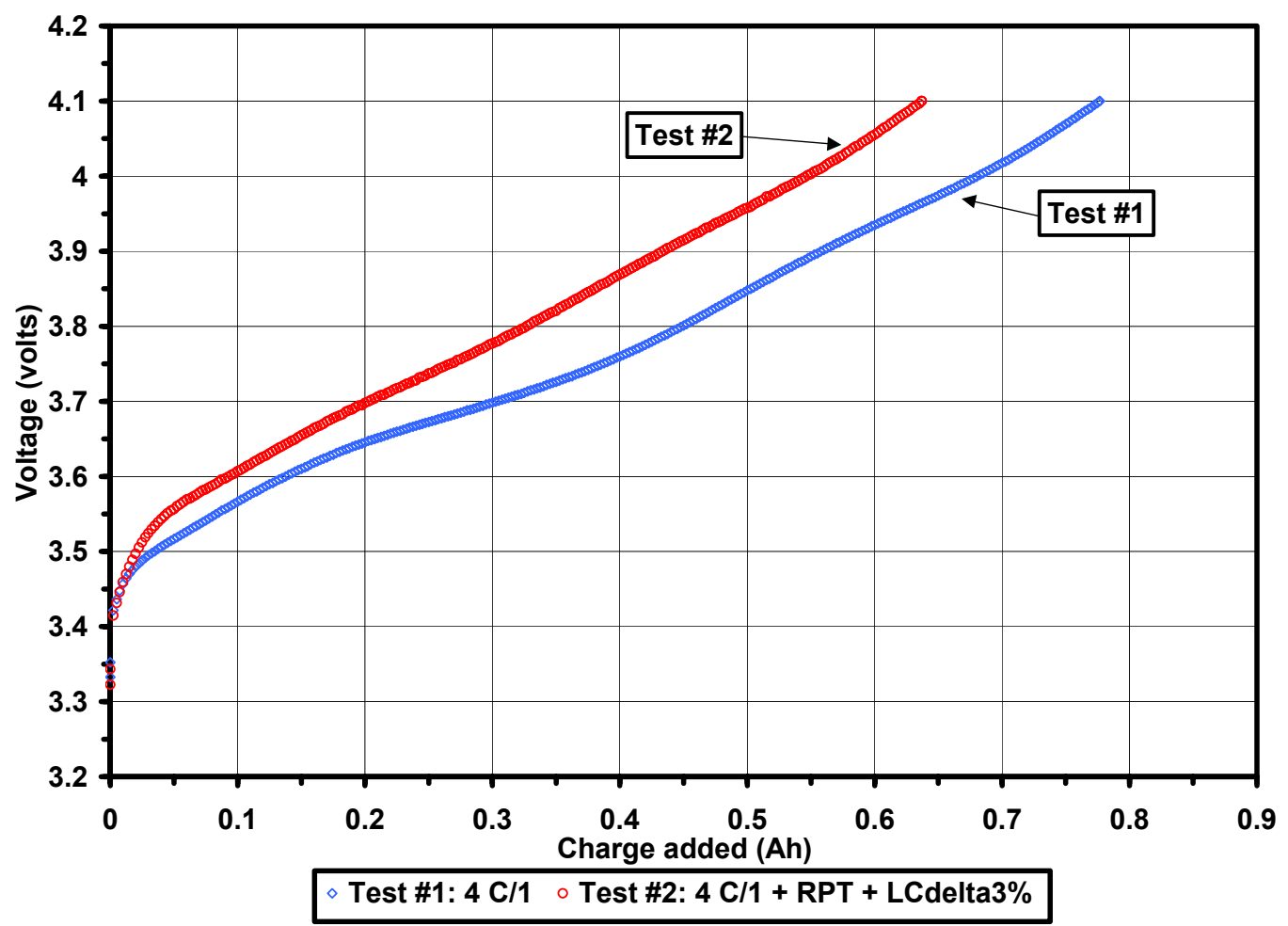

Figure 61. Constant current C/1 charge on ATD GEN I cell test (60340). 


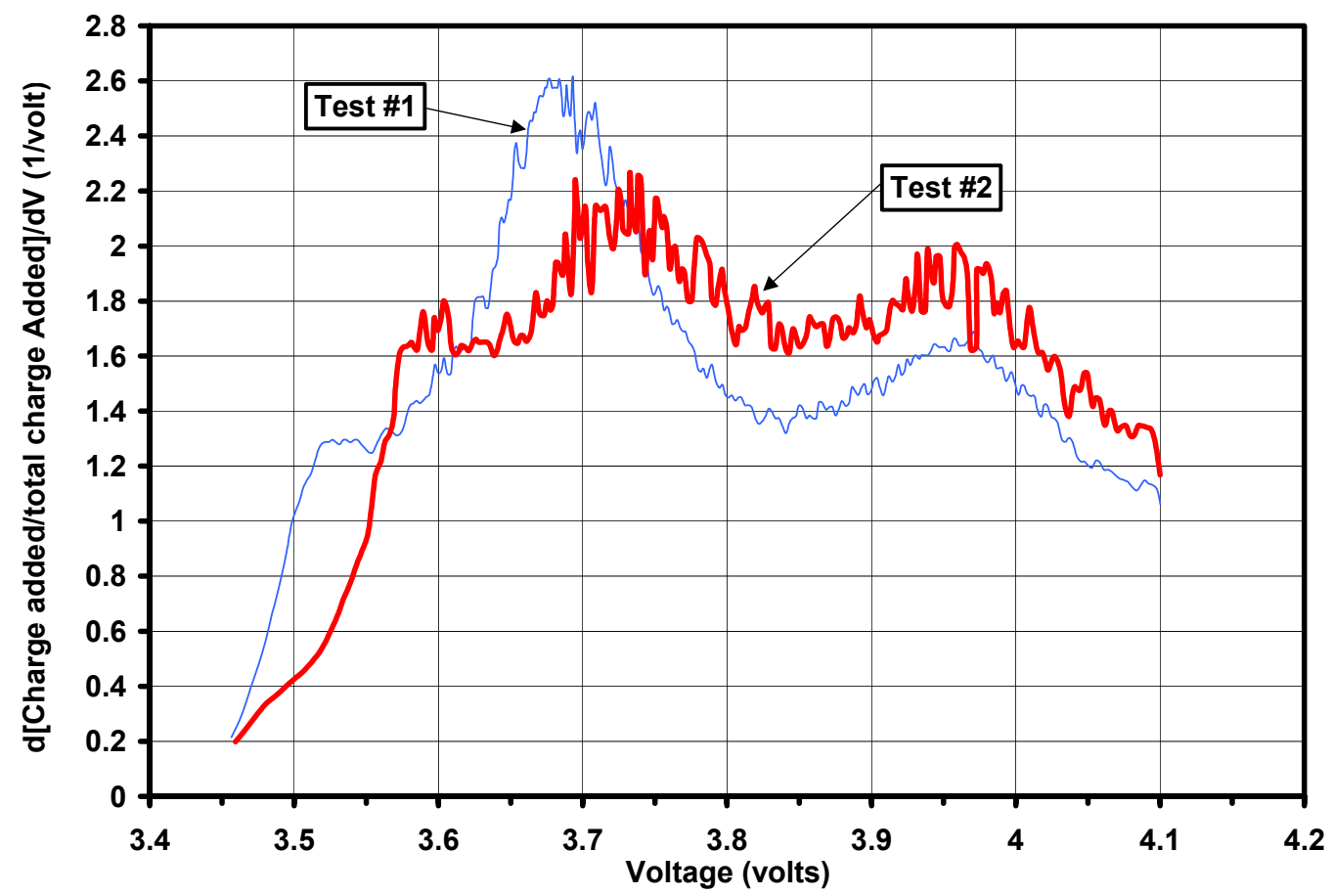

5 per. Mov. Avg. (Test \#1: 4 C/1) -5 per. Mov. Avg. (Test \#2: 4 C/1 + RPT + LCdelta3\%)

Figure 62. Constant current C/1 charge on ATD GEN I cell test (60340).

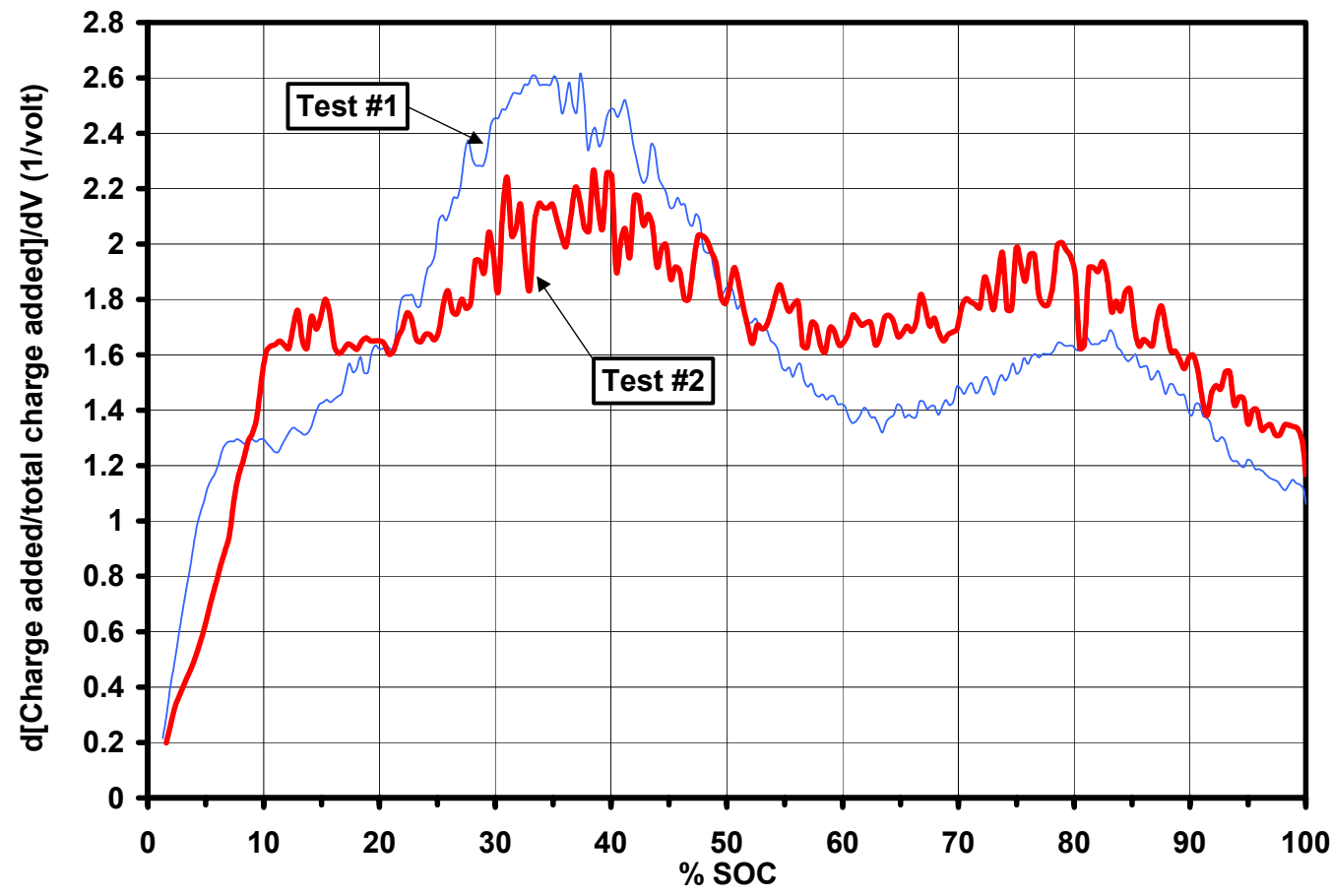

-5 per. Mov. Avg. (Test \#1: 4 C/1) -5 per. Mov. Avg. (Test \#2: 4 C/1 + RPT + LCdelta3\%)

Figure 63. Constant current C/1 charge on ATD GEN I cell test (60340). 


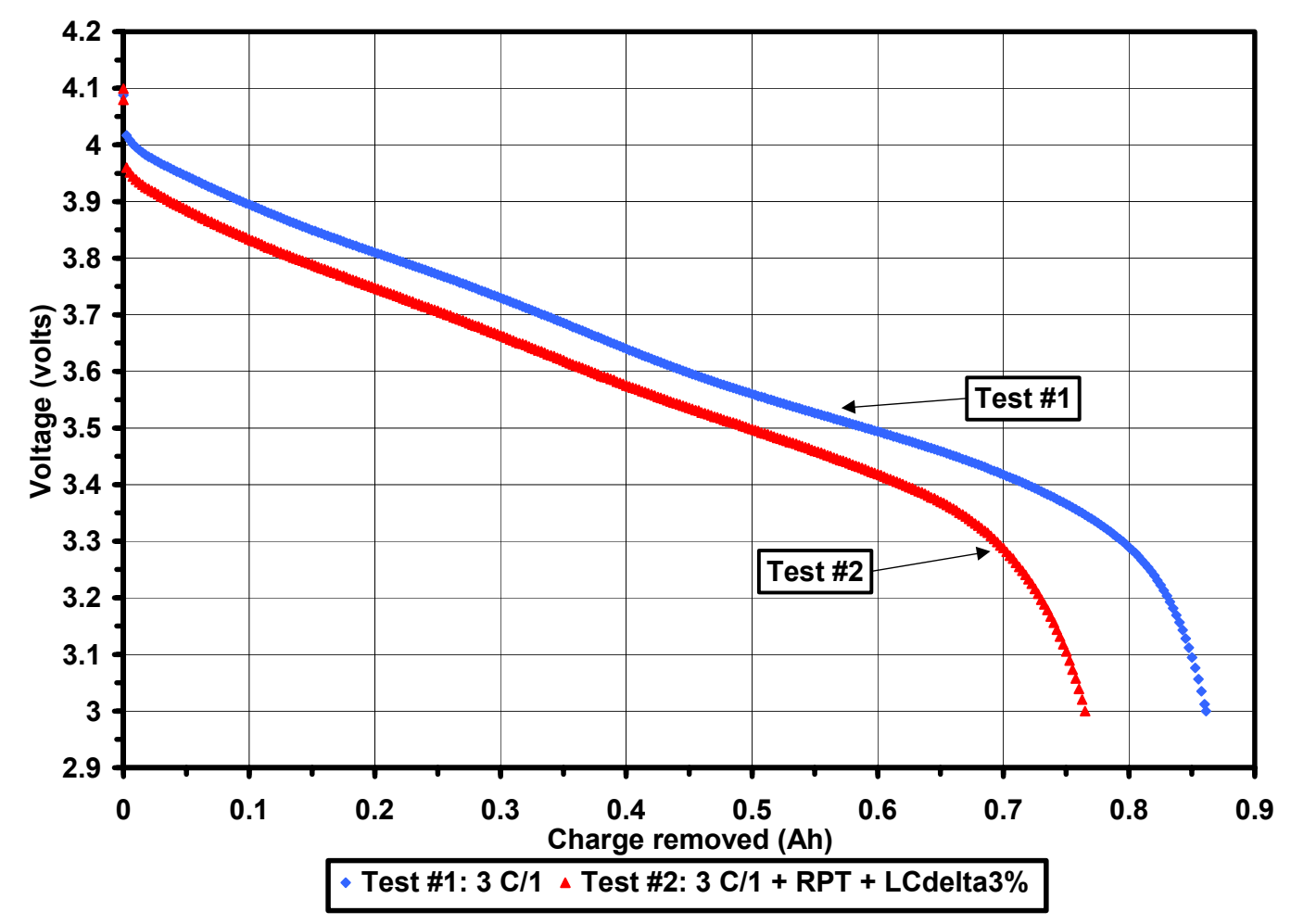

Figure 64. Constant current C/1 discharge on ATD GEN I cell test (60340).

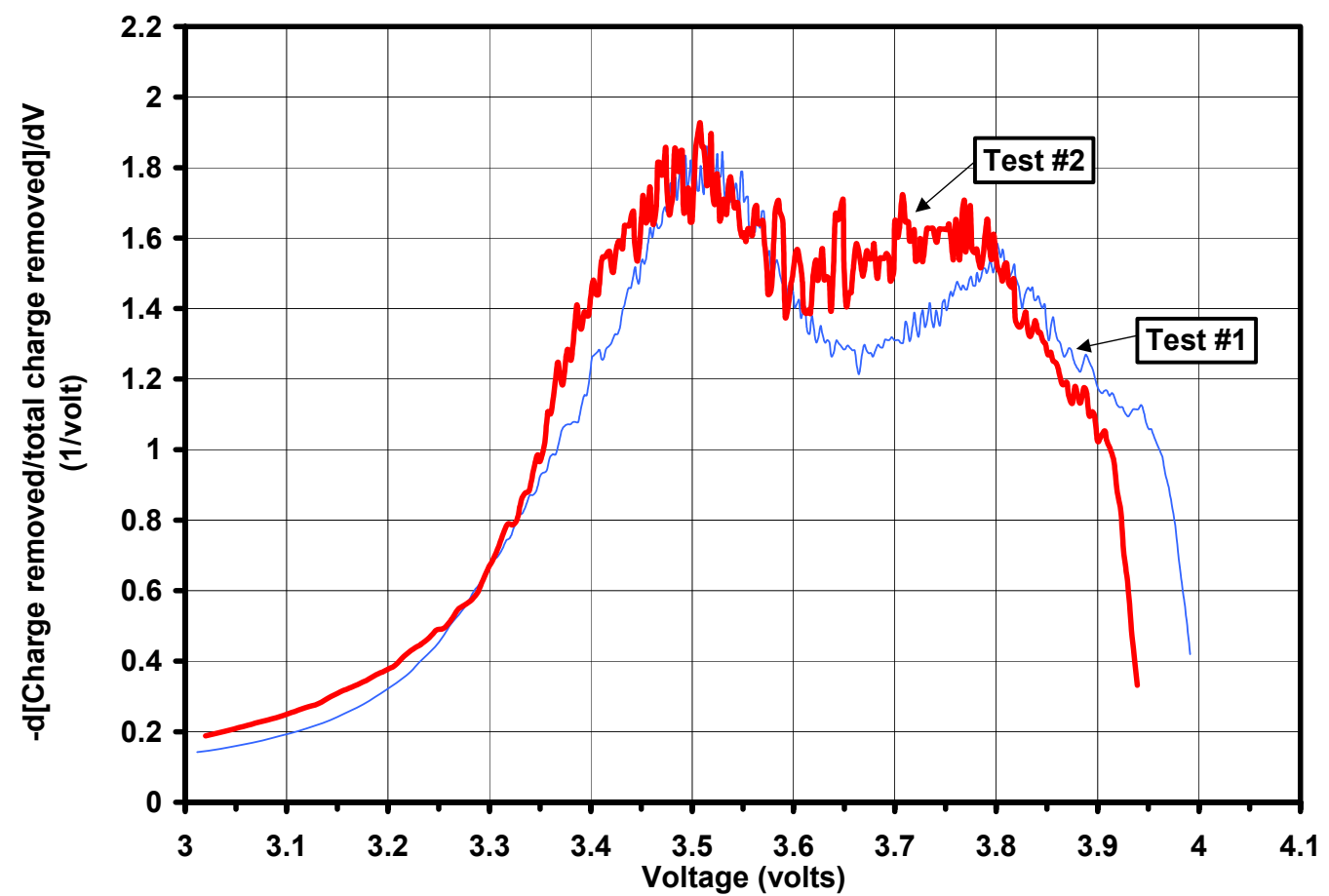

5 per. Mov. Avg. (Test \#1: 3 C/1) -5 per. Mov. Avg. (Test \#2: 3 C/1 + RPT + LCdelta3\%)

Figure 65. Constant current C/1 discharge on ATD GEN I cell (60340). 


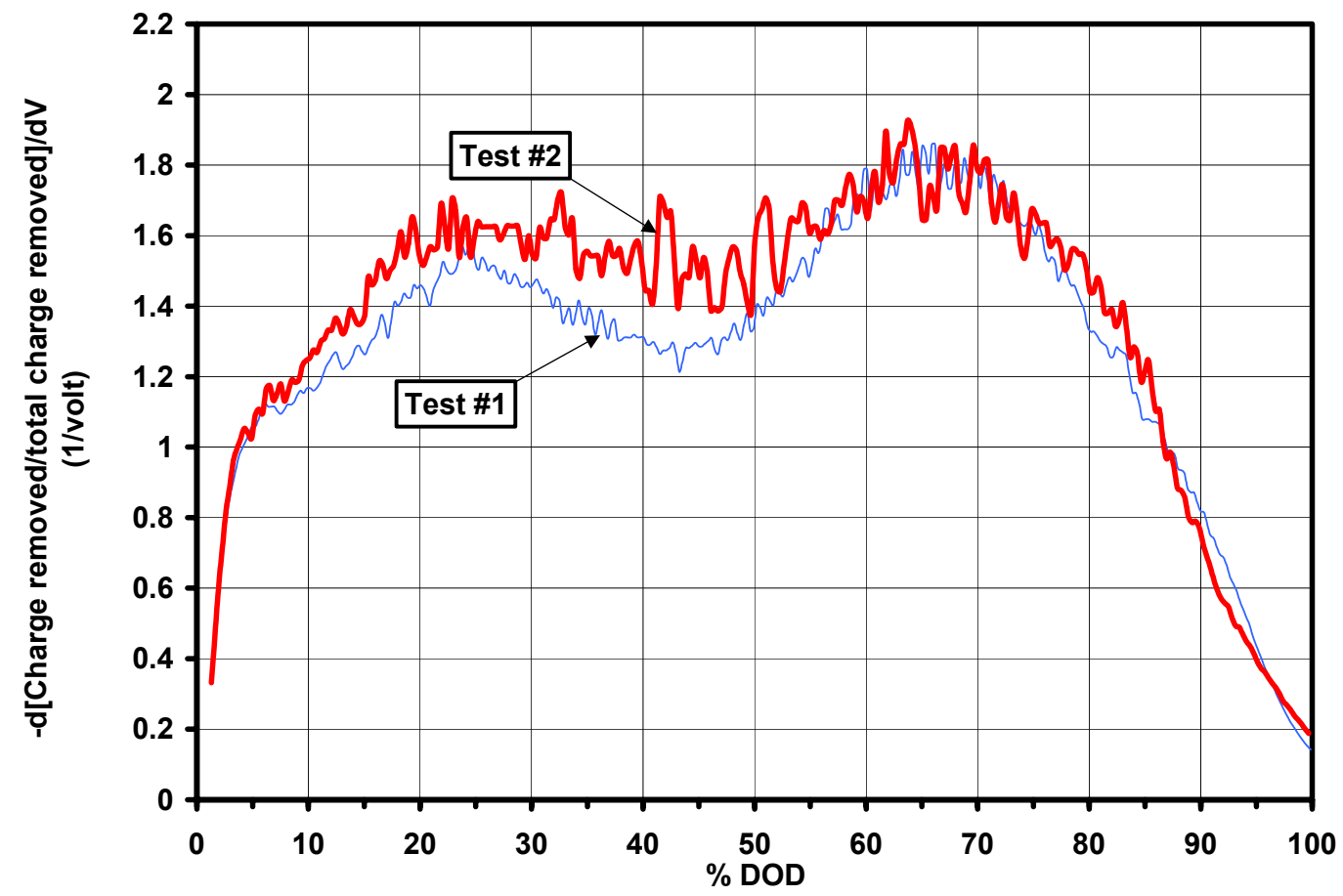

5 per. Mov. Avg. (Test \#1: 3 C/1) -5 per. Mov. Avg. (Test \#2: 3 C/1 + RPT + LCdelta3\%)

Figure 66. Constant current C/1 discharge on ATD GEN I cell test (60340). 


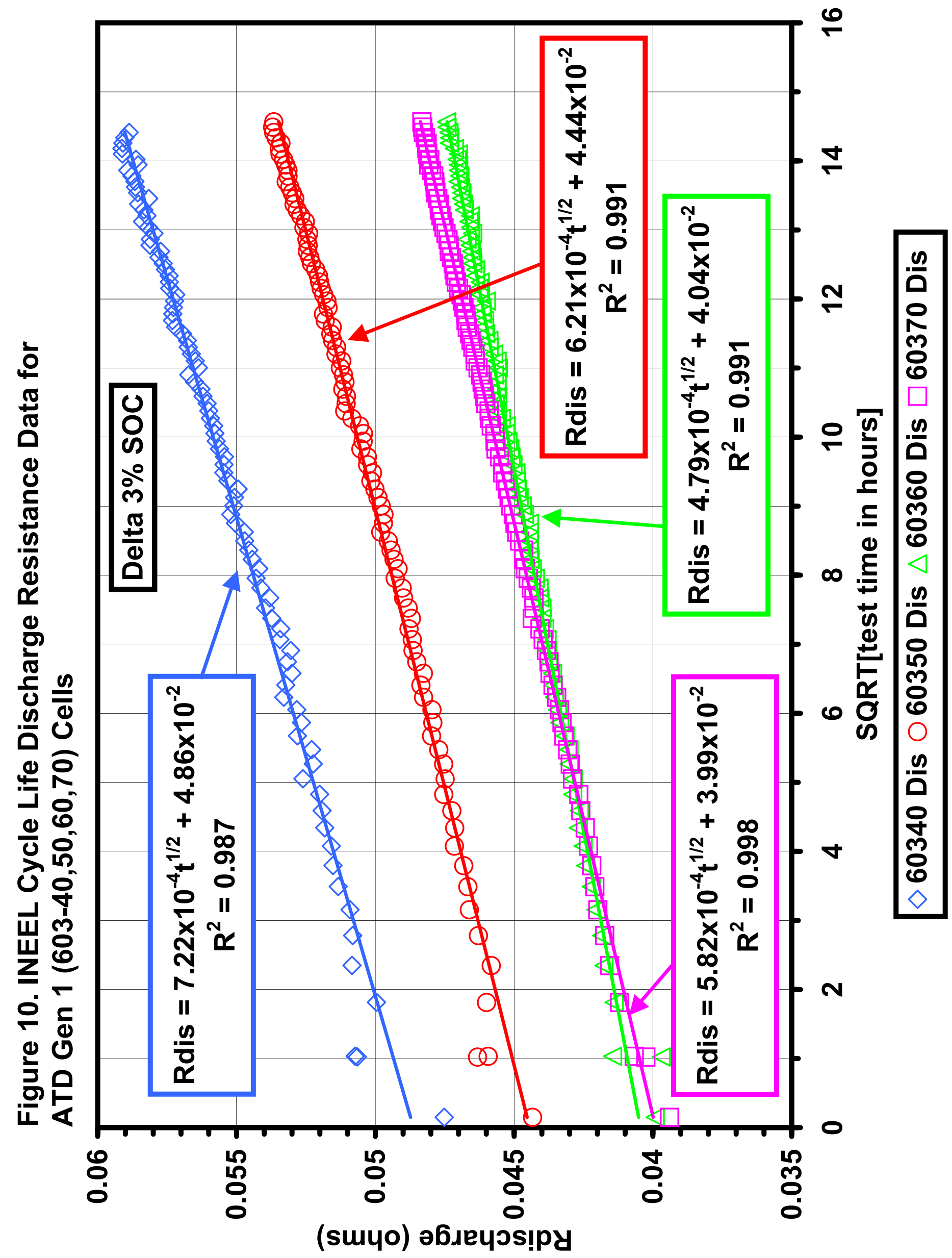

